Aus der Klinik für Kardiologie und Pneumologie

(Prof. Dr. med. G. Hasenfuß)

der Medizinischen Fakultät der Universität Göttingen

\title{
Übereinstimmung in der Beurteilung zwischen Pneumologen und dem Zytopathologen, die identisches Pleuraergussmaterial untersucht haben
}

\author{
INAUGURAL-DISSERTATION \\ zur Erlangung des Doktorgrades \\ der Medizinischen Fakultät der \\ Georg-August-Universität zu Göttingen
}

vorgelegt von

Sebastian Pietrzak

aus

Thorn (Polen)

Göttingen 2016 
Dekan:

Referent:

Ko-Referent:
Prof. Dr. rer. nat. H.K. Kroemer

Prof. Dr. med. S. Andreas

Prof. Dr. med. H.-U. Schildhaus

Datum der mündlichen Prüfung: 27.10.2016 
Hiermit erkläre ich, die Dissertation mit dem Titel "Übereinstimmung in der Beurteilung zwischen Pneumologen und dem Zytopathologen, die identisches Pleuraergussmaterial untersucht haben" eigenständig angefertigt und keine anderen als die von mir angegebenen Quellen und Hilfsmittel verwendet zu haben.

Göttingen, den 31.03.2016

Sebastian Pietrzak 


\section{Inhaltsverzeichnis}

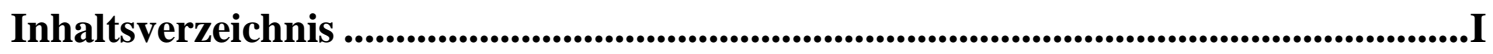

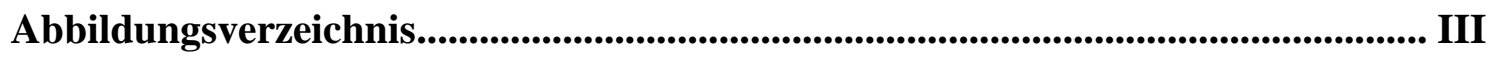

Tabellenverzeichnis .......................................................................................................... V

Abkürzungsverzeichnis .................................................................................... VII

$1 \quad$ Einleitung ............................................................................................................. 1

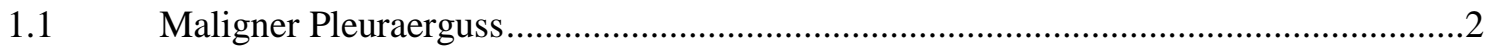

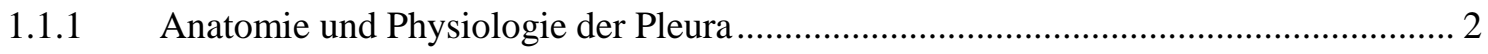

1.1.2 Pathophysiologie des malignen Pleuraergusses ....................................................... 3

1.1.3 Epidemiologie und Ätiologie des malignen Pleuraergusses ........................................ 5

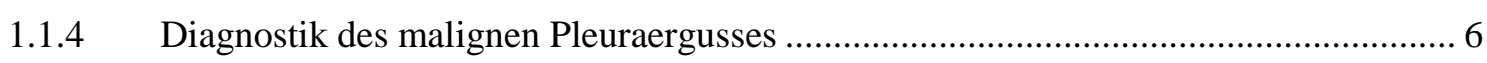

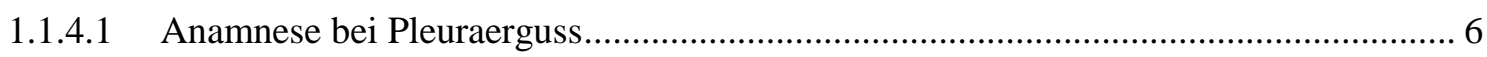

1.1.4.2 Körperliche Untersuchung beim Pleuraerguss ........................................................... 7

1.1.4.3 Bildgebende Basisdiagnostik des malignen Pleuraergusses ...................................... 8

1.1.4.4 Laborchemische Analyse des malignen Pleuraergusses ............................................ 10

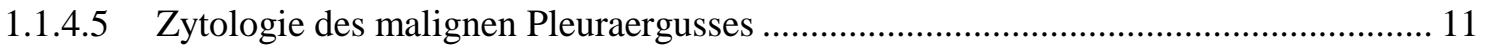

1.1.4.6 Histologische Sicherung der Diagnose bei Verdacht auf malignen Pleuraerguss ....... 13

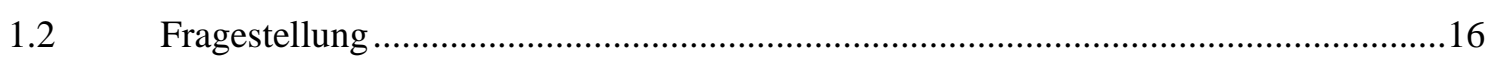

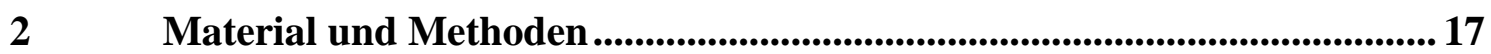

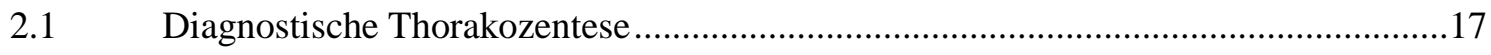

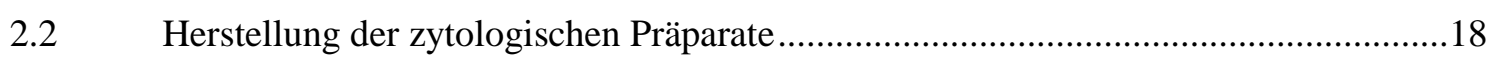

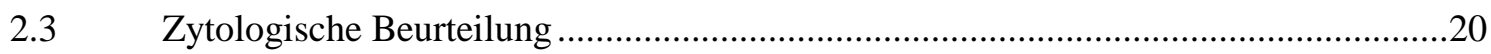

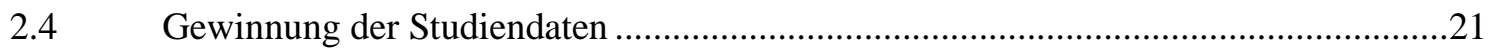

2.5 Zytologische Befundung der Pleuraergüsse ..........................................................2.

2.6 Kategorisierung der zytologischen und histologischen Befunde für diese Studie .......28

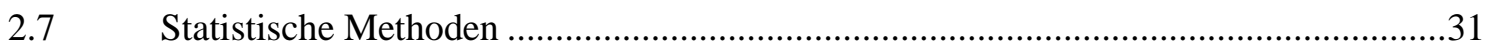

2.7.1 Übereinstimmungsbeurteilung bei Beurteilung durch zwei verschiedene Beobachter: den Pneumologen und dem Zytopathologen (interrater agreement)....... 31

2.7.2 Überprüfung von Sensitivität, Spezifität sowie positivem und negativem Prädikationswert der zytologischen Befunde beider Beurteiler. 
2.7.3 Modell der logistischen Regression zur Voraussagekraft der zytologischen Befunde beider Beurteiler ..................................................................................... 36

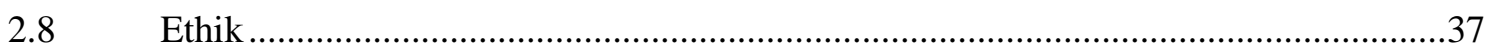

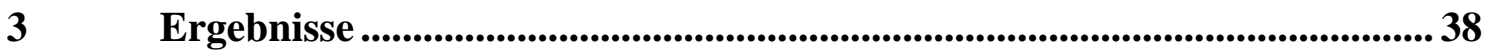

3.1 Beurteilerübereinstimmung der zytologischen Befunde ….......................................

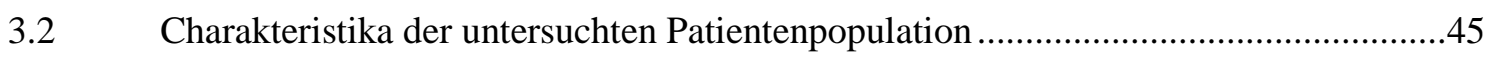

3.2.1 Allgemeine Daten bezüglich der Patienten und der untersuchten Pleuraergüsse........ 45

3.2.2 Charakteristika der Pleuraergüsse nach endgültigen klinischen Diagnosen ............... 46

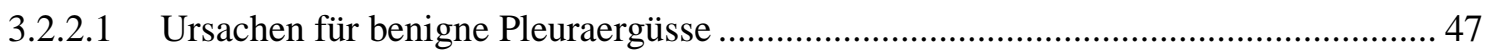

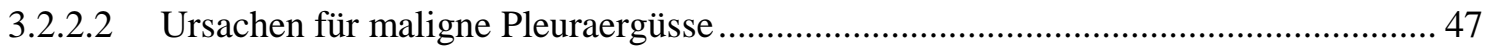

3.3 Sensitivität und Spezifität der zytologischen Befunde der beiden Beurteiler ...............49

3.3.1 Vergleich der zytologischen Ergebnisse mit den histologischen Befunden der Thorakoskopie...

3.3.2 Beurteilung der Aussagekraft der zytologischen Befunde in einem Modell der

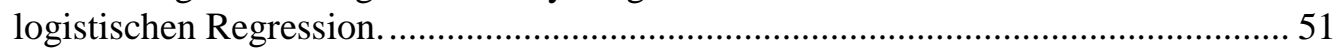

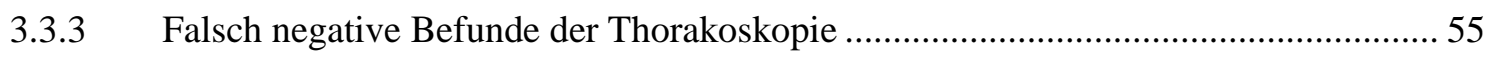

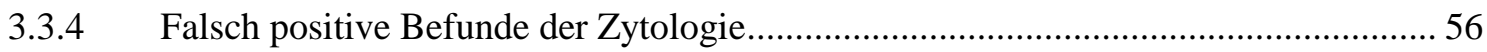

$4 \quad$ Diskussion ......................................................................................................... 57

4.1 Die untersuchte Patientenpopulation im Vergleich zu anderen Studien .......................58

4.2 Sensitivität und Spezifität der zytologischen Befunde ................................................61

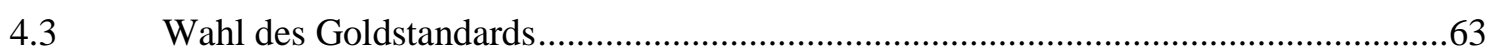

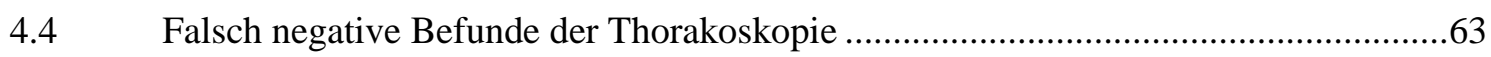

4.5 Falsch positive Befunde der Zytologie im Vergleich zur Thorakoskopie.....................64

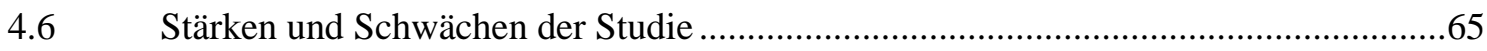

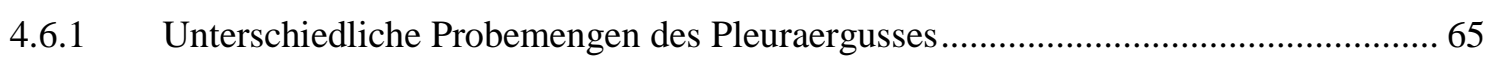

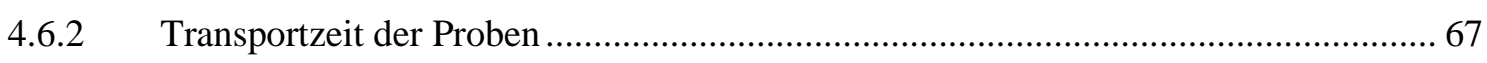

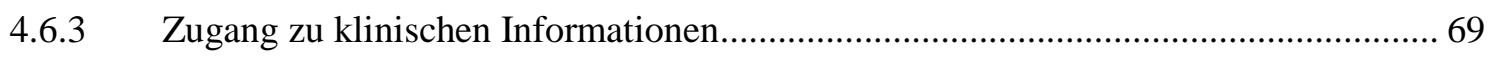

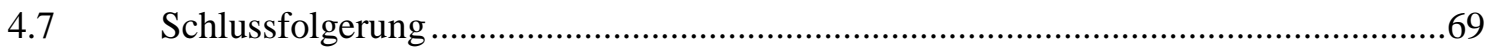

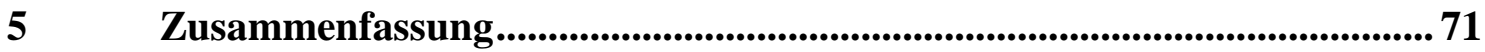

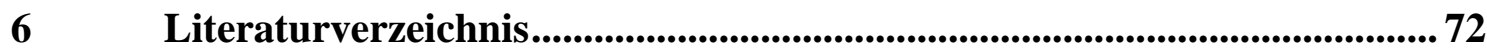




\section{Abbildungsverzeichnis}

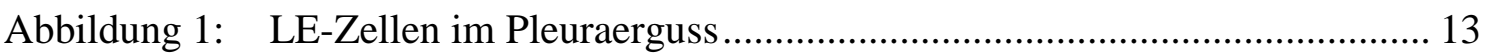

Abbildung 2: $\quad$ Pleuraergussprobe im Heparin-Röhrchen ......................................... 18

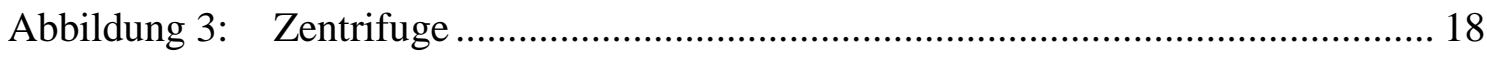

Abbildung 4: Pleuraerguss nach Behandlung in der Zentrifuge................................. 19

Abbildung 5: Trennung des Überstandes nach Behandlung in der Zentrifuge ........... 19

Abbildung 6: Pipettieren des Sediments.............................................................. 19

Abbildung 7: Ausstreichen des zytologischen Präparates ...................................... 19

Abbildung 8: Vorrichtung für May-Grünwald-Färbung ….................................... 20

Abbildung 9: Zytologische Präparate nach May-Grünwald-Färbung ......................... 21

Abbildung 10: Mikroskop Primo Star Fa. Zeiss in der Lungenfachklinik Immenhausen ........................................................................... 22

Abbildung 11: Zellen eines kleinzelligen Bronchialkarzinoms der Lunge im Pleuraerguss

Abbildung 12: Zellen eines verhornenden Plattenepithelkarzinoms der Lunge im Pleuraerguss ................................................................................. 27

Abbildung 13: Zellen eines schleimbildenden Adenokarzinoms im Pleuraerguss ....... 27

Abbildung 14: Prozentuale Verteilung zytologischer Diagnosen von Pleuraergüssen von Pneumologen ........................................................ 40

Abbildung 15: Prozentuale Verteilung zytologischer Diagnosen von Pleuraergüssen vom Zytopathologen ................................................. 40

Abbildung 16: Alters- und Geschlechtsverteilung in der Gruppe von 605 Patienten ... 45

Abbildung 17: Verteilung der endgültigen klinischen Diagnosen nach Diagnosenkategorien der Studie.....

Abbildung 18: Verteilung der Patienten mit malignem Pleuraerguss bei Bronchialkarzinom je nach histologischem Tumortyp anhand endgültiger klinischer Diagnose

Abbildung 19: links: Verteilung der geschätzten Wahrscheinlichkeiten des kombinierten Klassifikators und der optimale Cutoff-Punkt nach dem Youden-Kriterium, rechts: ROC-Kurve, Punkt mit dem 
größten Youden-Index, AUC und 95\%-Konfidenzintervall des kombinierten Klassifikators. 54

Abbildung 20: ROC-Kurve und AUC sowie 95\%-Konfidenzintervalle vom kombinierten Klasifikator, Pneumologen und vom Zytopathologen. ... 55 


\section{Tabellenverzeichnis}

Tabelle 1: $\quad$ Zytomorphologische Differenzialdiagnose von Adenokarzinomen unterschiedlichen Ursprungs (in Anlehnung nach Pokieser 2001) ....... 26

Tabelle 2: $\quad$ Systematik der Zuordnung der zytologischen Befunde der Pneumologen zu dem Kategoriensystem der Studie

Tabelle 3: Systematik der Zuordnung der zytologischen Befunde des Zytopathologen zu den Kategorien der Studie

Tabelle 4: Übereinstimmungsmatrix bei 2 Beobachtern und mehreren (n) Objekten mit einem s-stufigen Kategoriensystem

Tabelle 5: Stärke der Übereinstimmung in der Abhängigkeit vom $\kappa$-Wert (nach Landis und Koch 1977)

Tabelle 6: $\quad$ Vierfeldertafel

Tabelle 7: Kontingenztabelle für die Kategorien maligne - benigne - suspekt für Pneumologen und den Zytopathologen

Tabelle 8: Kontingenztabelle für die Kategorien maligne-benigne für Pneumologen und den Zytopathologen

Tabelle 9: Kontingenztabelle mit zytologischen Befunden nach Diagnosenkategorien für Pneumologen und für den Zytopathologen

Tabelle 10: Prozentuale Übereinstimmung der zytologischen Befunde von Pneumologen und dem Zytopathologen (Zeilenprozente)

Tabelle 11: Prozentuale Übereinstimmung der zytologischen Befunde vom Zytopathologen und von den Pneumologen (Spaltenprozente)

Tabelle 12: Verteilung der malignen Pleuraergüsse nach Primarius bei Männern und Frauen

Tabelle 13: Kontingenztafel für die zytologischen Befunde der Pneumologen im Vergleich mit histologischen Befunden der Thorakoskopie....

Tabelle 14: Kontingenztafel für die zytologischen Befunde des Zytopathologen im Vergleich mit histologischen Befunden der Thorakoskopie.....

Tabelle 15: Zusammenstellung der Sensitivität, Spezifität, PPV, NPV und $95 \%$-Konfidenzintervalle der zytologischen Befunde der Pneumologen und des Zytopathologen im Vergleich mit histologischen Befunden der Thorakoskopie 
Tabelle 16: Mittelwert, Standardabweichung des Alters sowie absolute und relative Häufigkeit der Nominalvariablen für Patienten mit benignen und malignen Pleuraergüssen sowie der $\mathrm{p}$-Wert des generalisierten linearen Regressionsmodells

Tabelle 17: Resultate des generalisierten linearen Modells für die Berechnung der Aussagekraft der zytologischen Befunde in Kategorien maligne - benigne im Vergleich mit Thorakoskopie

Tabelle 18: Kontingenztabelle entsprechend dem optimalen Cutoff-Punkt des kombinierten Klassifikators. 


\section{Abkürzungsverzeichnis}

AUC

CEA

CUP-Syndrom

FN

FP

INR

K.

$\mathrm{K}_{+}$

LDH

LE

NHL

NPW

NSCLC

OPS

p.a.

$\mathrm{pH}$

PPW

PÜ

$\mathrm{p}$-Wert

RN

ROC-Kurve

RP

SCLC

$\mathrm{T}$.

$\mathrm{T}_{+}$

UpM

VATS

VEGF

$\kappa$
Area Under the Curve (Fläche unter der Kurve)

carcinoembryonales Antigen

Cancer of Unknown Primary (Karzinom bei unbekanntem

Primärtumor)

falsch negativ

falsch positiv

International Normalised Ratio

tatsächlich Gesunde

tatsächlich Erkrankte

Laktat-Dehydrogenase

Lupus Erythematodes

Non-Hodgkin-Lymphom

negativer Prädikationswert

nicht-kleinzelliges Bronchialkarzinom

Operationen- und Prozedurenschlüssel

posterior anterior

potentia hydrogenii

positiver Prädikationswert

prozentuale Übereinstimmung

Überschreitungswahrscheinlichkeit

richtig negativ

Receiver-Operating-Characteristic-Kurve

richtig positiv

kleinzelliges Bronchialkarzinom

Test negativ

Test positiv

Umdrehungen pro Minute

videoasisstierte Thorakoskopie

Vascular Endothelial Growth Factor

Cohens Kappa 


\section{Einleitung}

Die Thorakozentese ist im klinischen Alltag die erste wichtige Maßnahme zur Abklärung der Ätiologie des Pleuraergusses neben Anamnese, klinischer Untersuchung und bildgebender Diagnostik. Laut Riedel, der Kuntz zitiert (Riedel et al. 1999), findet sich bei etwa $10 \%$ der stationären Patienten einer allgemein-internistischen Abteilung ein Pleuraerguss.

Eine klinisch-chemische Analyse des Pleurapunktates zur Differenzierung zwischen einem Transsudat und Exsudat und insbesondere zur Bestimmung der Tumormarker hat in der Unterscheidung zwischen malignem und benignem Pleuraerguss nur eine auf die Notwendigkeit einer zytologischen Untersuchung hinweisende Bedeutung. Parallel ist die Zytologie die einfachste und die mit geringsten Komplikationen für den Patienten belastete Untersuchung zur Unterscheidung zwischen malignem und benignem Pleuraerguss.

Die Zellmorphologie sowohl der primären als auch metastatischen Pleuratumoren kann sehr vielseitig sein. Rein zytomorphologisch kann manchmal nur Malignität und nicht der Tumortyp festgestellt werden (Pokieser 2001). Das zunehmende Alter der Patienten mit Neoplasien erfordert im klinischen Alltag immer weniger invasive diagnostische Methoden zur Sicherung der Dignität. Meistens führt das dazu, dass die Diagnose anhand immer kleinerer Proben gestellt werden muss. Dies unterstreicht die Bedeutung der zytologischen Untersuchung und führt zur Entwicklung neuer immunzytochemischer und molekularzytologischer Diagnostikmethoden, insbesondere falls keine weiterführenden histologischen Befunde vorliegen.

Generell kann man zwei Typen zytologischer Untersuchung unterscheiden: Eine klinische Zytologie, bei der das entnommene Material direkt vor Ort von dem auch klinisch tätigen Arzt beurteilt wird, sowie eine so genannte „Versandzytologie“ mit Beurteilung des Materials in zytologischen Laboren, oft weit entfernt von dem Krankenhaus.

Im ersten Fall verfügt der zytologische Beurteiler durch direkte Involvierung in den Behandlungsprozess über vielfältige klinische Informationen wie Anamnese, Befunde der Bildgebung und ggf. auch die Ergebnisse einer histologischen Untersuchung. Bei „Versandzytologie“ sind diese Informationen oftmals eingeschränkt.

Zutreffende und schnelle zytologische Diagnostik ist wichtig für die Entscheidung über die weitere Behandlung der Patienten mit malignem Pleuraerguss. Diese Zeit kann im 
Fall der Untersuchung durch „Versandzytologie“ deutlich verlängert sein. Nach einer Studie aus Neuseeland (Lim et al. 2013) wurde die durchschnittliche Zeit zwischen Thorakozentese und dem Ankommen des zytologischen Befundes mit 8,7 Tagen gemessen.

\subsection{Maligner Pleuraerguss}

\subsubsection{Anatomie und Physiologie der Pleura}

Die Pleura ist ein dünnes Blatt der Tunica serosa, die die innere Wand des Thorax auskleidet (Pleura parietalis, Rippenfell) und überzieht die Lungenoberfläche (Pleura visceralis, Lungenfell). Die Serosa besteht histologisch aus drei Schichten. Die äußere Schicht - Mesothel, die direkt zur Pleurahöhle gerichtet ist, besteht aus einem einschichtigen Plattenepithel. Die Zellen des Plattenepithels nehmen hauptsächlich eine Transportfunktion ein.

Unter dem Mesothel befindet sich die Lamina propria serosa, ein Bindegewebe, das Fibrozyten, kleine Blutgefäße und Nervenfasern enthält. Hier erweitern sich, ausschließlich auf der Pleura parietalis, die Lymphgefäße zu lymphatischen Lakunen, die über die Stomata mit dem Pleuraspalt in Verbindung treten. Die Stomata findet man in höherer Dichte kaudal in den mediastinalen, intrakostalen und diaphragmalen Bereichen des Rippenfels (Wang 1975). Das dichte Netzwerk der Stomata ist in die Auffanggefäße kanalisiert, die über intrakostale und mammäre Lymphgefäße und hiläre und mediastinale Lymphknoten des Thorax in den Ductus thoracicus und in den rechten Ductus lymphaticus münden.

Die dritte Schicht der Serosa, Tela subserosa, besteht ebenfalls aus Bindegewebe. In der Pleura visceralis besteht die Tela subserosa vor allem aus elastischen Fasern und dringt dabei zwischen Lungen-Lobuli und -Lappen ein. In der Pleura parietalis ist diese Schicht deutlich dicker und besteht vor allem aus kollagenen Fasern und verbindet sich durch die Faszie mit der Thoraxwand und dem Zwerchfell.

Die Blutversorgung der Pleura visceralis erfolgt durch die Bronchialarterien und die der Pleura parietalis durch die Arterien des Systemkreislaufs.

Unter physiologischen Bedingungen sind die beiden Blätter der Pleura befeuchtet mit einer Flüssigkeit. Zwischen dem Rippenfell und dem Lungenfell befindet sich ein ca. 5$30 \mu \mathrm{m}$ dicker Raum, der Pleuraspalt. Produktion und Resorption des Pleuraergusses im 
Pleuraspalt bleiben in einer Homöostase bei kontinuierlicher Filtration von geringen Mengen an proteinarmer Flüssigkeit in den Mikrogefäßen der Pleura parietalis. In den Kapillaren der Pleura parietalis vermindert sich der hydrostatische Druck zunehmend mit deren Verlauf, jedoch bleibt er weiter positiv und presst das Wasser sowie wasserlösliche kleine Moleküle in das Interstitium. Große Moleküle, wie Eiweiß, verbleiben in den Gefäßkapillaren und bilden den osmotischen Druck des Plasmas, das gegen den positiven hydrostatischen Druck wirkt. Der Eiweißgehalt des physiologischen Pleuraergusses ist niedriger als die Eiweißkonzentration in der Lunge sowie der Lymphe. Die Homöostase ist von dem hydrostatischen Druck, der Membrandurchlässigkeit sowie vor allem von dem osmotischen Druck abhängig und durch die Starling-Gleichung beschrieben. Es werden ca. 100-200 ml des Pleuraergusses pro Tag produziert (Lynch 1993). Bei dieser Produktion nimmt auch in einer eingeschränkten Weise die Pleura visceralis teil.

Die Pleuraflüssigkeit wird durch die Pleura parietalis in den Pleuraspalt filtriert, dann über die Stomata der Pleura visceralis resorbiert und durch die lymphatischen Gefäße drainiert. Auf andere Weise kann die Rückführung der Flüssigkeit aus dem Pleuraspalt über das submesotheliale Interstitium in das venöse Ende der Kapillaren erfolgen, abhängig auch von der Stärke des osmotischen Drucks. Der venöse Abfluss aus den Kapillaren findet aus der Pleura visceralis weitgehend über die Lungenvenen und aus der Pleura parietalis über die Bronchialvenen statt (Sahn 1990).

Die Entfernung von Flüssigkeit aus dem Pleuraspalt wird durch die Bewegungen der Brustwand, die schrittweise den intrapleuralen Druck erhöhen, gefördert (Kinasewitz 1997).

\subsubsection{Pathophysiologie des malignen Pleuraergusses}

Das physiologische Gleichgewicht, das nur 5-10 ml (0,1 mg/kg des Körpergewichts) der Flüssigkeit (Noppen et al. 2000) zwischen Pleura visceralis und Pleura parietalis zulässt, kann aus einer Vielzahl von Gründen gestört sein. Die Übermengen an Flüssigkeit können zwischen diesen beiden Schichten akkumulieren und einen Krankheitszustand der Brusthöhle, den Pleuraerguss verursachen. Der Pleuraerguss komprimiert das Lungengewebe und trennt es von der Brustwand. Er kann in zwei Formen auftreten: Transsudat und Exsudat. 
Ein überproportionaler Anstieg des hydrostatischen Druckes in den Kapillaren oder ein Proteinmangel wird zur Entstehung des Transsudats führen. Die Mesothelzellen leisten dann keinen signifikanten Widerstand gegen die Bewegung der im Interstitium gelösten großen Moleküle in die Pleurahöhle.

Beim Anstieg der kapillären Permeabilität bilden sich Exsudate. Diese können bei einer akuten oder chronischen Inflammation der Pleura entstehen. Bei dieser Störung der Permeabilität entweichen die großen Moleküle in das Interstitium und sodann in die Pleurahöhle. Die Exsudate haben eine hohe Proteinkonzentration im Bereich von $3 \mathrm{~g} / \mathrm{dl}$ und mehr. Im Exsudat finden sich oft auch Entzündungszellen sowie aktivierte Mesothelien.

Zu den Exsudaten gehört auch ein maligner Pleuraerguss, der durch Nachweis von malignen Zellen in der Pleuraflüssigkeit oder im Pleuragewebe bestimmt wird. Eine Kombination aus erhöhter Pleuraflüssigkeitsbildung und einer verminderten Fähigkeit der Lymphgefäße, die Flüssigkeit zu entfernen, führt zur Entstehung eines malignen Pleuraergusses (Light und Hamm 1997). Zum malignen Befall der Pleura parietalis kommt es - in Abhängigkeit von der Histologie und Lokalisation des Primarius - unter anderem durch Verbreitung von Tumorzellen über den Pleuraspalt aus der Pleura visceralis. Dies geschieht dann über vorhandene pleurale Verwachsungen oder solche, die durch den malignen Prozess entstanden sind. Auch aus der Pleura visceralis exflorierte maligne Zellen können sich in der Pleura parietalis verbreiten. Pleurale Metastasen des Lungenkarzinoms entstehen normalerweise aus den Embolien bei neoplastischer Invasion der Pulmonalarterie, unabhängig vom histologischen Tumortyp (Chernow und Sahn 1977; Sahn 1997).

Ein anderer Weg zur Entstehung der pleuralen Metastasen ist eine hämatogene Aussaat. Im Falle des Bronchialkarzinoms wurde dies insbesondere in der Gegenwart von hepatischen Metastasen beobachtet (Meyer 1966). Die erhöhte Flüssigkeitsbildung in der Pleura ist eine Folge der tumorösen Neovaskularisation, induziert durch die aus Tumorzellen stammenden Faktoren der Angiogenese, insbesondere den Vascular Endothelial Growth Factor (VEGF). Die neuen Blutgefäße des Tumorgewebes sind sehr durchlässig, was zu vermehrtem Austreten sowohl der Pleuraflüssigkeit als auch von Eiweiß sowie von Blutzellen führt (Mishra et al. 2009). Die Störung der Flüssigkeitsentfernung ist eine Folge der fehlenden Integrität des lymphatischen Systems zwischen den Stomata der Pleura parietalis und den mediastinalen Lymphknoten. Meyer fand einen starken 
Zusammenhang zwischen der Infiltration der mediastinalen Lymphknoten und der Entstehung eines Pleuraergusses (Meyer 1966; Chernow und Sahn 1977).

Die Pleuraergüsse, die nicht durch Tumorbeteiligung der Pleura entstehen, aber in Beziehung zum Primärtumor stehen, heißen paraneoplastische oder paramaligne Pleuraergüsse (Loddenkemper 2005). Diese Pleuraergüsse können entstehen bei:

- retrostenostischer Pneumonie

- Verlegung des Ductus thoracicus mit Entwicklung eines Chylothorax

- Lungenembolien

- niedrigen onkotischen Drücken als Folge einer Kachexie

- Behandlung eines Primärtumors (z. B. als Folge einer Strahlentherapie oder durch Medikamente)

- erniedrigtem Druck im Pleuraraum (z. B. bei Atelektasen)

Ein paramaligner Pleuraerguss kann auch ein Transsudat sein. Dieser kann bei ,gefesselter Lunge“ aufgrund großflächigen Tumorbefalls der viszeralen Pleura oder bei Vena-cava-superior-Syndrom aufgrund von erhöhten systemischen Venendruck entstehen (Antony 1999). Ein Transsudat schießt eine Operabilität bei Lungenkrebs nicht aus.

\subsubsection{Epidemiologie und Ätiologie des malignen Pleuraergusses}

Fast 1,5 Millionen Menschen in den USA entwickeln jährlich einen Pleuraerguss (Light 2011). Die malignen Pleuraergüsse sind dort mit einer Zahl von ca. $150.000 / J a h r$ bei jährlich steigender Rate von neu diagnostizierten malignen Erkrankungen ein wachsendes Problem (Bibby et al. 2015).

Es gibt nur wenige Studien zur Häufigkeit des Pleuraergusses in der allgemeinen Population. Eine tschechische Arbeit betreffend die Allgemeinpopulation Zentralböhmens (Marel et al. 1993) beschreibt Ende der 1980er Jahre eine Häufigkeit des Pleuraergusses von $0,32 \% .46 \%$ aller Pleuraergüsse in der untersuchten Population beruhten auf einer Linksherzinsuffizienz, $22 \%$ auf malignem, $17 \%$ auf parapneumonischem Pleuraerguss und 5,6 \% auf einer Lungenembolie. Seltenere Ursachen waren Hämatothorax, Pathologien im Bereich des Abdomens, Urämie sowie rheumatoide Arthritis. Bei einer Tuberkuloseinzidenz von 18 Fällen pro 100.000 Personen in der untersuchten Population fanden sich nur 8 Patienten mit Tuberkulose, keiner davon mit einem spezifischen Pleuraerguss. 
Eine spanische Studie (Valdés et al. 1996), betreffend ein Gebiet mit hoher Inzidenz von Tuberkulose (95 Fälle pro 100.000 Bewohner), beschreibt diese mit $25 \%$ als häufigste Ursache für einen Pleuraerguss. Nach dieser Studie beruhen 22,9\% auf einem malignen Pleuraerguss und 17,9\% auf Linksherzinsuffizienz.

Die ätiologische Verteilung der Pleuraergüsse ist offensichtlich von der untersuchten Population abhängig.

Nach Marel et al. (1995) waren $45 \%$ aller Pleuraergüsse maligne; untersucht wurden Patienten einer Universitätslungenklinik in Prag. Niedrigere Prozentsätze von $17 \%$ wurden in der farbigen Bevölkerungspopulation in Südafrika beobachtet (Burgess et al. 1996).

Häufigste Ursache für einen malignen Pleuraerguss ist ein Bronchialkarzinom (Meyer 1966; Chernow und Sahn 1977; Johnston 1985; Hsu 1987; Marel et al. 1995; Valdés et al. 1996).

Nach diesen Studien waren 32 bis $52 \%$ der maligen Pleuraergüsse auf ein Bronchialkarzinom zurückzuführen. Die zweithäufigste Ursache war ein Mammakarzinom, in unterschiedlicher Häufigkeit ein Ovarialkarzinom, Karzinome des Verdauungstraktes, Lymphome und ein Pleuramesotheliom. Zwischen 7 und $23 \%$ aller Patienten mit einem Bronchialkarzinom entwickeln einen malignen Pleuraerguss, zu dem alle histologischen Typen des Bronchialkarzinoms führen können. Dies gilt für das Adenokarzinom mit $40 \%$, für das kleinzelliges Bronchialkarzinom mit etwa $25 \%$ der Fälle. Bei einem Befall der peripheren Lungenabschnitte durch den häufigsten Typ des Bronchialkarzinoms, das Adenokarzinom, kommt es wahrscheinlich zu einer Invasion der Pleura visceralis (Johnston 1985).

\subsubsection{Diagnostik des malignen Pleuraergusses}

\subsubsection{Anamnese bei Pleuraerguss}

Die Symptome bei Patienten mit einem Pleuraerguss sind im Wesentlichen durch die zugrunde liegende Haupterkrankung bestimmt und somit wenig spezifisch oder sensitiv. Da die Entwicklung dieser Symptome auch von der Menge des Ergusses abhängig ist, zeigen manche Patienten gar keine Symptome, die auf eine Pleuraerkrankung deuten. 
Nach der Studie von Chernow und Sahn (1977) zeigten $23 \%$ der untersuchten Patienten bezüglich eines malignen Pleuraergusses keine Symptome.

Unabhängig davon, ob es sich um eine primäre oder sekundäre, zum Pleuraerguss führende Erkrankung handelt, kann man die drei folgende Symptome (Hausheer und Yarbro 1987) hervorheben:

Ein Schmerz bei Pleuritis ist stechend und oft atemabhängig. Um den Schmerz zu vermeiden, nimmt der Patient eine Schonatmung ein, die die Atemmechanik beeinflusst. Manche Patienten mit Pleuraerguss verspüren zuerst kaum merkliche, dumpfe und schlecht lokalisierbare Empfindungen des Thorax (Marel et al. 1995). Dies kann für einen tumorösen Befall der Pleura, etwa eine sekundäre Pleurakarzinose, oder für eine primäre Neoplasie der Pleura, ein Pleuramesotheliom, sprechen. Im letzteren Fall kann der Schmerz, insbesondere bei einer Infiltration der Thoraxwand, einen persistierenden und bohrenden Charakter annehmen. Dazu ist anzumerken, dass sensorische Nervenrezeptoren nur in der Pleura parietalis und nicht in der Pleura visceralis vorhanden sind. Die intracostalen Nerven versorgen das Rippenfell und periphere Teile des Zwerchfells. Das erklärt ein Verspüren des Schmerzes im Abdomen bei Befall der peripheren Zwerchfellanteile. Der zentrale Teil des Zwerchfells ist durch den Nervus phrenicus versorgt. Schmerzen in der ipsilateralen Schulterregion können auf eine Irritation durch eine Neoplasie in diesem Zwerchfellbereich beruhen (Eberli und Russi 2005).

Das zweite Symptom eines Pleuraergusses ist ein trockener und unproduktiver Husten, dessen pathologischer Mechanismus noch nicht endgültig geklärt ist.

Als drittes Symptom eines Pleuraergusses ist eine Dyspnoe zu nennen. Diese entsteht vor allem durch Kompression der Lunge in Folge der Verbreiterung des Pleuraspaltes, was zu einem Missverhältnis zwischen Ventilation und Perfusion der Lunge führt und die Auswurffraktion des Herzens beeinflusst.

\subsubsection{Körperliche Untersuchung beim Pleuraerguss}

Unser Wissen über die Rolle der körperlichen Untersuchung bei der Diagnose eines Pleuraergusses basiert vor allem auf Einschätzungen von Experten und nur in geringem Umfang auf Studien, zumeist mit kleinen Fallzahlen. Die Studien suggerieren, dass die klinische Untersuchung weniger genau als eine Pleurasonographie ist. Manche Arbeiten 
ergaben: Die klinische Untersuchung ist genauer als konventionelle Röntgenaufnahmen des Thorax (Diaz-Guzman und Budev 2008).

Bei großen Ergussmengen kann schon eine Inspektion des Thorax das Bild eines Nachschleppens der ein - oder beidseitigen Atemexkursionen zeigen. Ein anderer indirekter Hinweis auf einen Pleuraerguss kann eine Tachypnoe sein. Eine Palpation ergibt unter Umständen einen abgeschwächten Stimmfremitus, gelegentlich verbunden mit der schon genannten ungleichen Thoraxexpansion.

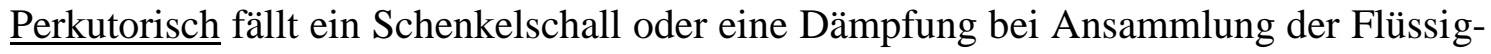
keit zwischen der Lunge und Thoraxwand auf. Zu einer solchen Detektion des Pleuraergusses müssen in dem Pleuraraum mindestens $500 \mathrm{ml}$ Flüssigkeit vorhanden sein.

Die Auskultation ist wahrscheinlich die häufigste Methode zur Erkennung eines Pleuraergusses. Zuerst hat diese Methode Laennec, der auch das Stethoskop erfunden hat, beschrieben. Abwesenheit oder vermindertes Atemgeräusch auf einer Seite weist differentialdiagnostisch auf einen Erguss hin. Am oberen Grenzbereich des Pleuraergusses können ggf. das Bronchialatmen und nicht klingelnde Rasselgeräusche gehört werden. Ein Pleurareiben gehört zu weiteren, für den Pleuraerguss charakteristischen, auskultatorischen Nebengeräuschen. Dieses entsteht durch das Aneinanderreiben der entzündeten Pleura visceralis und der Pleura parietalis und wird häufig bei Pleuritis sicca beobachtet. Ein Plätschergeräusch, Succussio Hippocratis, entsteht beim Schütteln des Patienten und spricht manchmal für einen Seropneumothorax. Die Überprüfung der Fortleitung der Sprache des Patienten über die Thoraxwand, Bronchophonie, beruht ebenso wie der Stimmfremitus auf unterschiedlichen Leitungsqualitäten des Lungengewebes für hohe und tiefe Schallfrequenzen. Eine pathologische Bronchophonie im Falle eines Pleuraergusses kann eine Ägophonie (Ziegenmeckern) sein. Dieser hoch-näselnd-meckernde Klang kann oberhalb eines Pleuraergusses entstehen (Dahmer 2006).

\subsubsection{Bildgebende Basisdiagnostik des malignen Pleuraergusses}

Die Menge eines malignen Pleuraergusses variiert von einigen Millilitern bis zu mehreren Litern mit einer Verschiebung des Mediastinums auf die kontralaterale Seite. Meistens werden Pleuraergüsse bildgebend bei einem entsprechenden Verdacht oder zufällig entdeckt. 
Das Verhalten von Pleuraflüssigkeit beschreibt Felson et al. (1968, S. 141) wie folgt: „Freie Pleuraflüssigkeit [...] ist schwerer als die mit Luft gefüllte Lunge und sinkt daher in aufrechter Position auf die Basis der Pleurahöhle ab“. Bis ca. $75 \mathrm{ml}$ zeigt sich noch keine Verschattung der kostophrenischen Winkel in der posterior-anterior (p.a.)Aufnahme. Größere Ergussmengen können im Röntgenbild einen Zwerchfellhochstand vortäuschen oder eine Abflachung und/oder Obliteration der kostophrenischen Winkel verursachen (Mulvey 1965). Eine Untersuchung mit Injektion von Flüssigkeit in die Pleurahöhle zeigte, dass erst ab einer Menge von mehr als $175 \mathrm{ml}$, und in einigen Fällen erst ab $500 \mathrm{ml}$, die lateralen kostophrenischen Winkel auf einer p.a.-Aufnahme verschattet waren (Colins et al. 1972). Nach Moskowitz et al. (1973) ist bei einem Pleuraerguss von ca. $1.000 \mathrm{ml}$ eine Verschattung bis zur 4. Rippe sichtbar. Bei der Seitenaufnahme können schon sehr geringe Flüssigkeitsmengen zu einer diskreten Verschattung des dorsalen Winkels führen.

Thorakale Sonographie ist eine leichte und schnell einsetzbare Methode zur Diagnostik von Pleuraerkrankungen und insbesondere des Pleuraergusses. Eine Sonographie kann unter anderem zur Identifikation des Pleuraergusses, zur Findung der Punktionstelle bei Thorakozentese oder Pleurabiopsie sowie bei Anlage einer Pleuradrainage hilfreich sein. Auch dient die Sonographie der Identifikation der Pleuraverdickungen, semiquantitativer Beurteilung der Flüssigkeitsmenge, Differenzierung zwischen einem Pyopneumothorax und Lungenabszess, der Beurteilung eines Effektes der Pleurodese und der schnellen Evakuation des Hämatothorax und Pneumothorax bei Traumapatienten.

Bei einer Totalverschattung des Lungenflügels in konventioneller Röntgenaufnahme des Thorax erlaubt eine Sonographie schnell zwischen einem massiven Pleuraerguss und einer Totalatelektase durch Verschluss des Hauptbronchus bei zentralem Tumorwachstum zu differenzieren.

Eine Computertomographie mit Gabe von Kontrastmittel kann zusätzliche Informationen über die Genese des Pleuraergusses liefern. Im Falle eines malignen Ergusses können es mediastinale Lymphadenopathien, neoplastische intrapulmonale Raumforderungen und tumoröse Pleuraverdickungen sein. Die Letzteren lassen sich computertomographisch am besten bei noch bestehendem Pleuraerguss darstellen. 
Bei einem sekundären Pleuraerguss durch Lungenembolie lassen sich Thromben nachweisen. So kann die Genese des Pleuraergusses geklärt werden, wenn keine weiteren computertomographischen Hinweise vorlegen.

Ähnlich wie eine Thoraxsonographie erlaubt die Computertomographie die Feststellung von weniger als $10 \mathrm{ml}$ Flüssigkeit im Pleuraraum.

\subsubsection{Laborchemische Analyse des malignen Pleuraergusses}

Schon das Aussehen des punktierten Pleuraergusses kann Hinweise auf einen malignen Pleuraerguss liefern. Bereits geringe Mengen des Blutes aus dem blutenden pleuralen Tumor können den Pleuraerguss rötlich verfärben. In solchen Fällen sollte immer ein Hämatokrit-Wert bestimmt werden. Meistens werden hier Werte von weniger als $5 \%$ ermittelt. An einen Hämatothorax sollte man denken bei einem Hämatokrit im Pleuraerguss von mehr als $50 \%$ des Bluthämatokrits. Dies ist oft eine Indikation zur Anlage einer notfallmäßigen Pleuradrainage.

Viele maligne Zellen verursachen ein trübes Aussehen des Pleuraergusses. Die durch erhöhten Hyaluronsäurespiegel gesteigerte Viskosität des malignen Pleuraergusses suggeriert ein Pleuramesotheliom. Selten wird eine weißliche Verfärbung des Ergusses beobachtet. Dies ist charakteristisch für einen Chylothorax, der bei einer mechanischen Zerstörung der Kontinuität des Ductus thoracicus durch Tumormassen entsteht. Ein Chylus im Pleurapunktat ist dann durch einen erhöhten Spiegel der Triglyzeride erkennbar.

Der nächste Schritt zur Analyse des Pleuraergusses ist die laborchemische Differenzierung zwischen einem Transsudat und einem Exsudat. Light hat bewiesen, dass die gleichzeitige Bestimmung des Laktat-Dehydrogenase- (LDH) und Eiweiß-Spiegels im Serum und im Pleurapunktat in $99 \%$ der beurteilten Pleuraergüssen eine korrekte Klassifikation als Transsudat oder Exsudat erlaubt (Light et al. 1972)

Ein Exsudat muss nach Light mindestens eine der folgenden Kriterien erfüllen:

(1) Verhältnis vom Gesamteiweiß im Pleuraerguss zur Gesamteiweiss im Serum $>0,5$

(2) Verhältnis der LDH im Pleuraerguss zur LDH im Serum > 0,6

(3) LDH im Pleuraerguss über $2 / 3$ der oberen Laborgrenze vom normalem Serum $\mathrm{LDH}$ 
Neuere Studien (Romero-Candeira et al. 2001) haben gezeigt, dass die Light-Kriterien fast alle Exsudate richtig, aber $25 \%$ der Transsudate fälschlich als Exsudate klassifiziert haben. Die Transsudate haben in solchen Fällen einen Albumingradienten größer als 1,2 g/dl und einen Gesamteiweißgradienten größer als 3,1 g/dl (Bielsa et al. 2012).

Die malignen Pleuraergüsse sind fast immer Exsudate, sodass eine zytologische Untersuchung der Transsudate in Richtung der malignen Zellen standardmäßig nicht empfohlen wird (Assi et al. 1998). Das Verhältnis zwischen dem Gesamteiweis im Pleuraerguss und im Serum ist geringer als 0,5 bei ca. $20 \%$ der malignen Pleuraergüsse. Jedoch entscheidet das erhöhte Verhältnis der LDH in beiden Flüssigkeiten nach Light-Kriterien über die Klassifikation als Exsudat. Der LDH- Spiegel ist ein Indikator für die pleurale Inflammation (Light et al. 1972).

Zur weiteren Differenzierung des malignen Pleuraergusses kann die Bestimmung des pHs sinnvoll sein. Ein $\mathrm{pH}<7,3$ ist bei malignem Pleuraerguss prognostisch ein sehr ungünstiger Faktor. Patienten mit niedrigem pH-Wert und niedrigem Glucose-Spiegel (< $60 \mathrm{mg} / \mathrm{dl}$ ) im malignen Pleuraerguss leben kürzer (Rodríguez-Panadero und López Mejías 1989).

Die Arbeit von Porcel et al. (2004) zeigt, dass nur ca. $50 \%$ der Patienten mit malignem Pleuraerguss durch ein Panel der Tumormarker identifiziert werden können. Die Tumormarker sind in der Routinediagnostik nicht empfohlen zur Feststellung eines malignen Pleuraergusses, da sich andere klinische Parameter als besser erwiesen haben. Tumormarker können nützlich zur Vorbereitung weiterer invasiver diagnostischer Maßnahmen sein. Lediglich der Wert des carcinoembryonalen Antigens (CEA) wird häufiger routinemäßig benutzt, um zwischen Adenokarzinomen und malignen Pleuramesotheliomen zu unterscheiden (Rittmeyer et al. 2004).

\subsubsection{Zytologie des malignen Pleuraergusses}

Eine der wichtigsten Aufgaben in der zytologischen Diagnostik des Pleuraergusses ist die Feststellung der malignen Zellen. Laut Atay und Topalidis (1994) erlaubt nur eine Kombination von verschiedenen Malignitätsmerkmalen eine sichere oder wahrscheinliche Malignitätsdiagnose. Für eine Feststellung der Malignitätskriterien ist eine genaue Kenntnis der ortsüblichen Zellen und ihrer Variationen bei funktionellen oder entzündlichen Krankheiten notwendig. Die entscheidenden Malignitätskriterien wurden durch Atay und Topalidis wie folgt zusammengestellt: 
- Poikilonukleose

- unregelmäßige Anisokaryose

- Mehrkernigkeit mit unterschiedlicher Kerngröße

- Kernüberlappung

- unregelmäßige Begrenzung des Kernes

- feinretikuläres Chromatin.

Die schwerwiegenden Kriterien sind:

- hellblaue Nukleolen

- Zunahme der mittleren Kerngröße

- grobes und unregelmäßig verteilte Chromatin

- abnorme Kernlagerung

- Kernreichtum

- Mitosen und Zellkannibalismus.

Das Vorkommen von zwei dieser Kriterien in einer Zelle bestätigt die Malignität mit an Sicherheit grenzender Wahrscheinlichkeit (so Atay und Topalidis 1994).

Die meisten Ergüsse zeigen mikroskopisch großteils unspezifische Befunde bestehend aus Neutrophilen, Lymphozyten, Makrophagen, Erythrozyten, Fibrin, reaktivierten Mesothelien und gelegentlich Eosinophilen. Bis auf wenige Ausnahmen ist es nicht sicher möglich, anhand der zytologischen Untersuchung eines Pleuraergusses die zugrunde liegende benigne Ätiologie zu ermitteln (Pereira et al. 2006).

Auch entzündliche Ergüsse können einen normalen zellulären Inhalt aufweisen und die Vermehrung einer Zellpopulation muss keine wesentliche diagnostische Bedeutung haben (Atay und Topalidis 1994). Es lassen sich jedoch einige zytologische Ausnahmen in der Diagnostik von benignen Pleuraergüssen abgrenzen. Eine Vermehrung von Neutrophilen Granulozyten kann zum Beispiel bei einem parapneumonischen Pleuraempyem beobachtet werden (Light 2006). Ein lymphozytärer Erguss, wenn mehr als $50 \%$ der vorhandenen Leukozyten Lymphozyten sind, zusammen mit spärlichen Mesothelzellen suggeriert eine Pleuratuberkulose. Bei Lupus erythematodes (LE) sind zytologisch im Pleuraerguss neben vielen Neutrophilen und ggf. auch eosinophilen Granulozyten LEZellphänomene in Form von Nukleophagozytosen nachweisbar. LE-Körper sind durch Antikörper zerstörtes Zellkernmaterial (Pokieser 2001). 


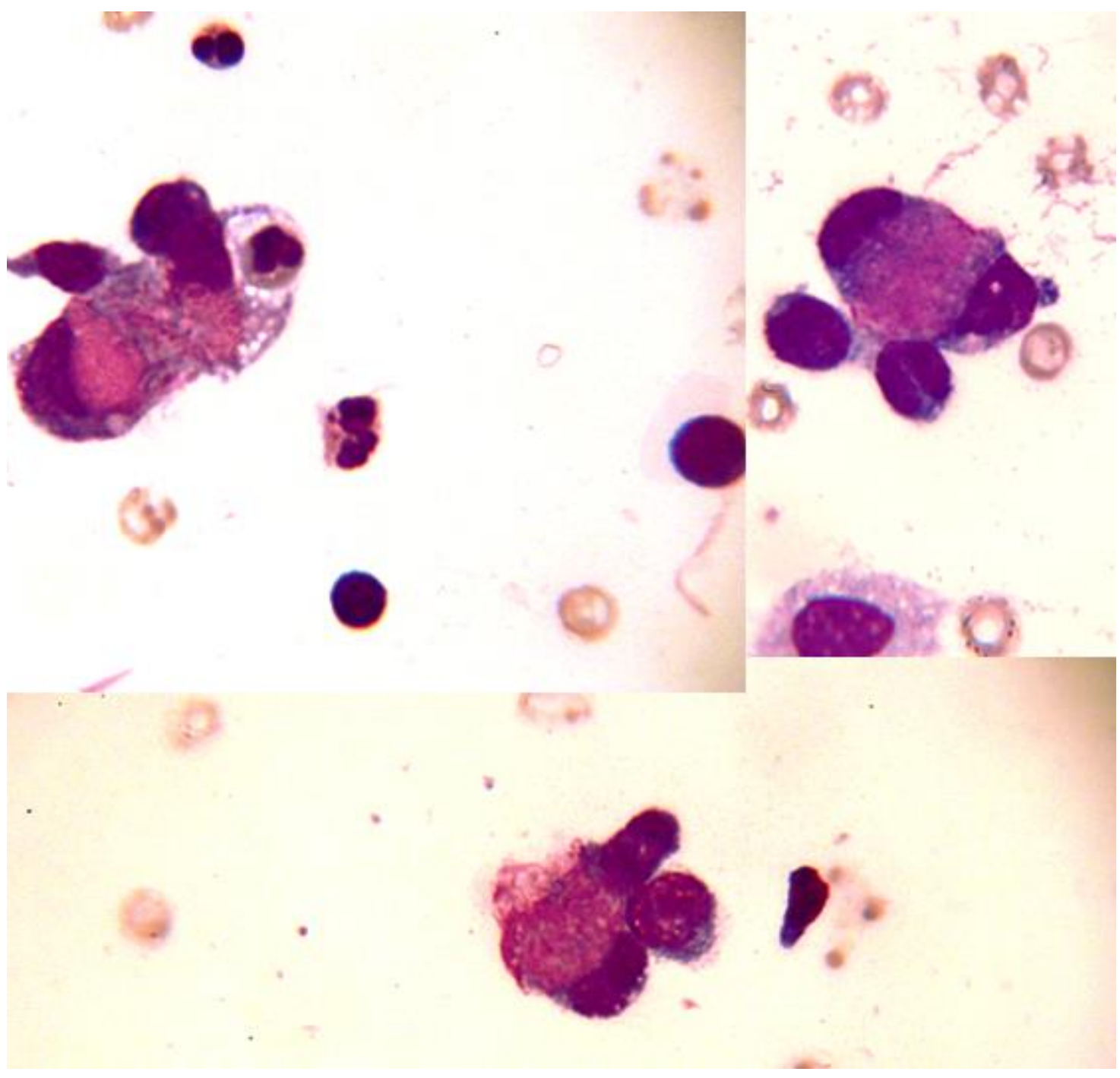

Abbildung 1: LE-Zellen im Pleuraerguss (Präparat der Lungenfachklinik Immenhausen; freundlicherweise überlassen von Dr. Rittmeyer)

Seröse Schleimhäute sind äußerst empfindlich und reagieren auf geringste Reize mit fast identischen zellulären Mustern, fast immer mit Vermehrung von Mesothelzellen und Lymphozyten.

\subsubsection{Histologische Sicherung der Diagnose bei Verdacht auf malignen Pleura- erguss}

Hat eine zytologische Untersuchung des Pleurapunktates keine malignen Zellen nachweisen können, ist bei entsprechender klinischer Notwendigkeit eine histologische Sicherung der Pleurakarzinose anzustreben. Zur histologischen Sicherung sind Methoden der Wahl nach den Leitlinien der British Thorax Society (Hooper et al. 2010) zum einen bei vorhandener nodulärer Pleuraveränderung mit unilateralem Pleuraerguss unklarer Genese eine bildgesteuerte transcutane Pleurabiopsie mit Tru-Cut-Nadel und zum ande- 
ren eine Thorakoskopie. In der histologischen Abklärung der malignen Pleuraergüsse zeigen die computertomographisch oder ultraschallgesteuerte Pleurabiopsien eine höhere diagnostische Erfolgsquote als sogenannte Blindbiopsien der Pleura.

Die ersten Blindbiopsien wurden in 50iger Jahren in den USA eingeführt (Defrancis et al. 1955). Eine Blindbiopsie ist nur angezeigt bei Patienten mit Pleuraerguss oder Pneumothorax.

Eine Blindbiopsie der Pleura zeigt für $44 \%$ der untersuchten Patienten ein zutreffendes Ergebnis (Loddenkemper 1981). Chakrabarti et al. (2006) fanden dieses Ergebnis bei $38 \%$ der untersuchten Patienten. Bei diesen, bei denen das Pleuragewebe suffizient mit einer Abrahms-Nadel entnommen wurde, betrug die Sensitivität allein für eine Neoplasie $51 \%$.

Die geringe diagnostische Zuverlässigkeit der durch eine Blindbiopsie gewonnenen histologischen Pleuraproben ist bei malignen Pleuraergüssen von der benutzten Nadel unabhängig. Bei der Verwendung einer Blindbiopsie wird nur das intracostale Rippenfell erreicht. Die typischen Metastasen der Pleura werden unabhängig von dem histologischen Typ des Tumors bei einer Blindbiopsie nicht erreicht. Denn die Ausbreitung der Pleurakarzinose findet von basalen Abschnitten der Hemithoraces in aufwärtiger Richtung statt (Canto et al. 1983). Deswegen ist für manche Autoren eine ungezielte Pleurabiopsie in der Diagnostik der Pleurakarzinose obsolet (Köhler et al. 2015). Gleichwohl empfiehlt man heutzutage die Anwendung von Blindbiopsien in Ländern mit geringen finanziellen Ressourcen im Gesundheitssystem zur Diagnostik einer Tuberkulose bei einer Sensitivität von 80 \% (Koegelenberg et al. 2010).

Der Goldstandard der histologischen Pleuradiagnostik ist die Thorakoskopie. Sie ist höchstsensitiv bei der Diagnose einer Pleurakarzinose, wenn die zytologischen Ergebnisse des Pleuraergusses negativ sind (Ferrer et al. 2005). Nach Loddenkemper (1981) lag die diagnostische Ausbeute im Falle eines malignen Pleuraergusses bei $97 \%$.

Die Methode der Brustkorbspiegelung wurde im Jahre 1910 durch Christian Jacobaeus veröffentlicht. Die von Jacobaeus beschriebene thorakoskopische Adhäsiolyse verbesserte die Technik der Anlage eines künstlichen Pneumothorax und war bis Mitte des 20. Jahrhunderts das Standardverfahren der Pneumologen in Europa und Nordamerika in der Therapie (Bergmann et al. 2006). In den 1950iger Jahren, mit Einführung einer Chemotherapie der Tuberkulose, wurde die sogenannte Jacobaeus-Operation weniger 
angewandt. Nur im kontinentalen Europa wurde die Thorakoskopie als diagnostische Methode der Pleuraerkrankungen in einigen Zentren weiterentwickelt (Marchetti et al. 2011). Mit der Entwicklung videooptischer Verfahren und endoskopisch-chirurgischer Instrumente in den 80er und 90er Jahren des 20. Jahrhunderts erfuhr die Thorakoskopie eine Renaissance. Als videoasisstierte Thorakoskopie (VATS) ermöglicht sie nicht nur eine diagnostische Klärung des Pleuraergusses, sondern auch die Entnahme von Keilresektaten der Lunge zur weiteren histologischen Diagnostik von interstitiellen Lungenerkrankungen sowie peripheren Lungenrundherden (Bergmann et al. 2006).

Heutzutage ist die Thorakoskopie eine Methode, die sowohl von Pneumologen als auch Thoraxchirurgen angewandt wird. Eine internistische Thorakoskopie wird in allgemeinen durchgeführt mit Lokalanästhesie in einem Endoskopieraum und unter Einsatz von Mehrweginstrumenten. Die Thorakoskopie wird über eine Trokar-Zugangstelle durchgeführt und dient vor allem diagnostischen Zwecken. Die Hauptindikationen sind exsudative Ergüsse unklarer Ätiologie, das Staging bei malignem Mesotheliom oder Lungenkrebs sowie bei Behandlung von malignen oder anderen chronischen Ergüssen mittels Talkum-Pleurodese (Loddenkemper 2005). In den letzten Jahren wurde eine semirigide internistische Thorakoskopie entwickelt. Es wurde nachgewiesen, dass diese Methode trotz der kleineren Biopsiegröße ähnliche diagnostische Ausbeute erzielen kann wie herkömmliche Instrumente (Khan et al. 2012). Im Gegensatz dazu ist die videoassistierte Thorakoskopie eine minimal-invasive chirurgische Prozedur in einem OP-Saal, unter intravenöser Vollnarkose und mit Anwendung eines Doppellumen-Tubus mit der Möglichkeit von seitengetrennter Beatmung (Rodriguez-Panadero et al. 2006). Je nach Indikation sind hier bis zu vier Zugangsstellen notwendig.

Bei Bronchialkarzinom, Evaluation von unklaren pulmonalen Raumforderungen, Staging von mediastinalen Lymphknoten sowie Resektion von primären und metastasierten Lungentumoren kommt VATS zur Anwendung (Lin und Iannettoni 2003). Beim Wechsel von VATS auf eine laterale Thorakotomie kann im OP-Saal eine Erweiterung der Operation auf eine Lobektomie mit systemischer mediastinaler Lymphknotendissektion erfolgen (Schirren et al. 1994). Im Vergleich mit einer internistischen Thorakoskopie nur durch VATS können mit einer Adhäsiolyse die Verwachsungen gelöst und die Kammerungen geöffnet werden (Bergmann et al. 2006). So ist VATS die Methode der Wahl bei der Behandlung von septierten chronischen Pleuraergüssen oder organisierten Pleuraempyemen in den Händen von Chirurgen. 


\subsection{Fragestellung}

Seit vielen Jahren wird der in der Lungenfachklinik Immenhausen durch Thorakozentese gewonnene Pleuraerguss zur zytologischen Beurteilung in die LungenClinic Großhansdorf versandt. Der dort hauptberuflich tätige pneumologische Zytopathologe verfügt über 35 Jahre Erfahrung in der Beurteilung der zytologischen Präparate. In Großhansdorf werden jährlich ca. 36.000 Präparate vor allem aus den Atemwegen und der Pleura zytologisch beurteilt. Trotz einer guten logistischen Organisation kann eine „Versandzytologie“ zu einer Zeitverzögerung zwischen der Entnahme des Materials und dem Befund sowie Verfälschung der Befunde durch Einfluss von Umweltfaktoren auf das versandte Material unterwegs zum externen Labor führen. Entsprechend werden in der Lungenfachklinik Immenhausen die Pleuraergüsse meist noch am Entnahmetag anhand zytomorphologischen Kriterien parallel auch durch zwei Pneumologen vor Ort beurteilt.

Die diagnostische Treffsicherheit der Pleurazytologie ist von der Erfahrung des Untersuchers abhängig (Johnston 1985). Das Ziel dieser retrospektiven Studie ist es, bei identischem Untersuchungsmaterial zu überprüfen, wie stark die zytomorphologischen Befunde zweier klinisch tätigen Pneumologen mit den Befunden eines hauptberuflichen Zytopathologen übereinstimmen. Insbesondere sollen die Cohens-Kappa-Werte ( $\kappa-$ Werte) für die Beurteilerübereinstimmung, prozentuale Übereinstimmung sowie die Treffsicherheit der Befunde der beiden Beurteiler ermittelt werden.

Können die Pneumologen unter real-life-Bedingungen zytologisch verlässlich die malignen Pleuraergüsse erkennen? Hierzu wurden insgesamt 795 Pleuraergusszytologien aus dem Zeitraum zwischen den Jahren 2011 und 2014 verglichen. 


\section{Material und Methoden}

\subsection{Diagnostische Thorakozentese}

Zur Abklärung eines Pleuraergusses werden die Patienten der Lungenfachklinik Immenhausen standardmäßig einer Thorakozentese unterzogen. Eine Pleuraergusspunktion erfolgt nach internen Leitlinien der Lungenfachklinik. Vor der Punktion findet eine Prüfung der Kontraindikationen mit Ausschluss einer hämorrhagischen Diathese statt. Die Patienten werden diagnostisch nicht punktiert, wenn der INR-Wert $<1,5$ und/oder der PTT-Wert $>50 \mathrm{~s}$ ist und/oder Thrombozyten von $<50.000 / \mu \mathrm{l}$ im Blut sind und bei therapeutischer Antikoagulation.

Die diagnostische Thorakozentese erfolgt standardmäßig in einer sitzenden Position des Patienten. Nach einer sonographischen Lokalisation wird die Punktionsstelle in der hinteren Axillarlinie oder Skapularlinie am entsprechenden Rippenoberrand markiert. Die Punktion findet nach lokaler Hautdesinfektion der Punktionsstelle und nach Lokalanästhesie statt. Hier wird die Haut sowie subkutanes Gewebe und der Rippenoberrand mit 5-10 ml $1 \%$ Scandicain-Lösung mit einer langen G20-Kanüle infiltriert. Die Kanüle wird unter ständigem Wechsel von Injektion des Lokalanästhetikums und Aspiration vorgeschoben. Nach Aspiration des Pleuraergusses wird die LokalanästhetikumInjektion sofort unterbrochen. Nach der Lokalanästhesie wird die Punktionskanüle zurück in die subkutane Position gezogen und die neue, leere Spritze auf diese Kanüle aufgesetzt. Unter ständiger Aspiration wird die Kanüle zurück in den Pleuraraum vorgeschoben bis sich erneut ein Pleuraerguss aspirieren lässt. Zur weiteren Untersuchung entnimmt man standardmäßig ca. $40 \mathrm{ml}$ Pleuraerguss. Die Nadel wird unter VasalvaManöver nach der Punktion entfernt und ein Verband an der Punktionstelle angelegt. Die entnommene Flüssigkeit wird in das Labor gebracht. Bei jeder ersten diagnostischen Pleurapunktion des Patienten der Lungenfachklinik Immenhausen werden aus dem Erguss Gesamteiweiß, Glukose, LDH, Cholesterin, pH und CEA bestimmt. Zusätzlich wird eine Mykobakterien-Kultur angelegt und Material zur zytologischen Untersuchung gesichert. Nur wenn während der Punktion makroskopisch Empyem oder trüber Erguss auftritt sowie bei klinischen Zeichen einer Infektion oder Pneumonie werden Bakterienkulturen aus dem Pleurapunktat angelegt. 


\subsection{Herstellung der zytologischen Präparate}

Die Pleuraergussprobe (maximal 7,5 ml) für das zytologische Labor der LungenClinic Großhansdorf wird jeweils unbearbeitet in einem heparinisierten Röhrchen per Kurierpost versandt. Ab Freitagnachmittag und ab dem Nachmittag am Vortag eines Feiertages wird der Erguss im Kühlschrank bis zum nächsten Arbeitstag aufbewahrt und dann versandt. Die Menge von maximal $15 \mathrm{ml}$ ist für die zytologische Untersuchung vor Ort vorgesehen.

Die weitere Aufarbeitung der Probe ist in den beiden Laboren gleich. Das Pleurapunktat wird in Zentrifugenröhrchen umgefüllt und 5 Minuten bei $2.000 \mathrm{UpM}$ zentrifugiert.

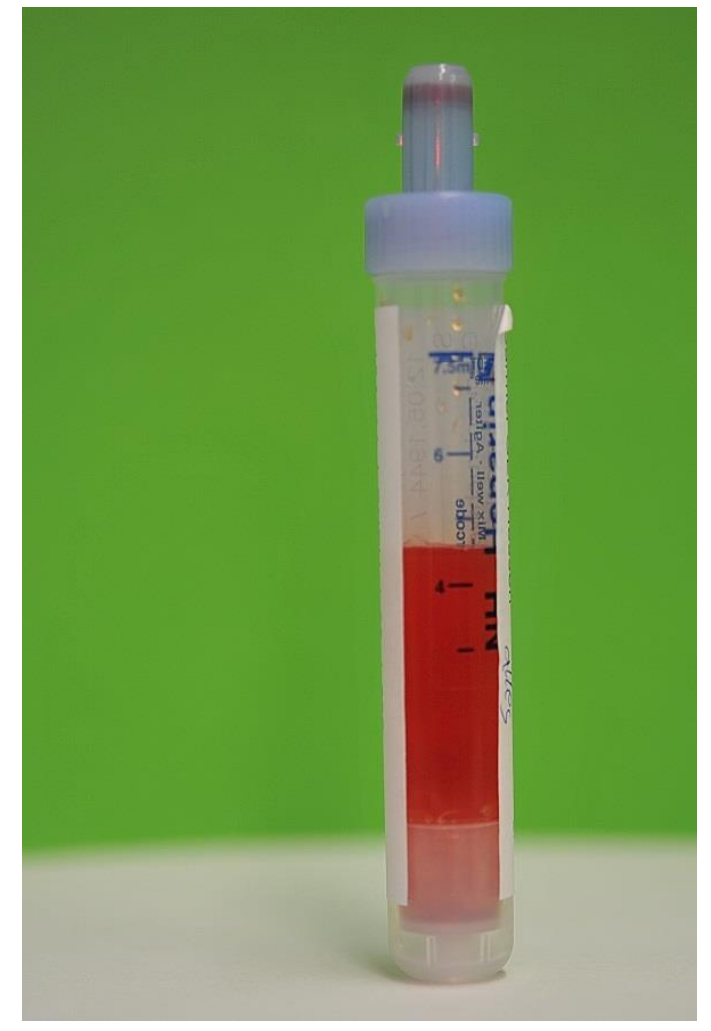

Abbildung 2: Pleuraergussprobe im Heparin-Röhrchen

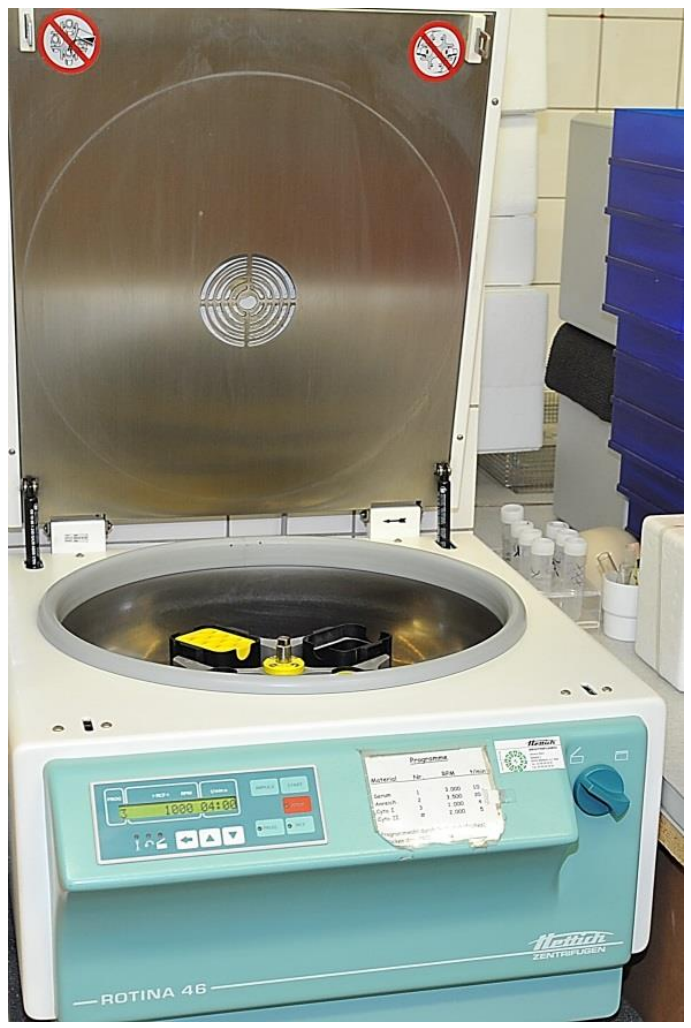

Abbildung 3: Zentrifuge

Der so entstandene Überstand wird abgeschüttet, die Röhrchen stehen einen Moment. Das Sediment wird vorschichtig gemischt. Dann werden mit der Pipette $20 \mu 1$ des Sediments entnommen und auf einen Objektträger gegeben. Mit einem zweiten Objektträger wird der Sedimenttropfen der Länge nach ausgezogen. Pro eingesandter Probe werden auf diese Weise mindestens fünf Ausstriche angefertigt, mit mindestens 15 Minuten einer Lufttrocknung und so dann einer Routinefärbung nach Pappenheim unterzogen. 


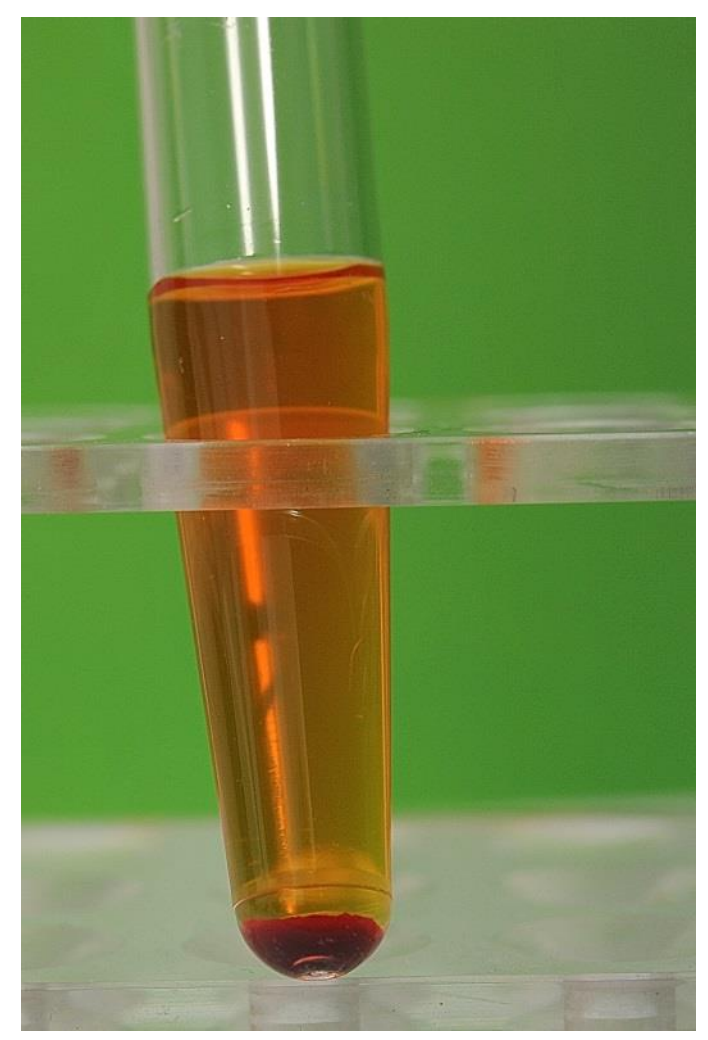

Abbildung 4: Pleuraerguss nach Behandlung in der Zentrifuge

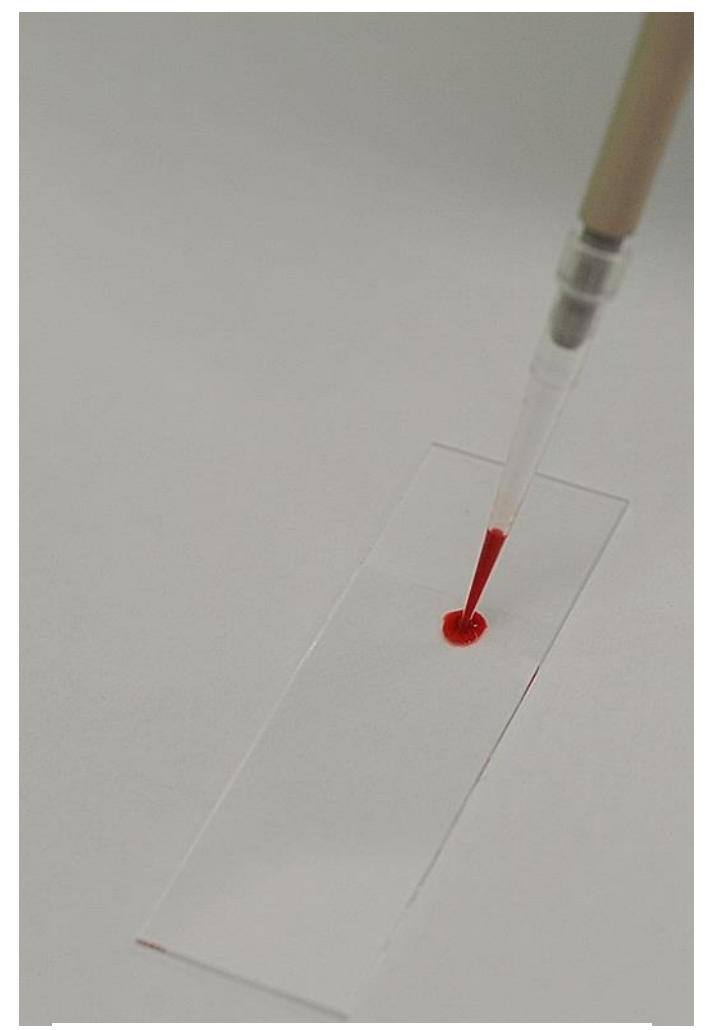

Abbildung 6: Pipettieren des Sediments

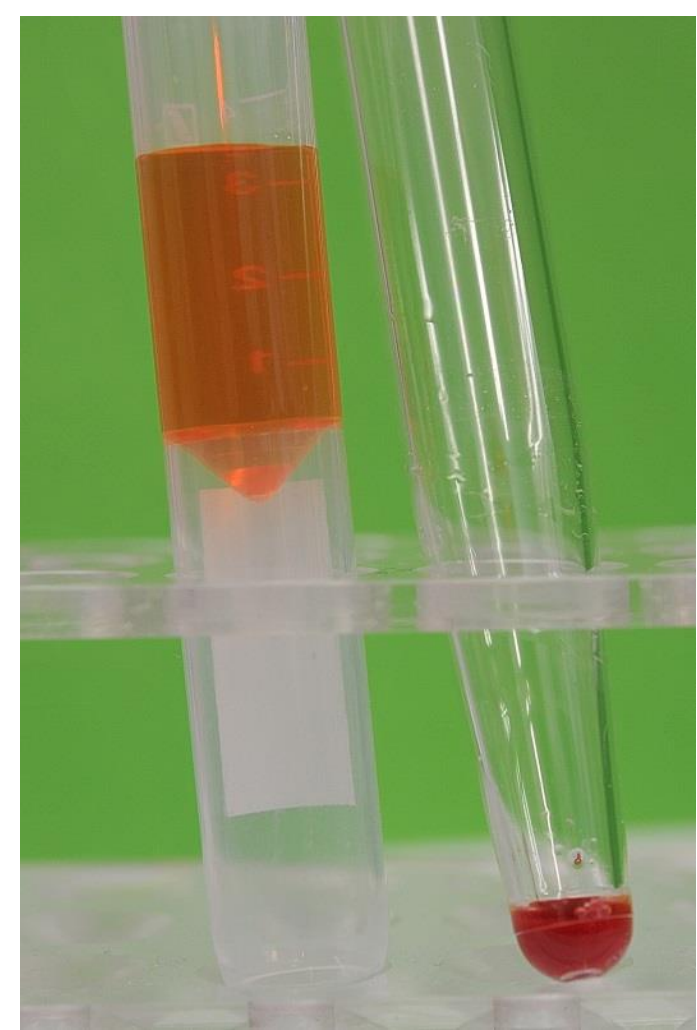

Abbildung 5: Trennung des Überstandes nach Behandlung in der Zentrifuge

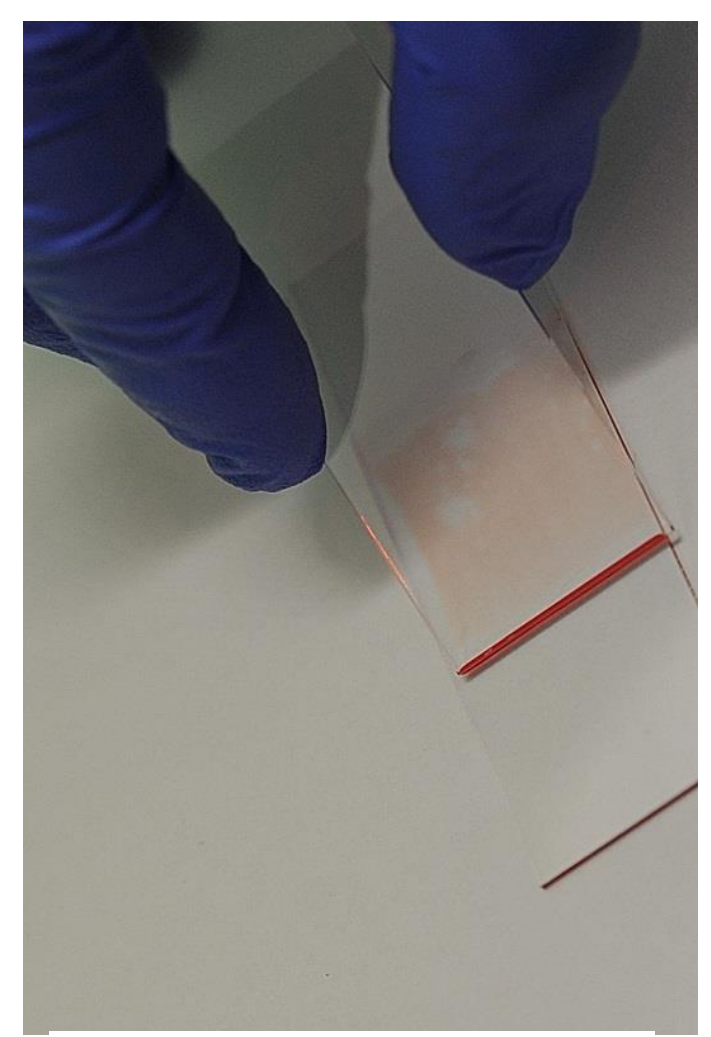

Abbildung 7: Ausstreichen des zytologischen Präparates 


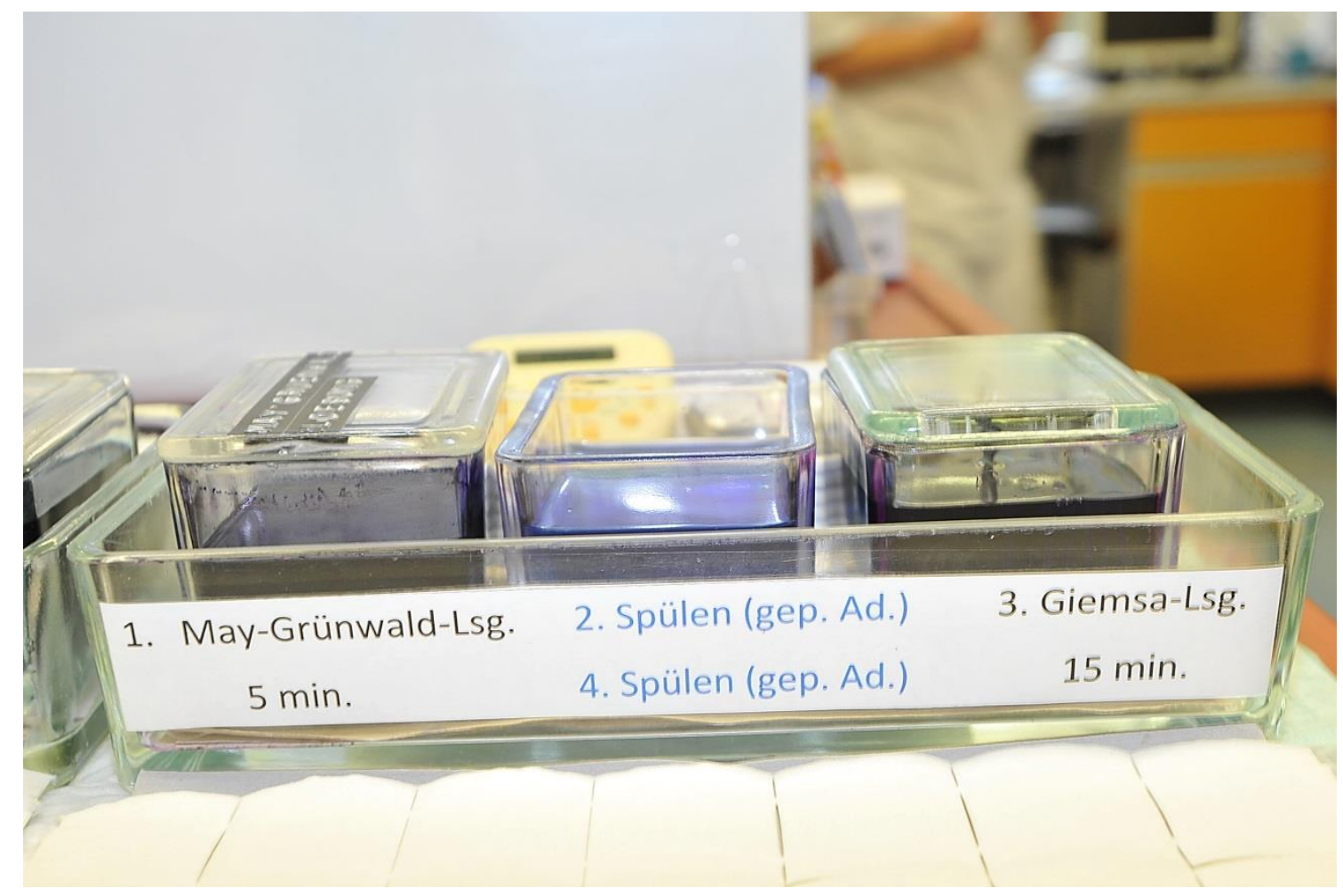

Abbildung 8: Vorrichtung für May-Grünwald-Färbung

Ein luftgetrocknetes Präparat wird in konzentrierter May-Grünwald-Lösung (modifiziert für Mikroskopie May-Grünwalds Eosin-Methylenblaulösung) fünf Minuten lang gefärbt. Anschließend spült man die Objektträger mit destilliertem Wasser und färbt in der Giemsa-Lösung (für die Mikroskopie modifizierter Azur-Eosin-Methylenblaulösung verdünnt 1:20 mit destiliertem Wasser) 15 Minuten lang. So bearbeitete Objektträger werden zum Schluss mit Leitungswasser abgespült.

\subsection{Zytologische Beurteilung}

Die fertig gefärbten Ausstrichpräparate werden einer zytologischen Beurteilung vorgelegt. In der Lungenfachklinik Immenhausen werden die Präparate durch zwei klinisch tätige Pneumologen zytologisch beurteilt. Diese sind Fachärzte für Innere Medizin und Pneumologie und auch oberärztlich in die Betreuung der Patienten mit einem Pleuraerguss eingebunden. Die beiden Pneumologen verfügen über 4 und 10 Jahre Erfahrung in der zytologischen Beurteilung des Materials. Diese Erfahrung beruht auf der Beurteilung von ca. 2.000 zytologischen Präparaten aus serösen Körperflüssigkeiten sowie Nadelaspiraten pro Jahr. Bei der Beurteilung der Zytologiepräparate konsultieren sich die beiden Fachärzte gegenseitig. 


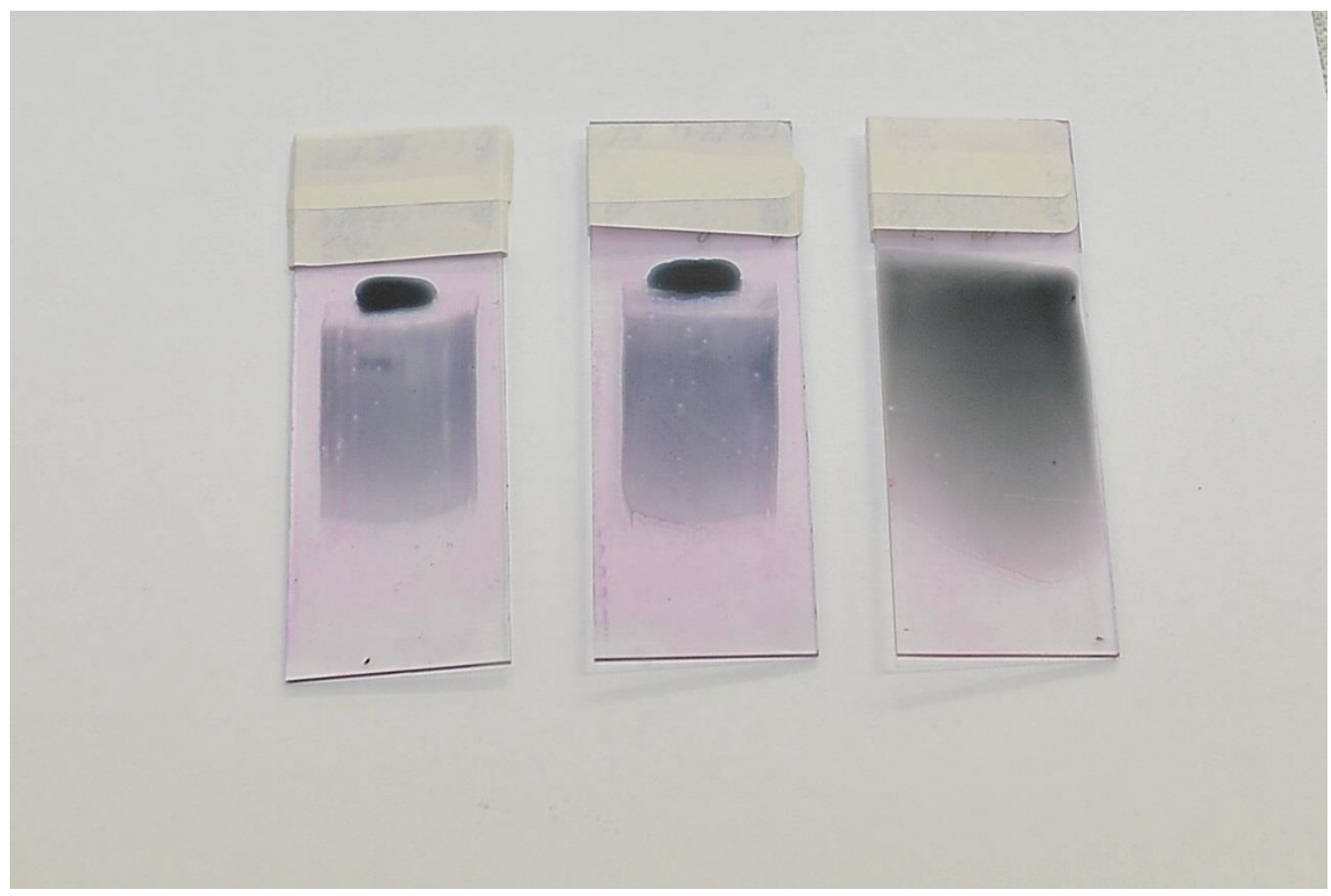

Abbildung 9: Zytologische Präparate nach May-Grünwald-Färbung

Im zytologischen Labor der LungenClinic Großhansdorf ist ein hauptberuflicher Zytopathologe mit einer entsprechenden Weiterbildung und mehrjähriger Erfahrung tätig. Es werden dort ca. 36.000 zytologische Präparate, sowohl aus der LungenClinic selbst als auch aus ganz Deutschland, jährlich beurteilt.

\subsection{Gewinnung der Studiendaten}

Zwecks Durchführung dieser retrospektiven Studie wurden insgesamt 1.054 Pleuraergusszytologien aus dem Zeitraum zwischen den Jahren 2011 und 2014 aus der Datenbank des klinisch-zytologischen Labors der Lungenfachklinik Immenhausen ausgewertet. Die Daten kommen ausschließlich von den stationär und ambulant behandelten $\mathrm{Pa}$ tienten dieser Klinik. Das Einzugsgebiet der Klinik erstreckt sich vor allem über Nordhessen. Wegen der geographischen Lage der Klinik werden auch viele Patienten aus Südniedersachsen und Ostwestfalen behandelt.

In der Datenbank des klinisch-zytologischen Labors der Lungenfachklinik sind alle Zytologiebefunde (u.a. auch Aszites-Zytologien sowie zytologische Befunde der transbronchialen Nadelaspirationen aus den thorakalen Lymphknoten) in einer chronologischen Folge gespeichert. Pleurazytologiebefunde wurden abgefragt und in einer ExcelTabelle übernommen. 


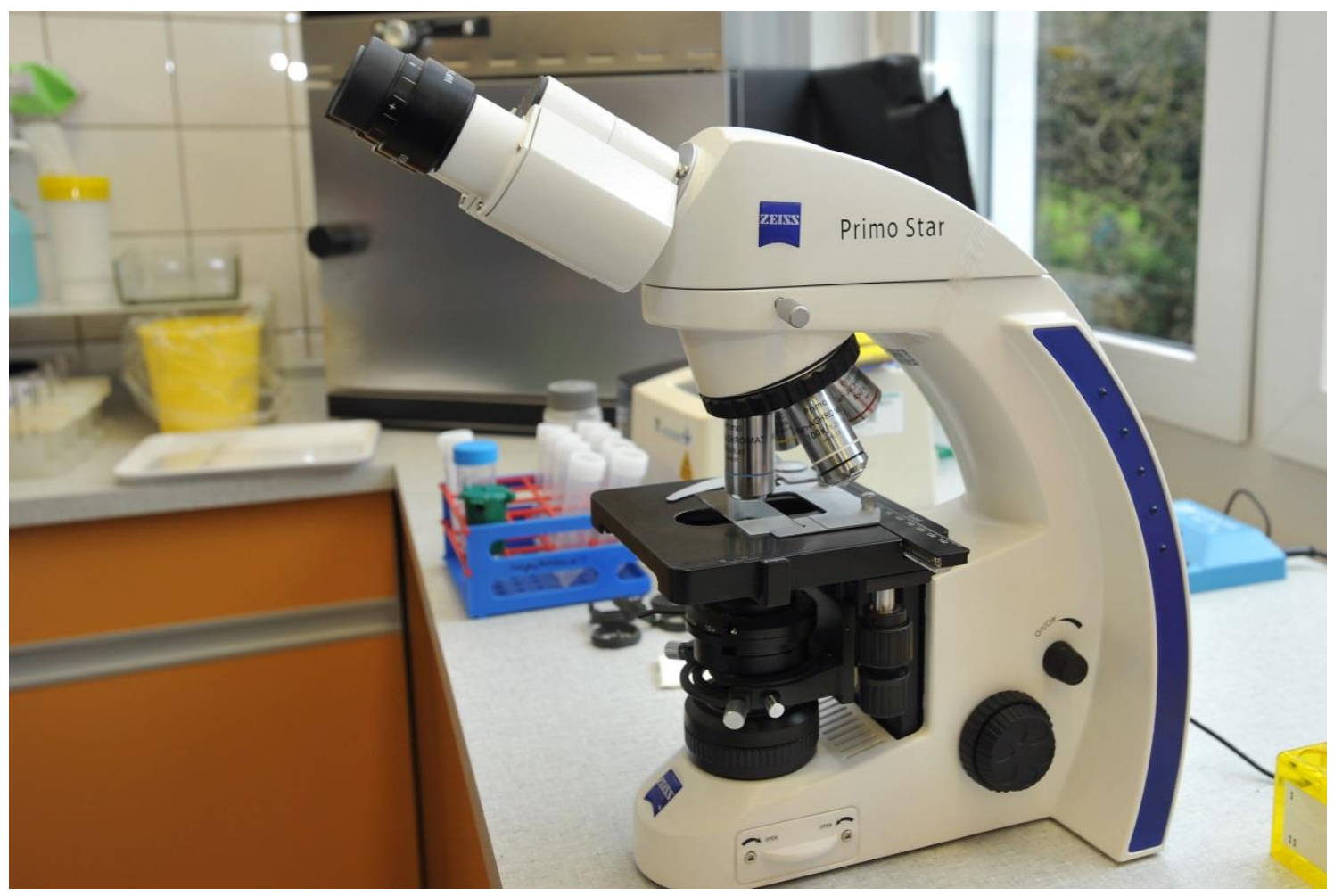

Abbildung 10: Mikroskop Primo Star Fa. Zeiss in der Lungenfachklinik Immenhausen

Es konnten die Namen der Patienten, Datum sowie Seitenlokalisation der Thorakozentese und die zytologische Befunde festgestellt werden. In dieser Datenbank fehlen die Geburtsdaten der Patienten.

Die Proben der Pleuraergüsse wurden routinemäßig zur zytologischen Beurteilung auch in das zytologische Labor der LungenClinic Großhansdorf versandt. Die schriftlichen Befunde der Pleuraergusszytologien werden den behandelnden Ärzten in der Lungenfachklinik Immenhausen per Post geliefert. Sie sind in den diagnostischen und therapeutischen Entscheidungen ebenso wie eigene zytologische Befunde der Lungenfachklinik Immenhausen einbezogen.

Anhand der vorbereiteten Excel-Tabelle der zytologischen Befunde der Pleuraergüsse aus der Lungenfachklinik Immenhausen erfolgte eine Datenbankabfrage der entsprechenden Befunde der LungenClinic Großhansdorf. Deren zytologische Befunde der Pleurapunktate wurden hier ebenso in einer Excel-Tabelle chronologisch gespeichert.

Anschließend erfolgte die Datenzuordnung der beiden Tabellen. Die fehlenden Geburtsdaten der Patienten aus der Datenbank des klinisch-zytologischen Labors der Lungenfachklinik Immenhausen konnten anhand der Operationen- und Prozedurenschlüssel (OPS) des digitalen Krankenhausinformationssystems ergänzt werden. Jede Pleuraer- 
gusspunktion, auch wiederholt, wird digital als OPS kodiert. Bei der Datenzuordnung wurden offensichtliche Fehler betreffend der Patientennamen oder des Geburtsdatums korrigiert. Im Datensatz der LungenClinic Großhansdorf war gelegentlich das Eingangsdatum der Probe in Großhansdorf als Entnahmedatum angegeben. Hier hatte der Verfasser eine Toleranzgrenze von 5 Tagen eingeräumt. Die Unterschiede des Datums der Entnahme von mehr als 5 Tagen wurden nicht toleriert und unklare Befunde aus der zusammengefügten Datenbank entfernt. In diese Datenbank sind auch die zytologischen Befunde der Pleuraergüsse, die mehrmals bei gleichen Patienten während eines stationären Aufenthaltes durchgeführt wurden, eingeflossen.

\subsection{Zytologische Befundung der Pleuraergüsse}

Die wesentliche Aufgabe der zytologischen Beurteilung der Pleuraergussausstriche unter rein morphologischem Aspekt ist die Feststellung, ob in der untersuchten Zellpopulation maligne Zellen vorliegen. Im ersten Schritt der Beurteilung ist zu unterscheiden zwischen reaktivierten Mesothelzellen und Zellen eines Malignoms. Mesothelzellen sind eine ubiquitäre Komponente bei den meisten serösen Ergüssen. Das Aussehen der Zellkerne und des Zytoplasmas von diesen hyperplastischen und hypertrophischen Zellen können die Eigenschaften einer neoplastischen Transformation imitieren (Bedrossian 1998). Sowohl die physiologisch vorkommenden als auch reaktiv veränderte Mesothelzellen können in der Pleuraflüssigkeit einzeln oder in Gruppen vorkommen. Reaktiv veränderte Mesothelzellen bilden oft dreidimensionale Zellverbände, die kugelig, papillär oder azinär sein können. Im Vergleich zu physiologischen Mesothelzellen sind die Kerne größer. Manchmal ist auch Mehrkernigkeit möglich, die Nukleolen nehmen an Größe zu (Pokieser 2001).

Sollten die abnormen Zellen eine eigene Population zwischen reaktivierten Mesothelzellen bilden, besteht ein Verdacht auf Malignität (Bedrossian 1998). Das wichtigste Merkmal eines malignen Mesothelioms ist eine Fülle von Zellen mit zytoplasmatischer Charakteristik reaktivierter Mesothelzellen. Die Zellen weisen ein verdichtetes Zytoplasma mit kleinen, homogenen zytoplasmatischen Vakuolen auf (Whitaker 2000). Die Zellen eines Mesothelioms können eng aneinander liegen oder sind durch einen schmalen Spalt getrennt (Pokieser 2001). Zu anderen Charakteristika der Mesotheliomzellen im Vergleich zur Mesothelzellen nach Atay und Topalidis (1994) gehören:

- häufige Kernabsprengungen 
- Doppelkernigkeit

- Bildung von Riesenzellen mit unregelmäßiger Anisokaryose

- aufgehobene Zellgrenzen

- Bildung von Mikrovilli.

Viel häufiger als reaktivierte Mesothelzellen bilden die Mesotheliomzellen kugelige oder papilläre Verbände (Atay und Topalidis 1994).

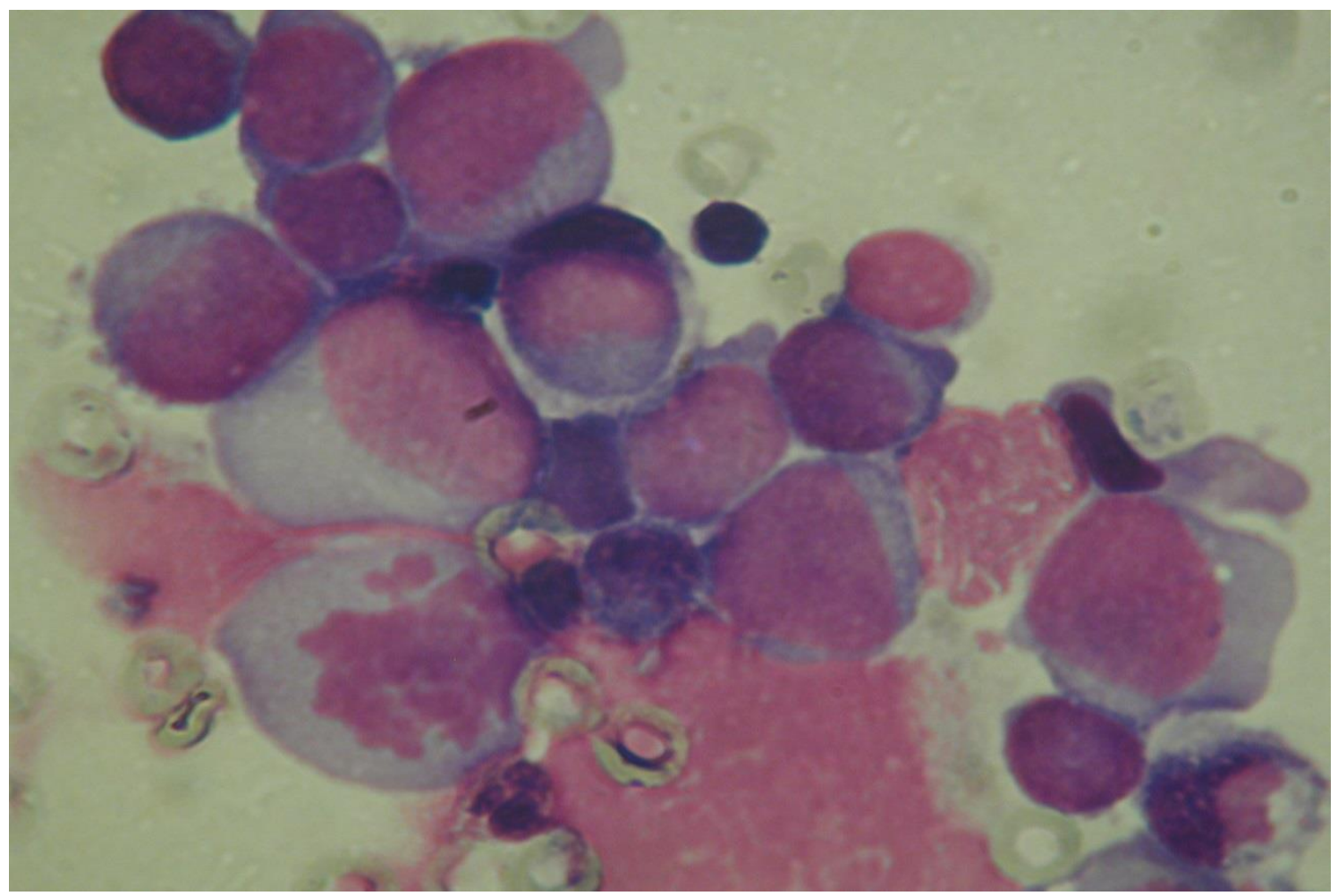

Abbildung 11: Zellen eines kleinzelligen Bronchialkarzinoms der Lunge im Pleuraerguss (Präparat der Lungenfachklinik Immenhausen; freundlicherweise überlassen von Dr. Rittmeyer)

In der zytomorphologischen Diagnostik der Pleuraergüsse bei einem Lungenkarzinom ist neben der Differenzierung zwischen malignen und benignen Pleuraergüssen eine Unterscheidung zwischen Pleuraerguss durch ein kleinzelliges und nicht-kleinzelliges Karzinom notwendig. Die exflorierten Zellen des kleinzelligen Bronchialkarzinoms sind klein und haben hauptsächlich spärliches Zytoplasma sowie kleine anaplastische Kerne mit feinretikulärer Chromatinstruktur (Motherby et al. 1999). Die Zellen bilden vorwiegend kleinere Zellverbände mit typischer Moulding-Lagerung (Schubert 2014). Auch Zellkanibalismus kann für ein kleinzelliges Bronchialkarzinom sprechen (Pokieser 2001). 
Eine rein zytologisch-morphologische Unterscheidung zwischen Pleuraerguss durch ein kleinzelliges Bronchialkarzinom und einem Non-Hodgkin-Lymphom ist eine große Herausforderung. Laut Pokieser et al. (2001) sind nur einzeln liegende Zellen und nicht - wie bei einem kleinzelligen Bronchialkarzinom die Zellverbände - ein wichtiges differenzialdiagnostisches Merkmal zur Unterscheidung eines Pleuraergusses durch NHL.

Etwas größere hyperchromatische Kerne und vermehrte Zellverbände können wichtige differentialdiagnostische Merkmale sein zur Unterscheidung zwischen Zellen eines SCLC und einem wenig differenzierten Adenokarzinom. Mit der Entwicklung von systemischen Behandlungsmethoden des fortgeschrittenen Bronchialkarzinoms nimmt auch die Bedeutung der Differenzierung zwischen Typen des nicht-kleinzelligen Bronchialkarzinoms zu. Zu den drei wichtigsten zytologischen Merkmalen eines gut differenzierten Plattenepithelkarzinoms gehören: Keratinisation der Zytoplasmas, Epithelperlen und intrazelluläre Brücken (Travis et al. 2013). Die gut differenzierten Plattenepithelkarzinome metastasieren selten in die Pleurahöhle. Bei einem mäßig differenzierten Plattenepithelkarzinom der Lunge (nicht verhornendes Plattenepithelkarzinom) können evtl. nur die Ansätze der Verhornung bei flachen Zellverbänden mit hoher Kerndichte (nuclear crowding) und meist schlechter Abgrenzbarkeit der einzelnen Zellen sichtbar werden. Dagegen dominieren beim niedrig differenzierten Plattenepithelkarzinom der Lunge nestartige und auch zapfenförmige Verbände und monomorphe einzelliegende Zellen mit nackten Kernen (Pokieser 2001).

Bei schlecht differenzierten Plattenepithel- oder Adenokarzinomen können die typischen morphologischen Merkmale fehlen und eine rein zytomorphologische Differenzierung im Lichtmikroskop unmöglich machen. Hier greift man z.B. zur weiteren Differenzierung zu einer Immunzytochemie (Travis et al. 2013). Ist die Kern-PlasmaRelation bei Plattenepithelkarzinomen kernbetont, zeigen die Adenokarzinome eine eher ausgewogene Relation (Atay und Topalidis 1994). Die Zellen des bronchialen Adenokarzinoms können zytologisch unterschiedliche Zellverbände - flach, dreidimensional, selten kugelig oder papillär - bilden. Das basophile Zytoplasma ist merklich granuliert oder schaumig, lichtdurchlässig und enthält Vakuolen (Travis et al. 2013). Bei gut differenzierten Adenokarzinomen kann man oft anhand der Lichtmikroskopie den Ursprung des Tumors erkennen. Ein Vergleich der wichtigsten Merkmale der verschiedenen Adenokarzinomen wird nach Pokieser et al. in Tabelle 1 dargestellt. 
Tabelle 1: Zytomorphologische Differenzialdiagnose von Adenokarzinomen unterschiedlichen Ursprungs (in Anlehnung nach Pokieser 2001)

\begin{tabular}{|c|c|c|c|c|c|}
\hline & Mammakarzinom & Ovarialkarzinom & Dickdarmkarzinom & Nierenkarzinom & Lungenkarzinom \\
\hline $\begin{array}{l}\frac{0}{0} \\
\frac{1}{10} \\
\frac{0}{2} \\
\stackrel{0}{1} \\
\bar{N}\end{array}$ & $\begin{array}{l}\text { Gleichförmig, kugelig, scharf begrenzt } \\
\text { oder dreidimensional, fingerförmig } \\
\text { und verzweigt; spärlich bis reichlich } \\
\text { monomorphe Einzelzellen beim inva- } \\
\text { siven duktalem Karzinom; monomor- } \\
\text { phe Einzelzellen und evtl. kleine Zell- } \\
\text { gruppen bei lobulärem Karzinom; } \\
\text { Polymorphe Einzelzellen, ev. Riesen- } \\
\text { zellen; kleinere und größere Zellver- } \\
\text { bände bei medullärem Karzinom }\end{array}$ & $\begin{array}{l}\text { Dreidimensionale Zellverbände } \\
\text { mit großen, ballonartigen Zellen } \\
\text { und kleinen uniformen Zellen bei } \\
\text { muzinösem Typ oder dichte pa- } \\
\text { pilläre Verbände mit konzent- } \\
\text { risch gesichteten Pasamomkör- } \\
\text { pern bei serösem und papillärem } \\
\text { Typ }\end{array}$ & $\begin{array}{l}\text { Große, polymorphe, } \\
\text { ungeordnete dreidi- } \\
\text { mensionale Zellverbän- } \\
\text { de oder papilläre Ver- } \\
\text { bände }\end{array}$ & $\begin{array}{l}\text { Einzeln liegende Zellen in } \\
\text { lockeren Verbänden }\end{array}$ & $\begin{array}{l}\text { Flache oder dreidimensionale } \\
\text { Zellverbände, evtl. kugelig oder } \\
\text { papillär, häufig auch mit Ver- } \\
\text { zweigungen und azinär }\end{array}$ \\
\hline 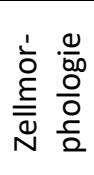 & $\begin{array}{l}\text { Zellen monomorph (duktales und } \\
\text { lobuläres Karzinom) oder polymorph } \\
\text { (medulläres Karzinom); Zellen rund } \\
\text { und ovalär (lobuläres Karzinom) }\end{array}$ & Mittelgroß, rund evtl. polygonal & $\begin{array}{l}\text { Große, hochzylindrische } \\
\text { Zellen }\end{array}$ & Mittelgroße Zellen & $\begin{array}{l}\text { Becherzellimitation mit rudi- } \\
\text { mentärer Pseudozilienbildung } \\
\text { (hochdifferenziertes Adeno- } \\
\text { karzinom) }\end{array}$ \\
\hline $\begin{array}{l}\frac{5}{d} \\
\frac{5}{2}\end{array}$ & $\begin{array}{l}\text { Mit Längsachse parallel zur glatten } \\
\text { Kugeloberfläche gestellt, hyperchro- } \\
\text { matisch mit feinem bis grob granulä- } \\
\text { rem Chromatin, evtl. ein kleiner Nuk- } \\
\text { leolus (duktales Karzinom); grobschol- } \\
\text { liges Chromatin und große Nukleolen } \\
\text { (medulläres Karzinom), vergröbertes } \\
\text { Chromatin mit mehreren prominen- } \\
\text { ten Nukleolen (apokrines Karzinom) }\end{array}$ & $\begin{array}{l}\text { Unterschiedliche Größe, poly- } \\
\text { morph, feines bis grobscholliges } \\
\text { Chromatin, evtl. Nukleolen }\end{array}$ & $\begin{array}{l}\text { Rund bis oval, grobe } \\
\text { Chromatinstruktur, ein } \\
\text { oder mehrere deutliche } \\
\text { Nukleolen }\end{array}$ & $\begin{array}{l}\text { Zentral oder peripher } \\
\text { gelegter Kern, dichte } \\
\text { retikuläre Chromatin- } \\
\text { struktur und kleines, } \\
\text { deutliches Nukleolus }\end{array}$ & $\begin{array}{l}\text { Exzentrisch, feingranuliertes } \\
\text { Chromatin, häufig prominente } \\
\text { große Nukleole }\end{array}$ \\
\hline $\begin{array}{l}\frac{\pi}{2} \\
\frac{0}{0} \\
\frac{\pi}{0} \\
\frac{0}{2} \\
\frac{1}{N}\end{array}$ & Schmal, scharf begrenzt & $\begin{array}{l}\text { Fein vakuolisiert, einzelne kleine } \\
\text { bis große Vakuolen, evtl. Riesen- } \\
\text { vakuolen }\end{array}$ & $\begin{array}{l}\text { Zartes Zytoplasma, evtl. } \\
\text { scharf begrenzte } \\
\text { Schleimvakuolen }\end{array}$ & $\begin{array}{l}\text { Reichlich, hell (pflanzen- } \\
\text { zellenähnlich) scharf } \\
\text { begrenzt, klar oder fein } \\
\text { vakuolisiert }\end{array}$ & Zart, mit Vakuolen \\
\hline
\end{tabular}




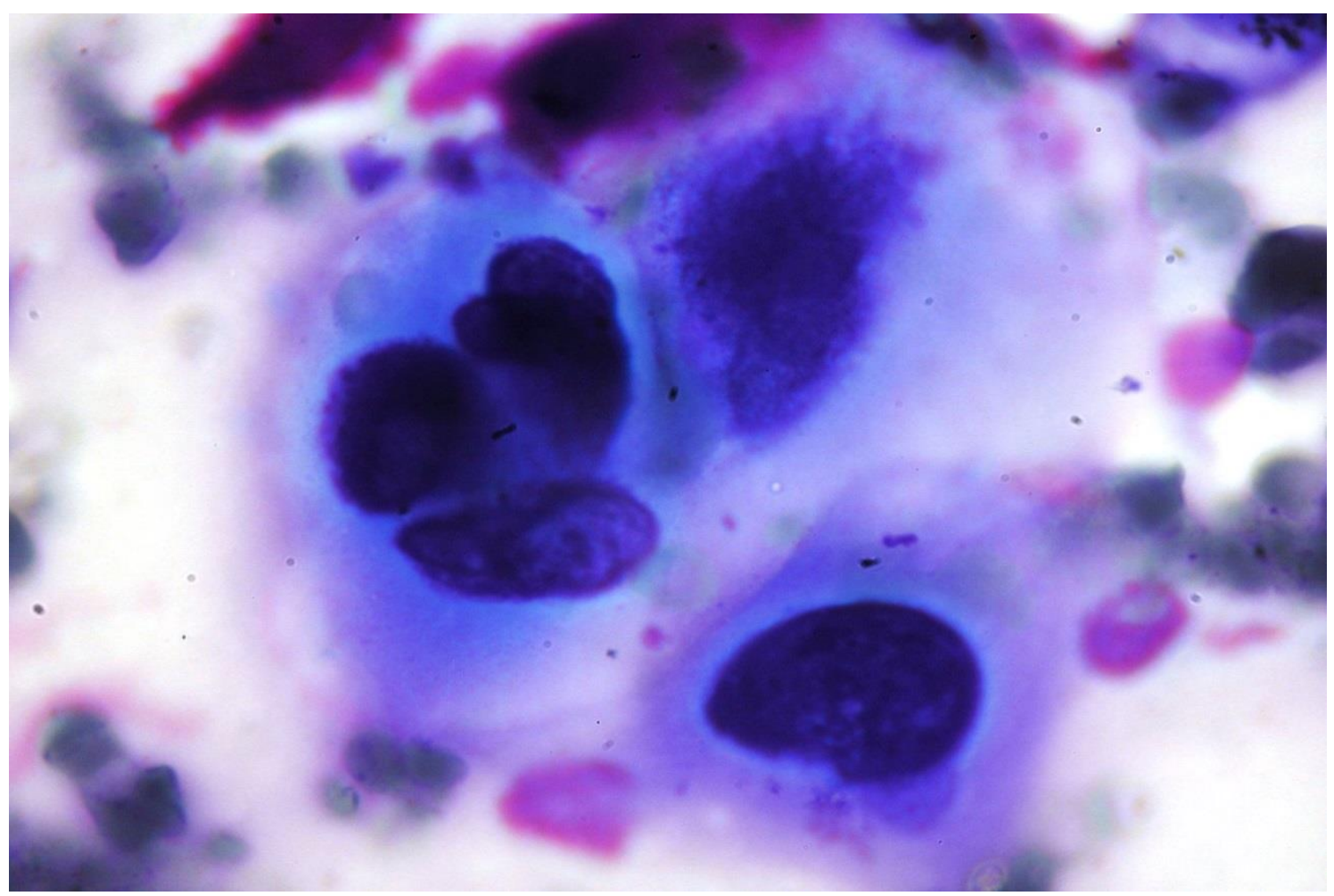

Abbildung 12: Zellen eines verhornenden Plattenepithelkarzinoms der Lunge im Pleuraerguss (Präparat der Lungenfachklinik Immenhausen; freundlicherweise überlassen von Dr. Rittmeyer)

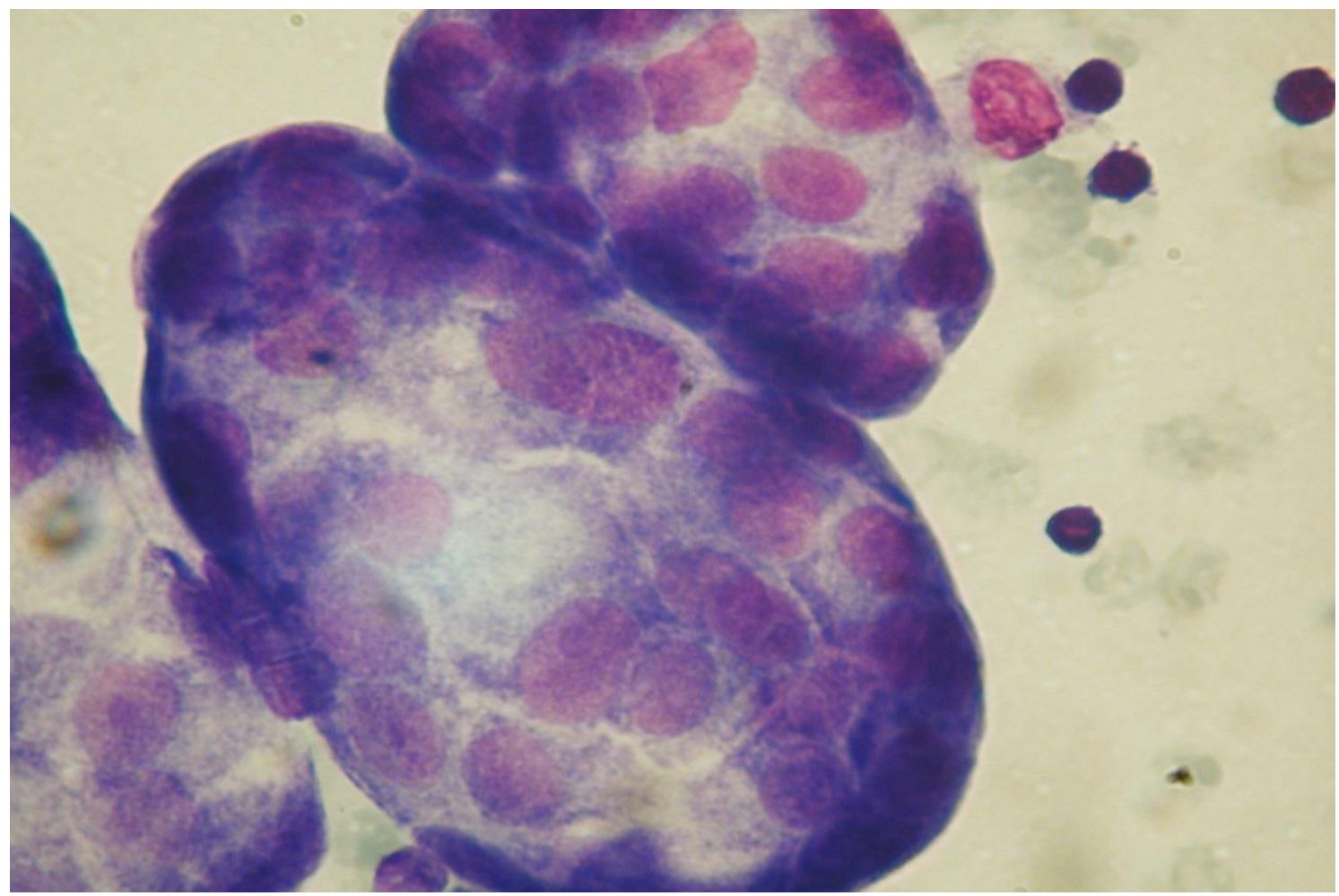

Abbildung 13: Zellen eines schleimbildenden Adenokarzinoms im Pleuraerguss (Präparat der Lungenfachklinik Immenhausen; freundlicherweise überlassen von Dr. Rittmey- 


\subsection{Kategorisierung der zytologischen und histologischen Befunde für diese Studie}

Sowohl die Pneumologen der Lungenfachklinik Immenhausen als auch der Zytopathologe der LungenClinic Großhansdorf befolgen in der zytologischen Befundung von Pleuraergussausstrichen einer von Böcking empfohlene Systematik (Böcking 1998). Wie in der histopathologischen Diagnostik werden die gleichen Ordnungsprinzipien, Termini und Klassifikationen verwendet. Einer zytologischen Diagnostik der Neoplasien im Pleuraerguss stehen nur kleine Zellverbände und oft nur einzelne Zellen zur Verfügung. Nach Böcking (1998) fehlt eine wesentliche gewebliche Verbandstruktur als entscheidende Informationsquelle und die Möglichkeiten zur histogenetischen Tumorklassifikation und zur Typisierung von Entzündungen sind aufgrund von lediglich morphologischen Kriterien begrenzt. Eine zytologische Diagnose allein liefert oft nur Hinweise für weitere differentialdiagnostische Überlegungen. Wesentliche Aufgabe der Zytologie ist die Dignitätsbeurteilung, ob in der untersuchten Zellpopulation maligne Zellen vorliegen. Das ist als Vorfelddiagnostik ausreichend.

Die Zuordnung der zytologischen Präparate in dieser Studie zu einer von drei Kategorien erfolgt durch die Beurteiler aufgrund der Klartextdiagnose und der Einstufung der Malignitätswahrscheinlichkeit in Anlehnung an die „Düsseldorfer Klassifikation“. Fehlen im zytologischen Präparat maligne Zellen, werden die Befunde der Kategorie „,benigne“ zugeordnet. Sind die Tumorzellen im Präparat nicht sicher nachweisbar, da z. B. abnorme und nicht weiter klassifizierbare Zellen vorliegen, ist der Befund zweifelhaft und wird der Kategorie „suspekt“ zugeordnet. Der dritten Kategorie „maligne“ werden die Befunde mit dringendem Verdacht auf Tumorzellen oder mit Tumorzellen zugeschrieben (Böcking 1998).

In der zweiten Zuordnung der Befunde der Beurteiler aus der Lungenfachklinik Immenhausen und aus der LungenClinic Großhansdorf wurden unter Berücksichtigung der wesentlichen zytomorphologischen Kriterien diese Befunde systematisiert und einer für diese Studie gebildeten zytologisch-diagnostischen Kategorien zugeordnet: Neoplasie, Karzinom, nicht-kleinzelliges Karzinom, Adenokarzinom, Mesotheliom, kleinzelliges Karzinom, Suspekt, Unspezifisch.

Bei fehlender Möglichkeit zur Durchführung einer Immunzytochemie wie in der Lungenfachklinik Immenhausen ist keine weitere Differenzierung von Adenokarzinomen 
oder Lymphomen gegeben. Somit wurden in dieser Studie nur zytomorphologische Befunde ohne Immunzytochemie berücksichtigt.

Die Systematik der Zuordnung der Befunde durch die Beurteiler der vorgenannten Kliniken wird in Tabelle 2 und Tabelle 3 dargestellt.

In der nächsten Stufe wurde nach Durchsicht der ärztlichen Dokumentation der betreffenden Patienten der weitere diagnostische Verlauf unter besonderer Berücksichtigung der Thorakoskopien festgestellt.

Die Thorakoskopien wurden internistisch in der Lungenfachklinik Immenhausen oder chirurgisch in der Klinik für Thorax-, Herz- und Gefäßchirurgie der Universitätsmedizin Göttingen durchgeführt. Die aufgrund einer Thorakoskopie erhaltenen histologischen Befunde von 128 Patienten dienen als „Goldstandard“ zur annähernden Berechnung der Spezifität und Sensitivität der zytologischen Befunde. Die histologischen Ergebnisse werden entsprechend der zytologischen Untersuchungen den Kategorien „maligne“ oder „benigne“ zugeschrieben. Suspekte oder zweifelhafte histologische Befunde der thorakoskopisch gewonnenen Pleuraproben fanden sich nicht.

Tabelle 2: $\quad$ Systematik der Zuordnung der zytologischen Befunde der Pneumologen zu dem Kategoriensystem der Studie

\begin{tabular}{|l|l|}
\hline Original Lungenfachklinik Immenhausen & \multicolumn{1}{c|}{ Studienkategorien } \\
\hline Carzinom & Karzinom \\
\hline Exsudat & Unspezifisch \\
\hline Hämolytisch & Unspezifisch \\
\hline Hämorrhagisch & Unspezifisch \\
\hline Lymphozytär & Unspezifisch \\
\hline Neutrophil & Unspezifisch \\
\hline NHL & Neoplasie \\
\hline Nicht-kleinzelliges Karzinom & Nicht-kleinzelliges Karzinom \\
\hline NSCLC & Nicht-kleinzelliges Karzinom \\
\hline Reaktiv & Unspezifisch \\
\hline Schmutzig & Unspezifisch \\
\hline Transsudat & Transsudat \\
\hline Zellarm & Unspezifisch \\
\hline Zellreich & Unspezifisch \\
\hline Zweifelhaft & Suspekt \\
\hline
\end{tabular}


Tabelle 3: $\quad$ Systematik der Zuordnung der zytologischen Befunde des Zytopathologen zu den Kategorien der Studie

\begin{tabular}{|c|c|}
\hline Original LungenClinic Großhansdorf & Studienkategorien \\
\hline $\begin{array}{l}\text { Adenokarzinom sicher - metastasierendes Mammakarzinom } \\
\text { möglich }\end{array}$ & Adenokarzinom \\
\hline $\begin{array}{l}\text { Adenokarzinom sicher - metastasierendes Mammakarzinom } \\
\text { wahrscheinlich }\end{array}$ & Adenokarzinom \\
\hline Akut aufgetretener Pleuraerguss & unspezifisch \\
\hline Chronisch-adaptierte Pleuritis & unspezifisch \\
\hline Einzelzellen eines niedrig differenzierten Adenokarzinoms. & Adenokarzinom \\
\hline Entzündlicher Pleuraprozess & unspezifisch \\
\hline Eosinophile Pleuritis & unspezifisch \\
\hline Eosinophiler Erguss & unspezifisch \\
\hline Granulozytäre Entzündung & unspezifisch \\
\hline Granulozytärer Erguss vom Transsudattyp & unspezifisch \\
\hline Haemorrhagische Pleuritis & unspezifisch \\
\hline Haemorrhagischer Pleuraerguss vom Transsudattyp & unspezifisch \\
\hline Haemorrhagischer Pleuraerguss & unspezifisch \\
\hline Kontrollbedürftiger Befund & suspekt \\
\hline $\begin{array}{l}\text { Maligner Tumor sicher - malignes epitheliales Pleurame- } \\
\text { sotheliom sehr wahrscheinlich }\end{array}$ & Mesotheliom \\
\hline Maligner Tumor sicher - Plasmozytom sehr wahrscheinlich & Neoplasie \\
\hline Malignes epitheliales Mesotheliom & Mesotheliom \\
\hline Malignes, epitheliales Pleuramesotheliom & Mesotheliom \\
\hline Mäßig differenziertes Adenokarzinom. & Adenokarzinom \\
\hline Mäßig differenziertes, pulmonales Adenokarzinom & Adenokarzinom \\
\hline Mäßig differenziertes, schleimbildendes Adenokarzinom & Adenokarzinom \\
\hline Niedrig differenzierter maligner Tumor & Neoplasie \\
\hline $\begin{array}{l}\text { Niedrig differenziertes Adenokarzinom sicher - hyperne- } \\
\text { phroides Karzinom möglich }\end{array}$ & Adenokarzinom \\
\hline $\begin{array}{l}\text { Niedrig differenziertes Adenokarzinom sicher - metastasie- } \\
\text { rendes Mammakarzinom möglich }\end{array}$ & Adenokarzinom \\
\hline Niedrig differenziertes Adenokarzinom & Adenokarzinom \\
\hline Niedrig differenziertes, nicht-kleinzelliges Karzinom & $\begin{array}{l}\text { Nicht-kleinzelliges Kar- } \\
\text { zinom }\end{array}$ \\
\hline Niedrig differenziertes, schleimbildendes Adenokarzinom & Adenokarzinom \\
\hline $\begin{array}{l}\text { Niedrig differenziertes, vermutlich neuroendokrines Karzi- } \\
\text { nom }\end{array}$ & Karzinom \\
\hline Pleuraerguss vom Transsudattyp & unspezifisch \\
\hline Pleurakarzinose eines kleinzelligen Bronchialkarzinoms & $\mathrm{SCLC}$ \\
\hline Pleurakarzinose eines niedrig differenzierten Karzinoms & Karzinom \\
\hline Schleimbildendes Adenokarzinom & Adenokarzinom \\
\hline $\begin{array}{l}\text { Schleimbildendes Adenokarzinom sicher - DD metastasie- } \\
\text { rendes Ovarialkarzinom möglich }\end{array}$ & Adenokarzinom \\
\hline Transsudat sicher - "e vacuo" - Erguss sehr wahrscheinlich & unspezifisch \\
\hline
\end{tabular}


Tabelle 3: $\quad$ Fortsetzung von Seite 30

\begin{tabular}{|l|l|}
\hline Tumorverdächtiger Befund & suspekt \\
\hline Unspezifische Pleuritis & unspezifisch \\
\hline Unspezifische, chronisch - adaptierte Pleuritis & unspezifisch \\
\hline Unspezifische, granulozytäre Entzündung & unspezifisch \\
\hline Unspezifische, haemorrhagische Pleuritis & unspezifisch \\
\hline Unspezifische, hämorrhagische Pleuritis & unspezifisch \\
\hline Unspezifischer Erguss sicher - Transsudat wahrscheinlich & unspezifisch \\
\hline Unspezifischer Erguss & unspezifisch \\
\hline Unspezifischer granulozytärer Erguss vom Transsudattyp & unspezifisch \\
\hline Unspezifischer kardialer Erguss & unspezifisch \\
\hline Unspezifischer Pleuraerguss vom Transsudattyp & unspezifisch \\
\hline Unspezifischer Reizerguss & unspezifisch \\
\hline Unspezifischer, chronisch-adaptierter Erguss & unspezifisch \\
\hline Unspezifischer, mesothelialer Erguss & unspezifisch \\
\hline Unspezifisches Pleuraempyem & Empyem \\
\hline Unverdächtige Ausstriche peripheren Blutes & unspezifisch \\
\hline V.a. metastasierendes Mammakarzinom & Adenokarzinom \\
\hline Verdacht maligner Tumor & suspekt \\
\hline
\end{tabular}

\subsection{Statistische Methoden}

\subsection{1 Übereinstimmungsbeurteilung bei Beurteilung durch zwei verschiedene Beobachter: den Pneumologen und dem Zytopathologen (interrater agree- ment)}

Cohens-Kappa-Koeffizient ist die am häufigsten verwendete Methode zu Analyse der Urteile von zwei Beobachtern (Cohen 1960). Diese erfolgt durch Verwendung eines nominalskalierten Kategoriesystems. Nach Durchsicht der zytologischen Befunde von beiden Beobachtern wurde entschieden, welche von mehreren Kategorien vorliegt. Bei echt nominalskalierten Kategoriensystemen wiegen alle Nichtübereinstimmungen gleich schwer. Die Urteile zweier Beobachter sind nur dann zuverlässig, wenn beide gleich urteilen. Für nominalskalierte Daten kann somit als grobe Orientierung festgehalten werden, dass eine hohe Zuverlässigkeit der Urteile vorliegt, wenn sich zwei Beurteiler bezüglich der Kategorienzugehörigkeit jedes beliebigen Objektes im Allgemein einig sind und nur selten zu unterschiedlichen Urteilen kommen. Diese Information wird durch Maße der Übereinstimmung quantifiziert (Wirtz und Caspar 2002).

Die Beobachter führen ihre Beurteilungen unabhängig voneinander durch. Kein Beobachter kennt die Bewertung des anderen. 
Laut Wirtz und Caspar (2002) ist die prozentuale Übereinstimmung (PÜ) das einfachste Maß der Übereinstimmung. Sie spiegelt den prozentualen Anteil der Fälle, in denen zwei oder mehrere Rater das gleiche Urteil abgebe. Die PÜ gesamt ist wie folgt definiert:

$$
\text { PÜgesamt }=\frac{\text { Anzahl der von allen Beobachtern gleich beurteilten Zytologien }}{\text { Anzahl der insgesamt beurteilten Zytologien }} \cdot 100 \%
$$

Zur Berechnung des paarweisen Übereinstimmungsmaßes ist die quadratische Übereinstimmungsmatrix der Urteile der beiden Beobachter notwendig. In die Zeilen werden Beurteilungskategorien des Beobachter 1 und in die Spalten die Beurteilungskategorien des Beobachter 2 eingetragen. $\mathrm{n}_{\mathrm{ij}}$ bezeichnet die Anzahl der Fälle, in denen der Beobachter 1 Kategorie i und der Beobachter 2 Kategorie j gewählt hat. Zur Berechnung des Kappa-Koeffizienten werden die Beobachtungen verwendet, bei denen die vollständige Übereinstimmung vorlegt (fettgedruckte Häufigkeiten in der Übereinstimmungsmatrix)

Tabelle 4: $\quad$ Übereinstimmungsmatrix bei 2 Beobachtern und mehreren (n) Objekten mit einem s-stufigen Kategoriensystem

\begin{tabular}{|c|c|c|c|c|c|c|}
\hline & \multicolumn{6}{|c|}{ Beobachter 2} \\
\hline & & $\mathrm{k}_{1}$ & $k_{2}$ & $\ldots$ & $\mathrm{k}_{\mathrm{s}}$ & $\Sigma$ \\
\hline \multirow{5}{*}{ 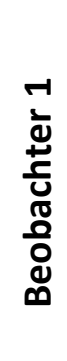 } & $\mathrm{k}_{1}$ & $\mathrm{n}_{11}$ & $\mathrm{n}_{12}$ & $\ldots$ & $\mathrm{n}_{1 \mathrm{~s}}$ & $\mathrm{n}_{1+}$ \\
\hline & $\mathrm{k}_{2}$ & $\mathrm{n}_{21}$ & $\mathrm{n}_{22}$ & $\ldots$ & $\mathrm{n}_{2 \mathrm{~s}}$ & $\mathrm{n}_{2+}$ \\
\hline & $\cdots$ & $\cdots$ & $\cdots$ & $\cdots$ & $\cdots$ & $\cdots$ \\
\hline & $\mathrm{k}_{\mathrm{s}}$ & $\mathrm{n}_{\mathrm{s} 1}$ & $\mathrm{n}_{\mathrm{s} 2}$ & $\cdots$ & $\mathbf{n}_{\text {ss }}$ & $\mathrm{n}_{\mathrm{s}+}$ \\
\hline & $\Sigma$ & $n_{+1}$ & $\mathrm{n}_{+2}$ & $\ldots$ & $n_{+s}$ & $\mathrm{~N}$ \\
\hline
\end{tabular}

Cohens-Kappa-Koeffizient basiert auf der prozentualen Übereinstimmung (PÜ) und berücksichtigt zusätzlich das Verhältnis der beobachteten zu der bei Zufall erwarteten Übereinstimmung und liefert eine standardisierte Maßzahl für das Ausmaß der positiven 
Abweichung der tatsächlich beobachteten Übereinstimmung von der Zufallserwartung. Die Ausprägung des Koeffizienten kann nicht durch überzufällig häufiges Auftreten von bestimmten Inkongruenzen zwischen zwei Beobachtern erhöht werden. CohensKappa-Koeffizient ist ein Maß, das direkt zur Quantifizierung der Beobachterübereinstimmung entwickelt wurde (Wirtz und Caspar 2002).

Der relative Anteil der Fälle, in denen die Beobachter identische Urteile abgegeben haben $\left(\mathrm{P}_{\mathrm{o}}\right)$, errechnet sich nach Wirtz und Caspar (2002)wie folgt:

$$
P_{o}=\frac{1}{100} \cdot \sum_{0=1}^{s} n_{i i}
$$

$\mathrm{n}_{\mathrm{ii}}=$ Anzahl der Übereinstimmungen bezüglich der Kategorie $\mathrm{i}$

$\mathrm{s}=$ Anzahl der Kategorien

Der relative Anteil der Übereinstimmungen bei zufälligem Rateverhalten $\left(\mathrm{P}_{\mathrm{e}}\right)$ wird nach Wirtz und Caspar wie folgt definiert

$$
P_{e}=\frac{1}{N^{2}} \times \sum_{j=1}^{s} n_{+j} \cdot n_{j+}=\sum_{j=1}^{s} h_{+j} \cdot h_{j+}
$$

$\mathrm{n}_{+\mathrm{j}}$ und $\mathrm{n}_{\mathrm{j}+}=$ Anzahl der Objekte, die vom Rater 1 bzw. 2 insgesamt Kategorie j zugewiesen wurden (Randsummen s. Tabelle 4)

$\mathrm{h}_{+\mathrm{j}}$ und $\mathrm{h}_{\mathrm{j}+}=$ entsprechende relative Häufigkeiten $(\mathrm{h}=\mathrm{n} / \mathrm{N})$

$\mathrm{N}=\quad$ Anzahl der Objekte

Cohens-Kappa folgt nach Wirtz und Caspar der Berechnungsformel:

$$
\kappa=\frac{P_{o}-P_{e}}{1-P_{e}}
$$

Der Wert des $\kappa$ liegt zwischen 1,0 für perfekte Übereinstimmung und -1,0 für völlig unterschiedliche Einschätzungen durch die beiden Beobachter. Im Normalfall ist der 
Variationsbereich von $\kappa$ eingeschränkt. Die o. g. extremen Werte können nur erreicht werden, wenn die Randsummenverteilung für beide Beobachter gleich sind.

Bei der Beurteilung der Güte von $\kappa$ sind keine allgemein gültigen Aussagen möglich. Diese sind immer von der konkreten Situation abhängig (Grouven et al. 2007). In der Literatur werden Richtwerte angegeben (wie in Tabelle 5).

Tabelle 5: $\quad$ Stärke der Übereinstimmung in der Abhängigkeit vom $\kappa$-Wert nach Landis und Koch (1977)

\begin{tabular}{|l|l|}
\hline \multicolumn{1}{|c|}{ Wert von $\mathbf{k}$} & \multicolumn{1}{c|}{ Stärke der Übereinstimmung } \\
\hline$<0,20$ & schwach \\
\hline $0,21-0,40$ & leicht \\
\hline $0,41-0,60$ & moderat \\
\hline $0,61-0,80$ & gut \\
\hline $0,81-1,00$ & sehr gut \\
\hline
\end{tabular}

\subsection{2 Überprüfung von Sensitivität, Spezifität sowie positivem und negativem Prädikationswert der zytologischen Befunde beider Beurteiler}

Bender (2001) schreibt, dass die Effizienz eines diagnostischen Tests sich aus einer Vierfeldertafel als eine bedingte Wahrscheinlichkeit ableiten lässt. Eine Vierfeldertafel ist eine 2 × 2 -Anordnung absoluter Häufigkeiten, die sich aus einer Kreuzklassifikation von zwei binären Merkmalen X und Y ergibt (Tabelle 6). Ein binäres Merkmal ist eine Variable mit nur zwei Ausprägungen.

Tabelle 6: $\quad$ Vierfeldertafel; $\mathrm{RP}=$ richtig positiv, $\mathrm{FP}=$ falsch positiv, $\mathrm{RN}=$ richtig negativ, $\mathrm{FN}=$ falsch negativ

\begin{tabular}{|l|c|c|c|}
\hline & Krankheit (+) & Krankheit (-) & Summe \\
\hline Test (+) & RP & FP & RP + FP \\
\hline Test (-) & FN & RN & FN + RN \\
\hline Summe & RP + FN & FP + RN & RP + FP + FN + RP \\
\hline
\end{tabular}


Die grundlegenden Effizienzmaße eines diagnostischen Tests sind Sensitivität und Spezifität (Altman und Bland 1994).

Die Sensitivität eines diagnostischen Testverfahrens beschreibt die Wahrscheinlichkeit, dass tatsächlich Erkrankte $\left(\mathrm{K}_{+}\right)$in einem Test auch als krank $\left(\mathrm{T}_{+}\right)$erkannt werden. Sensitivität ist der Quotient aus richtig positiven Testergebnissen und der Summe aus richtig positiven und falsch negativen Testergebnissen.

$$
\text { Sensitivität: } \quad P\left(T_{+} \mid K_{+}\right)=\frac{P\left(T_{+} \cap K_{+}\right)}{P\left(K_{+}\right)}=\frac{R P}{R P+F N}
$$

Die Spezifität eines diagnostischen Testverfahrens gibt die Wahrscheinlichkeit an, dass tatsächlich Gesunde (K.) in einem Test als tatsächlich gesund (T_) erkannt werden. Die Spezifität ist der Quotient aus richtig negativen Testergebnissen und der Summe aus richtig negativen und falsch positiven Testergebnissen.

$$
\text { Spezifität: } P\left(T_{-} \mid K_{-}\right)\left(\frac{T_{-}}{K_{-}}\right)=\frac{P\left(T_{-} \cap K_{-}\right)}{P\left(K_{-}\right)}=\frac{R N}{R N+F P}
$$

Die Wahrscheinlichkeit für die Richtigkeit eines Testergebnisses lässt sich mit den Vorhersagewerten beantworten.

Ein positiver Prädikationswert (PPW) ist die Wahrscheinlichkeit, dass bei einem positiven Testergebnis die Krankheit auch tatsächlich vorliegt. Er berechnet sich aus dem Quotienten der richtig positiv getesteten Patienten zu allen positiv getesteten Patienten.

Positiver Prädikationswert: $P\left(K_{+} \mid T_{+}\right)=\frac{P\left(K_{+} \cap T_{+}\right)}{P\left(T_{+}\right)}=\frac{R P}{R P+F P}$

Ein negativer Prädikationswert (NPW) ist die Wahrscheinlichkeit, dass der Patient gesund ist, wenn das Ergebnis des diagnostischen Verfahrens negativ ist. Er berechnet 
sich aus dem Quotienten der richtig negativ getesteten Patienten zu allen negativ getesteten Patienten.

$$
\text { Negativer Prädikationswert: } P\left(K_{-} \mid T_{-}\right)=\frac{P\left(K_{-} \cap T_{-}\right)}{P\left(T_{-}\right)}=\frac{R N}{R N+F N}
$$

Zur Berechnung von Sensitivität und Spezifität sowie positivem und negativem Prädikationswert wurden die Befunde der Pneumologen und des Zytopathologen mit den histologischen Ergebnissen der Thorakoskopie verglichen. Es wurden nur eindeutig maligne oder benigne zytologische Ergebnisse berücksichtigt. Die suspekten zytologischen Befunde wurden aus dem Vergleich bei fehlendem diagnostischen Wert herausgenommen.

\subsubsection{Modell der logistischen Regression zur Voraussagekraft der zytologischen Befunde beider Beurteiler}

Die logistische Regression erlaubt eine statistische Auswertung des Einflusses erklärender Variablen auf eine Zielvariable (Y), die ein binäres Messniveau (z. B. Y = Krankheit ja/nein) besitzt (Bender et al. 2007).

Alle in der Studie erhobenen Parameter wurden durch das Institut für Medizinische Statistik der Universitätsmedizin Göttingen in einem logistischen Regressionsmodell kombiniert. Das Alter der Patienten sowie zytologische Ergebnisse beider Beurteiler in Kategorien maligne/benigne wurden zur Vorhersage der Malignität in einem logistischen Regressionsmodell betrachtet. Die vom Modell geschätzten Werte wurden mit der Receiver Operating Characteristic (ROC) - Kurve untersucht. Der optimale Cutoff-Punkt wurde mit Hilfe des Youden-Index bestimmt, der als Sensitivität + Spezifität - 1 definiert ist. Diesen bestimmt man für alle möglichen Cutoff-Punkte. Der Cutoff-Punkt mit dem größten Youden-Index wird als optimaler Cutoff-Punkt gewählt, da dann die Trennung der beiden Gruppen am besten gelingt. Das Signifikanzniveau wurde für alle statistischen Tests auf Alpha $=5 \%$ festgelegt. Die ROC-Kurve dient der Visualisierung, um den bestmöglichen Cutoff-Punkt zu finden, und die area under the curve (AUC) entspricht einem Gütekriterium. 
Die Bestimmung von Kappa-Werten, Sensitivität, Spezifität, PPW und NPW wurden mit Hilfe von Frau Xenia Schulz vom Institut für Medizinische Statistik der Universitätsmedizin Göttingen durchgeführt. Alle Analysen erfolgten mit der Statistiksoftware R (Version 3.1.2, www.r-project.org). Für die ROC-Analysen wurde das R-Paket "proc“ verwendet.

\subsection{Ethik}

Entsprechend der Deklaration von Helsinki gehört die Analyse von medizinischen Daten in den Bereich der medizinischen Forschung und muss damit entsprechend der ärztlichen Berufsordnung einer Ethikkommision vorgelegt werden. Dieser Verpflichtung wurde nachgekommen. Die Ethikkommision der Universitätsmedizin Göttingen äußerte keine Bedenken gegen die Durchführung dieser Studie (DOK_179_2015). Die Grundsätze des Datenschutzes wurden dem niedersächsischen Datenschutzgesetz entsprechend eingehalten. 


\section{Ergebnisse}

\subsection{Beurteilerübereinstimmung der zytologischen Befunde}

Von den 1.054 Pleuraergusszytologien aus der Lungenfachklinik Immenhausen konnte für 795 Proben von 606 Patienten ein Befund aus der LungenClinic Großhansdorf sicher zugeordnet werden.

In den Kategorien maligne-benigne-suspekt erreichte die Beurteilerübereinstimmung einen moderaten $\kappa$-Wert von 0,57 (95\% CI 0,52 - 0,63). Dies entspricht einer prozentualen Übereinstimmung von 80 \%. Die Kategorie „,suspekt“ beinhaltet jedoch Befunde, die in der täglichen klinischen Versorgung der Patienten keinen Einfluss auf die therapeutische Entscheidung haben. Nachdem von 795 Proben 96 Fälle von der Betrachtung ausgeschlossen wurden, bei denen sich die Beurteiler (die Pneumologen oder der Zytopathologe) zwischen der Diagnose maligne oder benigne nicht entscheiden konnten, ist die Beurteilerübereinstimmung mit einem $\kappa$-Wert von 0,76 (95\% CI 0,69-0,82) und prozentual von $90 \%$ gut. Nach Berücksichtigung aller Kategorien gemäß Tabelle 9 wurde eine moderate Übereinstimmung der Befunde zwischen den Pneumologen und dem Zytopathologen mit einem $\kappa$-Wert von 0,54 (95\% CI 0,49 - 0,6) erzielt. Dies entspricht einer gesamten prozentualen Übereinstimmung von $75 \%$.

Nach der Zuordnung der zytologischen Befunde von beiden Beurteilern der Befundkategorien zeigte sich, dass die Pneumologen prozentual mehr der verglichenen Pleurazytologien als maligne und suspekte beurteilt haben als der Zytopathologe. Der prozentuale Vergleich der Befunde von beiden Beurteilern wird in den Abbildungen 14 und 15 dargestellt. Die 5 Befunde kleinzelliger Karzinomen durch den Zytopathologen stimmten zu $100 \%$ mit den Befunden der Pneumologen überein. Jedoch nur 38,5\% der 13 Befunde eines kleinzelligen Bronchialkarzinoms durch die Pneumologen stimmten mit den Befunden des Zytopathologen überein.

Die beste Befundübereinstimmung zeigte sich in der Beurteilung von Adenokarzinomen. 79,9\% der Adenokarzinombefunde des Zytopathologen wurden auch als solche durch die Pneumologen beurteilt. $68 \%$ des Adenokarzinoms, befunden durch die Pneumologen, stimmten mit den Befunden des Zytopathologen überein. Die vom Zytopathologen beurteilten Adenokarzinome wurden von den Pneumologen lichtmikroskopisch auch als nicht-kleinzelliges Karzinom (6 Präparate $=4,3 \%)$, unspezifisch $(13$ 
Präparate $=9,4 \%)$, suspekt $(7$ Präparate $=5 \%)$ oder Karzinom $(2=1,4 \%)$ beurteilt, keine jedoch von den Pneumologen als Mesotheliom. Anderseits wurden die von den Pneumologen befundenen Adenokarzinome vom Zytopathologen als nicht kleinzelliges Karzinom (11 Präparate $=6,8 \%)$, Karzinom (1 Präparat $=0,6 \%)$, Neoplasie (2 Präparate $=1,2 \%$ ) und Mesotheliom (4 Präparate $=2,5 \%$ ) sowie suspekt (5 Präparate = $3,1 \%$ ) und unspezifisch (28 Präparate $=17,3 \%$ ) befunden.

25 (80,6 \%) der vom Zytopathologen befundenen Empyeme wurden auch als ein Empyem von den Pneumologen beurteilt. 5 (19,4\%) der vom Zytopathologen als Empyem klassifizierten Präparate wurden von den Pneumologen als unspezifisch gesehen. Die Pneumologen erreichten eine Übereinstimmung mit dem Zytopathologen bezüglich des Pleuraempyems von 86,2 \%; 13,8 \% der Empyeme wurden durch den Zytopathologen als unspezifisch gewertet. 


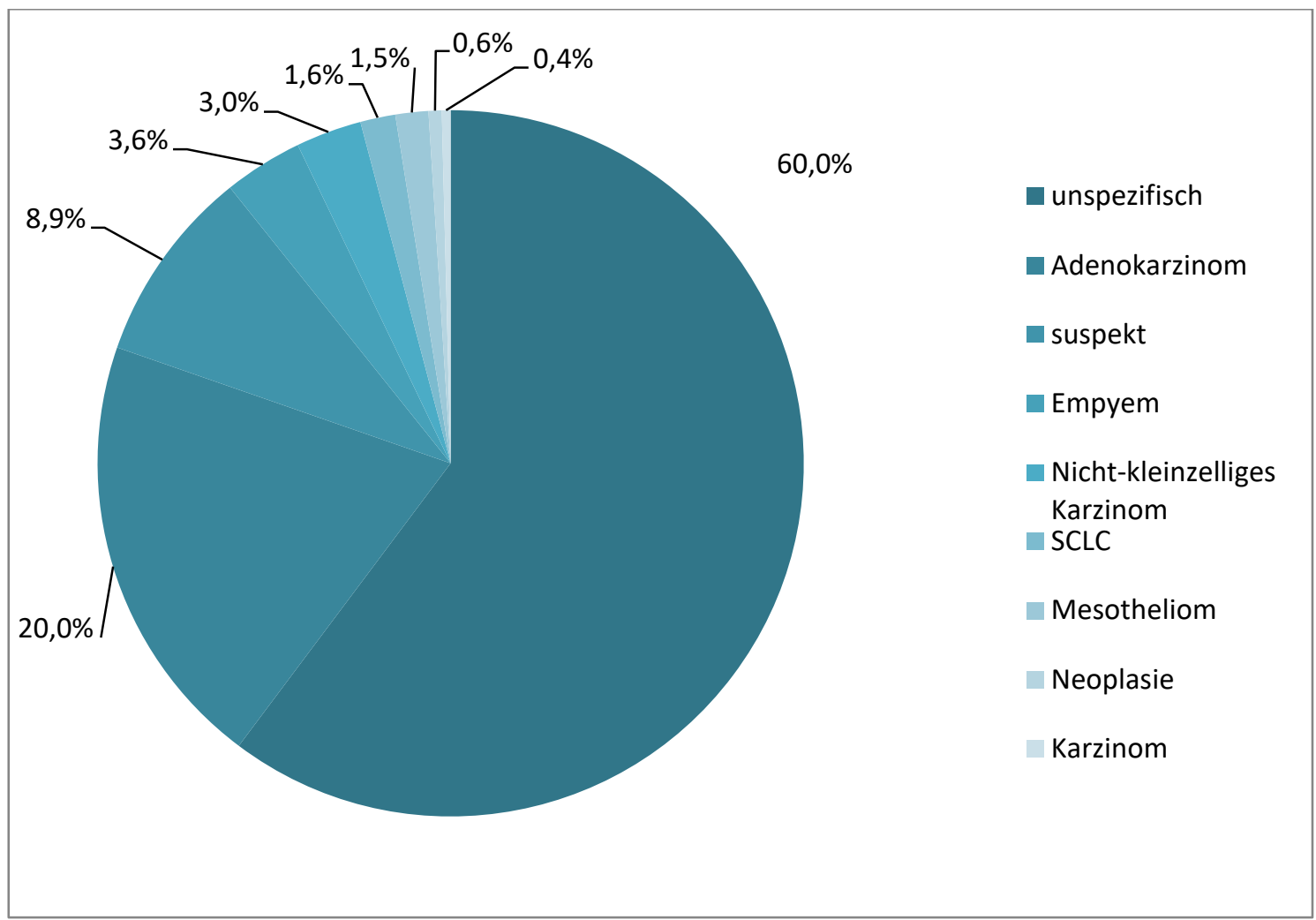

Abbildung 14: Prozentuale Verteilung zytologischer Diagnosen von Pleuraergüssen von Pneumologen $(\mathrm{N}=795)$

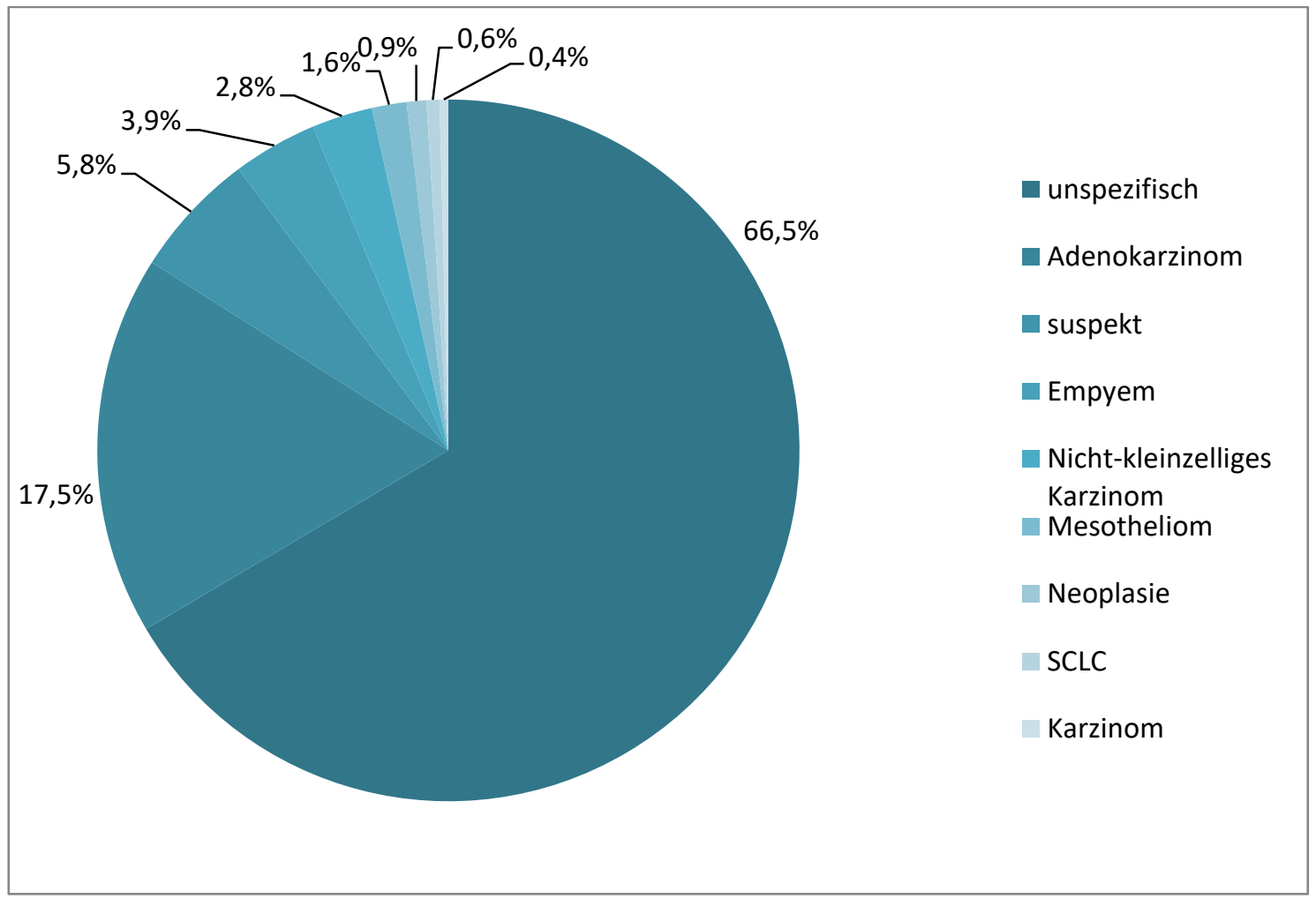

Abbildung 15:Prozentuale Verteilung zytologischer Diagnosen von Pleuraergüssen vom Zytopathologen $(\mathrm{N}=795)$ 
Tabelle 7: Kontingenztabelle für die Kategorien maligne - benigne - suspekt für Pneumologen und den Zytopathologen; $\kappa=0,57$ (95\%CI 0,52-0,63) entsprechend einer moderaten Übereinstimmung; PÜ $=80 \%$ )

\begin{tabular}{|l|c|c|c|}
\hline \multicolumn{1}{|c|}{$\mathbf{N = 7 9 5}$} & \multicolumn{3}{|c|}{ Zytopathologe } \\
\hline Pneumologen & benigne & maligne & suspekt \\
\hline benigne & 461 & 17 & 27 \\
\hline maligne & 51 & 160 & 8 \\
\hline suspekt & 48 & 12 & 11 \\
\hline
\end{tabular}

Tabelle 8: Kontingenztabelle für die Kategorien maligne-benigne für Pneumologen und den Zytopathologen; $\kappa=0,76$ (95\% CI 0,69-0,82) entsprechend einer guten Übereinstimmung; PÜ $=90 \%$ )

\begin{tabular}{|l|c|c|}
\hline \multicolumn{1}{|c|}{ N=699 } & \multicolumn{2}{|c|}{ Zytopathologe } \\
\hline Pneumologen & benigne & maligne \\
\hline benigne & 461 & 17 \\
\hline maligne & 51 & 160 \\
\hline
\end{tabular}


Tabelle 9: Kontingenztabelle mit zytologischen Befunden nach Diagnosenkategorien für Pneumologen und für den Zytopathologen; $\kappa=0,54$

(95\% CI 0,49 - 0,6) entsprechend einer moderaten Übereinstimmung; PÜ gesamt $=75 \%$

\begin{tabular}{|c|c|c|c|c|c|c|c|c|c|}
\hline & \multicolumn{9}{|c|}{ Zytopathologe } \\
\hline Pneumologen & Adeno-Ca & Empyem & Karzinom & Mesotheliom & Neoplasie & $\begin{array}{c}\text { Nicht- } \\
\text { kleinzelliges } \\
\text { Karzinom }\end{array}$ & SCLC & suspekt & unspezifisch \\
\hline Adeno-Ca & 111 & 0 & 1 & 4 & 2 & 11 & 0 & 5 & 28 \\
\hline Empyem & 0 & 25 & 0 & 0 & 0 & 0 & 0 & 0 & 4 \\
\hline Karzinom & 2 & 0 & 0 & 0 & 0 & 0 & 0 & 0 & 1 \\
\hline Mesotheliom & 0 & 0 & 0 & 8 & 0 & 0 & 0 & 0 & 4 \\
\hline Neoplasie & 0 & 0 & 0 & 0 & 0 & 0 & 0 & 1 & 4 \\
\hline $\begin{array}{l}\text { Nicht-kleinzelliges } \\
\text { Karzinom }\end{array}$ & 6 & 0 & 0 & 0 & 2 & 6 & 0 & 1 & 9 \\
\hline SCLC & 0 & 0 & 1 & 0 & 0 & 1 & 5 & 1 & 5 \\
\hline suspekt & 7 & 1 & 0 & 1 & 2 & 2 & 0 & 11 & 47 \\
\hline unspezifisch & 13 & 5 & 1 & 0 & 1 & 2 & 0 & 27 & 427 \\
\hline
\end{tabular}


Tabelle 10: $\quad$ Prozentuale Übereinstimmung der zytologischen Befunde von Pneumologen und dem Zytopathologen (Zeilenprozente)

\begin{tabular}{|c|c|c|c|c|c|c|c|c|c|}
\hline \multirow[b]{2}{*}{ Pneumologen } & \multicolumn{9}{|c|}{ Zytopathologe } \\
\hline & Adeno-Ca & Empyem & Karzinom & Mesotheliom & Neoplasie & $\begin{array}{c}\text { Nicht- } \\
\text { kleinzelliges } \\
\text { Karzinom }\end{array}$ & SCLC & suspekt & unspezifisch \\
\hline Adeno-Ca & 68.5 & 0 & 0.6 & 2.5 & 1.2 & 6.8 & 0 & 3.1 & 17.3 \\
\hline Empyem & 0 & 86.2 & 0 & 0 & 0 & 0 & 0 & 0 & 13.8 \\
\hline Karzinom & 66.7 & 0 & 0 & 0 & 0 & 0 & 0 & 0 & 33.3 \\
\hline Mesotheliom & 0 & 0 & 0 & 66.7 & 0 & 0 & 0 & 0 & 33.3 \\
\hline Neoplasie & 0 & 0 & 0 & 0 & 0 & 0 & 0 & 20 & 80 \\
\hline $\begin{array}{l}\text { Nicht-kleinzelliges } \\
\text { Karzinom }\end{array}$ & 25 & 0 & 0 & 0 & 8.3 & 25 & 0 & 4.2 & 37.5 \\
\hline SCLC & 0 & 0 & 7.7 & 0 & 0 & 7.7 & 38.5 & 7.7 & 38.5 \\
\hline suspekt & 10 & 0 & 0 & 1.4 & 2.9 & 2.9 & 0 & 15.7 & 67.1 \\
\hline unspezifisch & 2.7 & 1.3 & 0.2 & 0 & 0.2 & 0.4 & 0 & 5.7 & 89.5 \\
\hline
\end{tabular}


Tabelle 11: $\quad$ Prozentuale Übereinstimmung der zytologischen Befunde vom Zytopathologen und von den Pneumologen (Spaltenprozente)

\begin{tabular}{|c|c|c|c|c|c|c|c|c|c|}
\hline \multirow[b]{2}{*}{ Pneumologen } & \multicolumn{9}{|c|}{ Zytopathologe } \\
\hline & Adeno-Ca & Empyem & Karzinom & Mesotheliom & Neoplasie & $\begin{array}{c}\text { Nicht- } \\
\text { kleinzelliges } \\
\text { Karzinom } \\
\end{array}$ & SCLC & suspekt & unspezifisch \\
\hline Adeno-Ca & 79.9 & 0 & 33.3 & 30.8 & 28.6 & 50 & 0 & 10.9 & 5.3 \\
\hline Empyem & 0 & 80.6 & 0 & 0 & 0 & 0 & 0 & 0 & 0.8 \\
\hline Karzinom & 1.4 & 0 & 0 & 0 & 0 & 0 & 0 & 0 & 0.2 \\
\hline Mesotheliom & 0 & 0 & 0 & 61.5 & 0 & 0 & 0 & 0 & 0.8 \\
\hline Neoplasie & 0 & 0 & 0 & 0 & 0 & 0 & 0 & 2.2 & 0.8 \\
\hline $\begin{array}{l}\text { Nicht-kleinzelliges } \\
\text { Karzinom }\end{array}$ & 4.3 & 0 & 0 & 0 & 28.6 & 27.3 & 0 & 2.2 & 1.7 \\
\hline SCLC & 0 & 0 & 33.3 & 0 & 0 & 4.5 & 100 & 2.2 & 0.9 \\
\hline suspekt & 5 & 0 & 0 & 7.7 & 28.6 & 9.1 & 0 & 23.9 & 8.9 \\
\hline unspezifisch & 9.4 & 19.4 & 33.3 & 0 & 14.3 & 9.1 & 0 & 58.7 & 80.7 \\
\hline
\end{tabular}




\subsection{Charakteristika der untersuchten Patientenpopulation}

\subsubsection{Allgemeine Daten bezüglich der Patienten und der untersuchten Pleuraer- güsse}

Es lagen 539 Proben (67,8 \%) von Männern und 256 (32,2 \%) von Frauen vor. Das durchschnittliche Alter der Patienten betrug 68,89 $( \pm 11,73)$ Jahre, das der Frauen 66,48 $( \pm 12,06)$ Jahre und das der Männer 70,03 $( \pm 11,4)$ Jahre. Die Altersstruktur unter Berücksichtigung des Geschlechts wird in Abbildung 16 dargestellt.

332 Proben $(41,8 \%)$ stammen aus einem linksseitig punktierten und 463 Proben $(58,2 \%)$ aus einem rechtsseitig punktierten Pleuraerguss mit $636(80 \%)$ Exsudaten und $159(20 \%)$ Transsudaten.

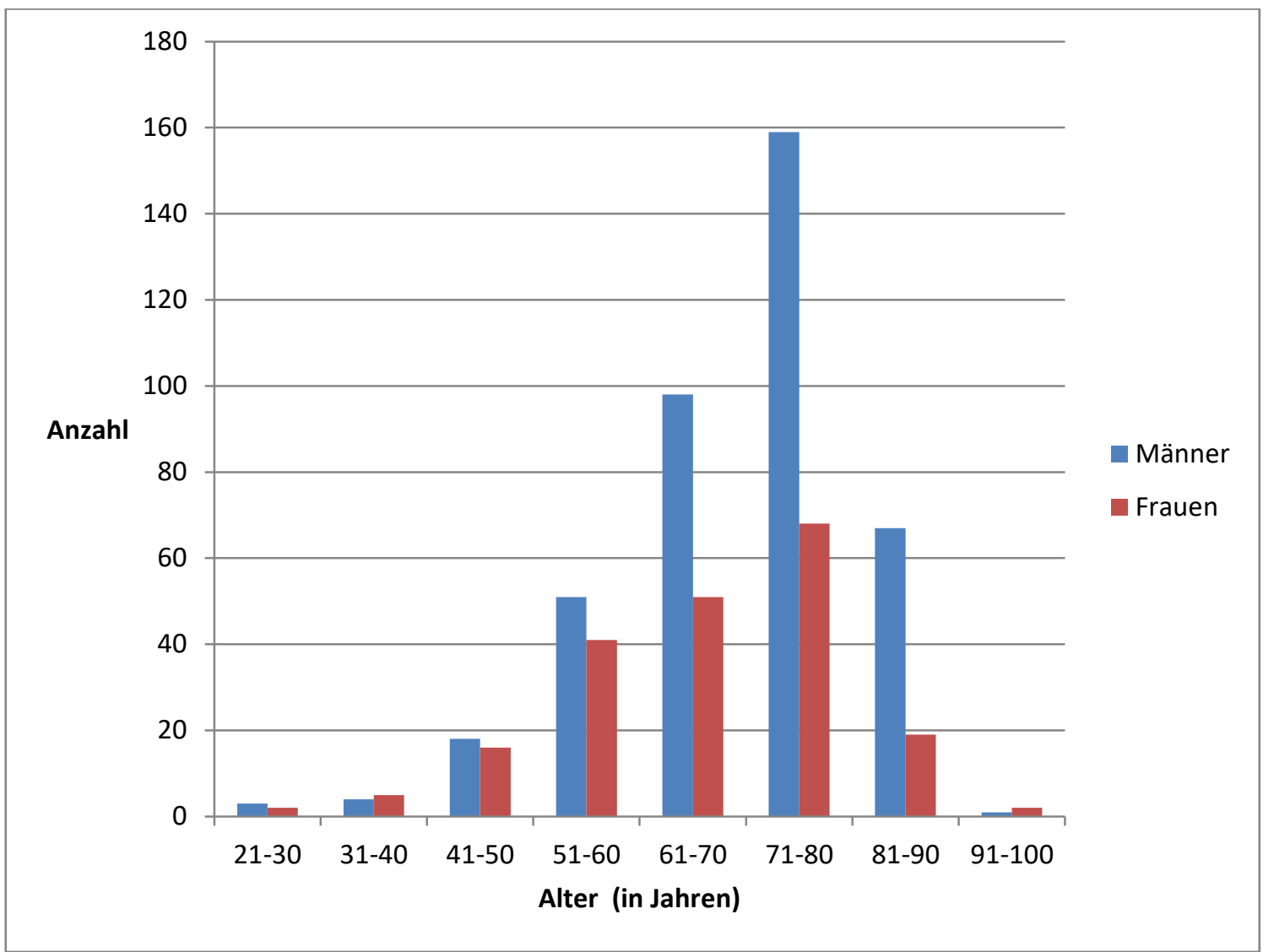

Abbildung 16: Alters- und Geschlechtsverteilung in der Gruppe von 605 Patienten 


\subsubsection{Charakteristika der Pleuraergüsse nach endgültigen klinischen Diagnosen}

Für 605 Patienten wurde nach den Ursachen des Ergusses in Patientenakten gesucht. Bei weiteren 15 Patienten wurden die Pleuraergüsse in einem großen Zeitabstand voneinander und teilweise auf einer anderen Pleuraseite punktiert. In diesen Fällen ergab sich eine neue Diagnose für die Ursache des Ergusses. Es wurden deswegen die Ursachen der Pleuraergüsse für nun 620 Patienten analysiert. Da es sich um eine retrospektive Studie handelt, konnten keine prospektiven Kriterien und Abläufe definiert werden. Die Zuordnung basiert jedoch auf etablierter klinischer Praxis und den aktuellen Leitlinien. Bei 80 Patienten wurden die Pleuraergüsse als unklar eingestuft. Die Verteilung der klinischen Diagnosen in Anlehnung an die zytologischen Diagnosenkategorien der Studie wird in Abbildung 17 dargestellt.

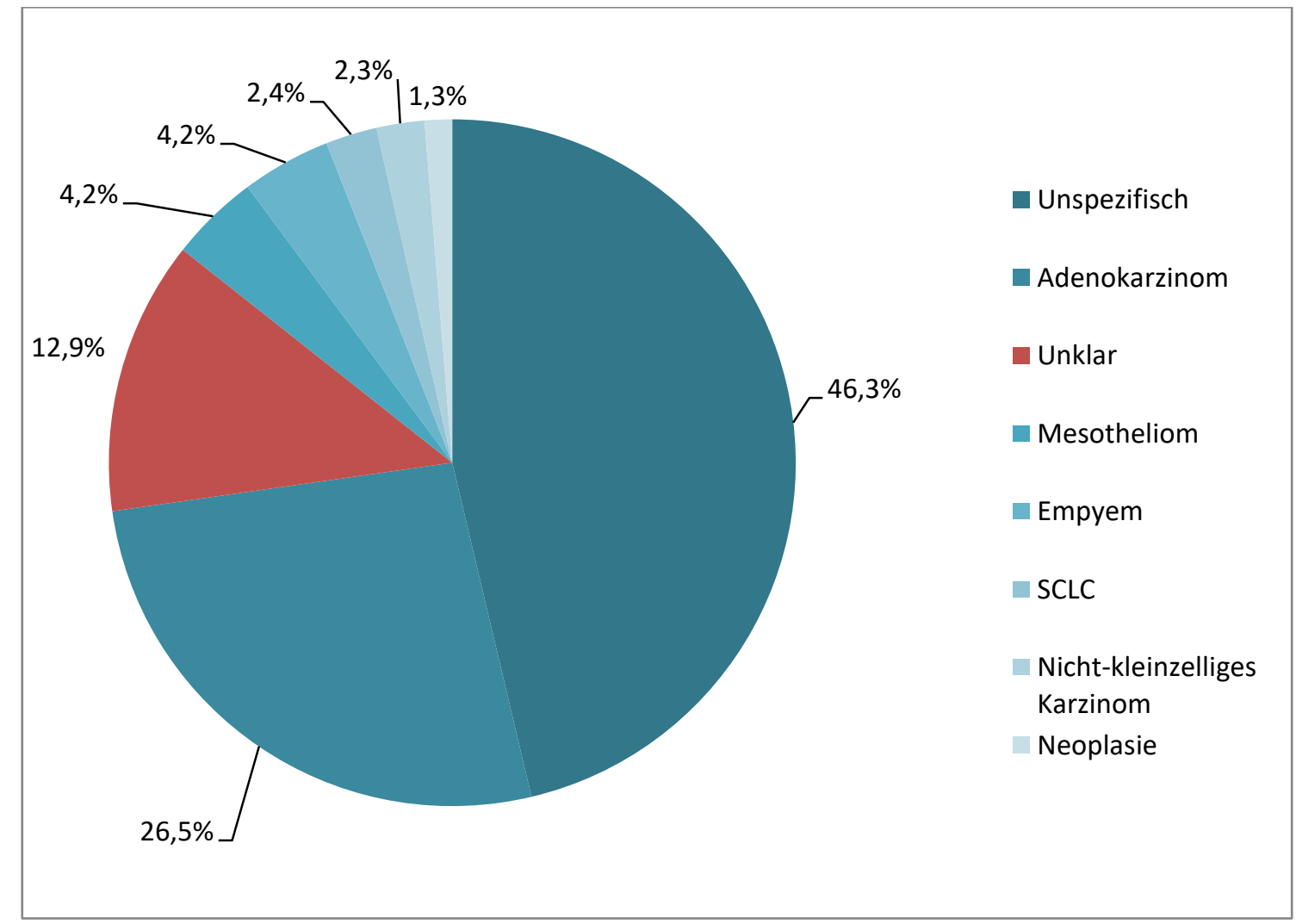

Abbildung 17: Verteilung der endgültigen klinischen Diagnosen nach Diagnosenkategorien der Studie $(\mathrm{N}=620)$ 


\subsubsection{Ursachen für benigne Pleuraergüsse}

Für 313 Patienten hatte der Pleuraerguss eine benigne Ursache. Sowohl bei Frauen als auch bei Männern war die häufigste Ursache für einen solchen Erguss bei 138 Patienten (44,1 \% aller Patienten mit benignem Pleuraerguss) eine pulmonale Stauung auf dem Boden der Linksherzinsuffizienz. Ursachen hierfür waren am häufigsten eine hypertensive Herzkrankheit, eine ischämische Herzkrankheit sowie auch Klappenfehler. Die nächste Gruppe von 53 benignen Ergüssen (16,9\% aller benignen Pleuraergüsse) entstand auf dem Boden einer unspezifischen Entzündung. Bei 45 Patienten wurde der Pleuraerguss als parapneumonisch gesehen und bei 28 weiteren Patienten handelte es sich um ein Pleuraempyem. Bei 13 männlichen Patienten wurde Pleuritis assoziiert mit asbestbedingten Pleuraplaques und bei 10 Patienten wurde als Ursache für den benignen Pleuraerguss eine rheumatoide Arthritis gefunden. Zu selteneren Ursachen des benignen Pleuraergusses in vorliegender Studie gehören: Hämatothorax (4 Patienten), Niereninsuffizienz (3 Patienten unter Dialysetherapie), Lungenembolie (2 Patienten), Zustand nach einer Perikardiotomie (2 Patienten) sowie eine Kollagenose (2 Patienten mit Pleuraerguss bei Lupus erythematodes), Chylothorax, Leberzirrhose und Nebenwirkung von Medikamenten (jeweils 1 Patient). Bei 10 Patienten - davon 8 männlichen - entstand der Pleuraerguss auf dem Boden einer tuberkulösen Pleuritis.

\subsubsection{Ursachen für maligne Pleuraergüsse}

Bei 227 Patienten wurde klinisch ein maligner Pleuraerguss diagnostiziert. Nach zytologischen Kategorien der Studie handelt sich um Adenokarzinome (164 Fälle), nichtkleinzellige Karzinome (14 Fälle), kleinzellige Karzinome (15 Fälle), Mesotheliome (26 Fälle) und Neoplasien (8 Fälle).

Klinisch wurde am häufigsten die Diagnose eines Bronchialkarzinoms (140 Fälle; $61,7 \%)$ gestellt. Dabei folgten auf das Adenokarzinom das kleinzellige Bronchialkarzinom (15 Fälle; 10,7 \%) und sodann das Plattenepithelkarzinom (9 Fälle; 6,4 \%). Weitere Fälle (3,6 \%) waren 2 Fälle eines großzelligen Karzinoms und 3 Fälle eines nichtkleinzelliges Karzinoms ohne weitere Differenzierung.

Andere Primarien bei malignen Pleuraergüssen waren Mamma-Karzinom (34 Fälle; $15 \%$ ), Mesotheliom (26 Fälle; 11,5 \%), Ovarial-Karzinom (7 Fälle; 3,1 \%), Nierenkarzinom (5 Fälle, 2,2 \%), Non-Hodgkin-Lymphom (NHL; 4 Fälle; 1,8 \%). 3,1 \% der malignen Pleuraergüsse waren auf Magenkarzinom (1 Fall), Uteruskarzinom (1 Fall), Kar- 
zinom des Apendix (1 Fall), Karzinosarkom (1 Fall), Sarkom (1 Fall), Multiples Myelom (1 Fall) und Melanom (1 Fall) zurückzuführen. In 4 Fällen identifizierte man ein Karzinom bei unbekanntem Primärtumor (CUP-Syndrom) durch ein Adenokarzinom.

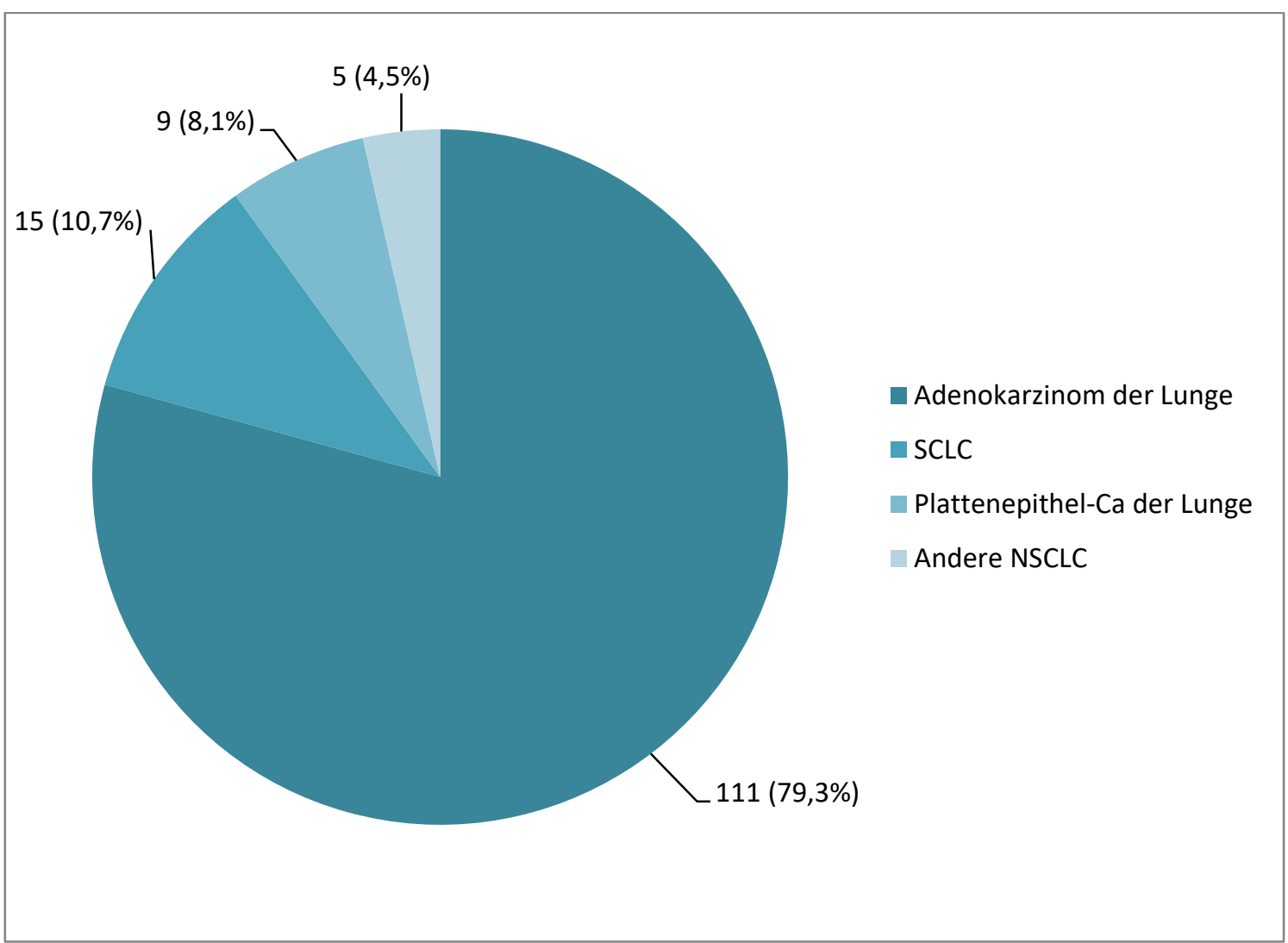

Abbildung 18: Verteilung der Patienten mit malignem Pleuraerguss bei Bronchialkarzinom je nach histologischem Tumortyp anhand endgültiger klinischer Diagnose

Die Verteilung des Adenokarzinoms variierte in Abhängigkeit vom Geschlecht. Das häufigste Adenokarzinom war sowohl bei Frauen als auch bei Männern eines der Lunge (entsprechend 42 Frauen und 69 Männer). Bei Frauen folgte sodann ein Mammakarzinom (32 Fälle) und ein Ovarialkarzinom (7 Fälle). Bei Männern war das zweithäufigste Adenokarzinom ein Nierenzellkarzinom (5 Fälle). 


\subsection{Sensitivität und Spezifität der zytologischen Befunde der beiden Beurteiler}

\subsubsection{Vergleich der zytologischen Ergebnisse mit den histologischen Befunden der Thorakoskopie}

Bei 128 der untersuchten Patienten wurde neben der Pleurapunktion eine Thorakoskopie zur Gewinnung von Proben zur histologischen Untersuchung durchgeführt.

Tabelle 12: Verteilung der malignen Pleuraergüsse nach Primarius bei Männern und Frauen ( $\mathrm{N}=227$ ); (a) Karzinom des Appendix, Karzinosarkom, Magenkarzinom und NHL, (b) Melanom, Multiples Myelom, Sarkom, Uteruskarzinom

\begin{tabular}{|c|c|c|c|c|c|}
\hline \multicolumn{3}{|l|}{ Männer } & \multicolumn{3}{|l|}{ Frauen } \\
\hline Adenokarzinom & 69 & $(54,3 \%)$ & Adenokarzinom & 42 & $(42 \%)$ \\
\hline Mesotheliom & 24 & $(18,9 \%)$ & Mammakarzinom & 32 & $(32 \%)$ \\
\hline SCLC & 11 & $(8,7 \%)$ & Ovarialkarzinom & 7 & $(7 \%)$ \\
\hline Plattenepithelkarzinom & 5 & $(3,9 \%)$ & Plattenepithelkarzinom & 4 & $(4 \%)$ \\
\hline Nierenkarzinom & 5 & $(3,9 \%)$ & SCLC & 4 & $(4 \%)$ \\
\hline NSCLC & 3 & $(2,4 \%)$ & $\mathrm{NHL}$ & 3 & $(3 \%)$ \\
\hline CUP-Syndrom & 2 & $(1,6 \%)$ & CUP-Syndrom & 2 & $(2 \%)$ \\
\hline Großzelliges Karzinom & 2 & $(1,6 \%)$ & Mesotheliom & 2 & $(2 \%)$ \\
\hline Mammakarzinom & 2 & $(1,6 \%)$ & Andere ${ }^{(b)}$ & 4 & $(4 \%)$ \\
\hline Andere $^{(\mathrm{a})}$ & 4 & $(2,4 \%)$ & & & \\
\hline
\end{tabular}

Indikationen zur Thorakoskopie waren:

- weitere histologische Abklärung bei zytologisch unklarem Pleuraerguss;

- weitere histologische Abklärung bei zytologisch malignem Pleuraerguss mit Indikation zur Pleurodese bei massivem oder nachlaufendem Pleuraerguss;

- Behandlung von kompliziertem Pleuraerguss (Pleuraempyem mit Adhäsionen)

Zur annähernden Beurteilung von Sensitivität und Spezifität werden die zytologischen Ergebnisse der beiden Beurteiler jeweils mit den histologischen Befunden aus den 
128 Thorakoskopien verglichen. Es wurden nur Ergebnisse in den Kategorien maligne - benigne berücksichtigt.

Drei histologische Befunde der Thorakoskopie waren falsch-negativ. Diese wurden zu positiven korrigiert. Nach Ausschluss der suspekten zytologischen Befunde konnten 111 zytologische Befunde der Pneumologen und 123 Befunde des Zytopathologen mit histologischen Ergebnissen der Thorakoskopien verglichen werden. Der Vergleich der Befunde für die Pneumologen und für den Zytopathologen wurde entsprechend in den Kontingenztafeln (Tabellen 13 und 14) dargestellt.

Tabelle 13: Kontingenztafel für die zytologischen Befunde der Pneumologen im Vergleich mit histologischen Befunden der Thorakoskopie $(\mathrm{N}=111)$.

\begin{tabular}{|c|c|c|}
\hline Pneumologen & Thorakoskopie benigne & Thorakoskopie maligne \\
\hline Zytologie benigne & $37(94,9 \%)$ & $22(30,6 \%)$ \\
\hline Zytologie maligne & $2(5,1 \%)$ & $50(69,4 \%)$ \\
\hline
\end{tabular}

Tabelle 14: Kontingenztafel für die zytologischen Befunde des Zytopathologen im

Vergleich mit histologischen Befunden der Thorakoskopie $(\mathrm{N}=123)$.

\begin{tabular}{|c|c|c|}
\hline Zytopathologe & Thorakoskopie benigne & Thorakoskopie maligne \\
\hline Zytologie benigne & $45(100 \%)$ & $33(42,3 \%)$ \\
\hline Zytologie maligne & $0(0 \%)$ & $45(57,7 \%)$ \\
\hline
\end{tabular}

Verglichen mit den histologischen Befunden der Thorakoskopie haben die zytologischen Befunde der Pneumologen eine Sensitivität von $69 \%$ (CI 0,57 - 0,8) und eine Spezifität von $95 \%$ (CI 0,83 - 0,99). Für den Zytopathologen wurde eine Sensitivität von $58 \%$ (CI 0,46-0,59) und Spezifität von $100 \%$ (CI 0,88-1) berechnet. Tabelle 15 stellt die Zusammenstellung von Sensitivität, Spezifität, positivem und negativem prädikativen Wert der zytologischen Befunde der beiden Beurteiler dar. 
Tabelle 15: Zusammenstellung der Sensitivität, Spezifität, PPV, NPV und $95 \%$ Konfidenzintervalle der zytologischen Befunde der Pneumologen und des Zytopathologen im Vergleich mit histologischen Befunden der Thorakoskopie (falsch negative Befunde der Thorakoskopie korrigiert als maligne).

\begin{tabular}{|l|l|l|}
\hline \multicolumn{1}{|c|}{ Parameter } & \multicolumn{1}{|c|}{ Wert für Pneumologen } & Wert für den Zytopathologen \\
\hline Sensitivität & $0,69(\mathrm{Cl} 0,57-0,80)$ & $0,58(\mathrm{Cl} 0,46-0,69)$ \\
\hline Spezifität & $0,95(\mathrm{Cl} 0,83-0,99)$ & $1,00(\mathrm{Cl} 0,88-1,00)$ \\
\hline PPV & $0,96(\mathrm{Cl} 0,87-1,00)$ & $1,00(\mathrm{Cl} 0,88-1,00)$ \\
\hline NPV & $0,63(\mathrm{Cl} 0,49-0,75)$ & $0,46(\mathrm{Cl} 0,46-0,69)$ \\
\hline
\end{tabular}

\subsubsection{Beurteilung der Aussagekraft der zytologischen Befunde in einem Modell der logistischen Regression.}

Aus den in der Studie erhobenen Parametern wurde ein Modell der logistischen Regression gebildet, um eventuell einen besseren Klassifikator für die Vorhersage der malignen/benignen Pleuraergüsse zu finden. Es wurde zuerst geschaut, ob Alter, Geschlecht, Punktionsseite, Exsudat oder Transsudat einen signifikanten Einfluss auf maligne/benigne Zytologiebefunde haben.

Um die Messwiederholungen zu berücksichtigen, wurde der p-Wert für einzelne Parameter berechnet und in Tabelle 16 dargestellt. Hier zeigte sich kein signifikanter Unterschied der Werte für die zytologischen Befunde in den Kategorien maligne/benigne, sodass die Parameter (außer dem Alter) bei der logistischen Regression nicht berücksichtigt wurden. Es handelt sich um 108 Patienten, bei denen die beiden zytologischen Beurteiler ein Urteil in der Kategorie maligne oder benigne abgegeben haben. Die suspekten Befunde wurden von der Betrachtung ausgeschlossen. Zusätzlich ist ins Modell das Alter der Patienten eingeflossen. Die Resultate des generalisierten linearen Modells wurden mit Werten des Koeffizienten, Odds Ratio, Standardfehlers sowie der Signifikanz (p-Wert) der Parameter in Tabelle 17 dargestellt. 
Tabelle 16: Mittelwert, Standardabweichung des Alters sowie absolute und relative Häufigkeit der Nominalvariablen für Patienten mit benignen und malignen Pleuraergüssen (überprüft durch Thorakoskopie, falsch-negative Befunde der Thorakoskopie wurden korrigiert zu malignen) sowie der p-Wert des generalisierten linearen Regressionsmodells

\begin{tabular}{|l|l|l|l|l|}
\hline \multicolumn{1}{|c|}{ Parameter } & \multicolumn{1}{|c|}{ Wert } & \multicolumn{1}{c|}{ benigne } & \multicolumn{1}{c|}{ maligne } & \multicolumn{1}{c|}{ p } \\
\hline Alter & & $64,1+/-13.41$ & $65,88+/-10.95$ & 0,4565 \\
\hline Geschlecht & m & $31(64,6 \%)$ & $43(53,8 \%)$ & 0,2617 \\
\hline & W & $17(35,4 \%)$ & $37(46,2 \%)$ & \\
\hline Punktionsseite & links & $25(52,1 \%)$ & $33(41,2 \%)$ & 0,2553 \\
\hline & rechts & $23(47,9 \%)$ & $47(58,8 \%)$ & \\
\hline Transsudat/Exsudat & Exsudat & $45(93,8 \%)$ & $77(96,2 \%)$ & 0,5740 \\
\hline & Transsudat & $3(6,2 \%)$ & $3(3,8 \%)$ & \\
\hline
\end{tabular}

Tabelle 17: Resultate des generalisierten linearen Modells für die Berechnung der Aussagekraft der zytologischen Befunde in Kategorien maligne - benigne im Vergleich mit Thorakoskopie.

\begin{tabular}{|l|l|l|l|l|}
\hline \multicolumn{1}{|c|}{ Parameter } & Regressionskoeffizient & \multicolumn{1}{|c|}{ OR } & Standardfehler & \multicolumn{1}{c|}{$\mathbf{p}$} \\
\hline Pneumologen & 3,328 & 27,89 & 0,99 & 0,0008 \\
\hline Zytopathologe & 42,71 & $5,53 e+18$ & 0,8979 & $<0,001$ \\
\hline Alter & 0,0496 & 1,05 & 0,03 & 0,0984 \\
\hline
\end{tabular}

Der optimale Cutoff-Punkt für die geschätzten Werte des Modells ist 0,78 (d. h. Befunde, bei denen der Wert > 0,78 ist, wurden als maligne klassifiziert, und die Befunde mit dem Wert < 0,78 als benigne). Durch diese Einteilung konnte man wieder eine Kontingenztabelle erstellen (Tabelle 18) und Sensitivität und Spezifität bestimmen.

Für den optimalen Cut-Off-Wert von 0,78 betreffend kombinierte Klassifikatoren, der mittels Youden-Index berechnet wurde, beträgt für das ganze Modell die Sensitivität $73,24 \%$, die Spezifität $100 \%$, PPV $100 \%$ und NPV 66,07\% und AUC 89\%. Tabel- 
le 18 stellt die Werte der Sensitivität $(73,2 \%)$ und Spezifität (100\%) abhängig vom Wert der kombinierten Klassifkatoren für die beiden Beurteiler dar. Die Flächen unter der Kurve (Abbildungen 19 und 20) können als Teil der korrekten Beurteilung der zytologischen Befunde betrachtet werden. Dies resultiert für die Pneumologen mit einer Fläche unter der Kurve (AUC) von 83,9 \% und für die Zytopathologen mit einer AUC von $80,3 \%$.

Allerdings überlappen sich die Konfidenzintervalle der Flächen unter der Kurve für den kombinierten Klassifikator, der Pneumologen und dem Zytopathologen, sodass der kombinierte Klassifikator nicht signifikant besser als die Beurteilung durch die Pneumologen bzw. den Zytopathologen im Hinblick auf maligne und benigne Befunde ist.

Tabelle 18: Kontingenztabelle entsprechend dem optimalen Cutoff-Punkt des kombinierten Klassifikators. Der Wert 0 präsentiert benigne Befunde und der Wert 1 maligne Befunde

\begin{tabular}{|c|c|c|}
\hline Kombinierte Klassifikatoren & Thorakoskopie 0 & Thorakoskopie 1 \\
\hline 0 & $37(100 \%)$ & $19(26.8 \%)$ \\
\hline 1 & $0(0 \%)$ & $52(73.2 \%)$ \\
\hline
\end{tabular}



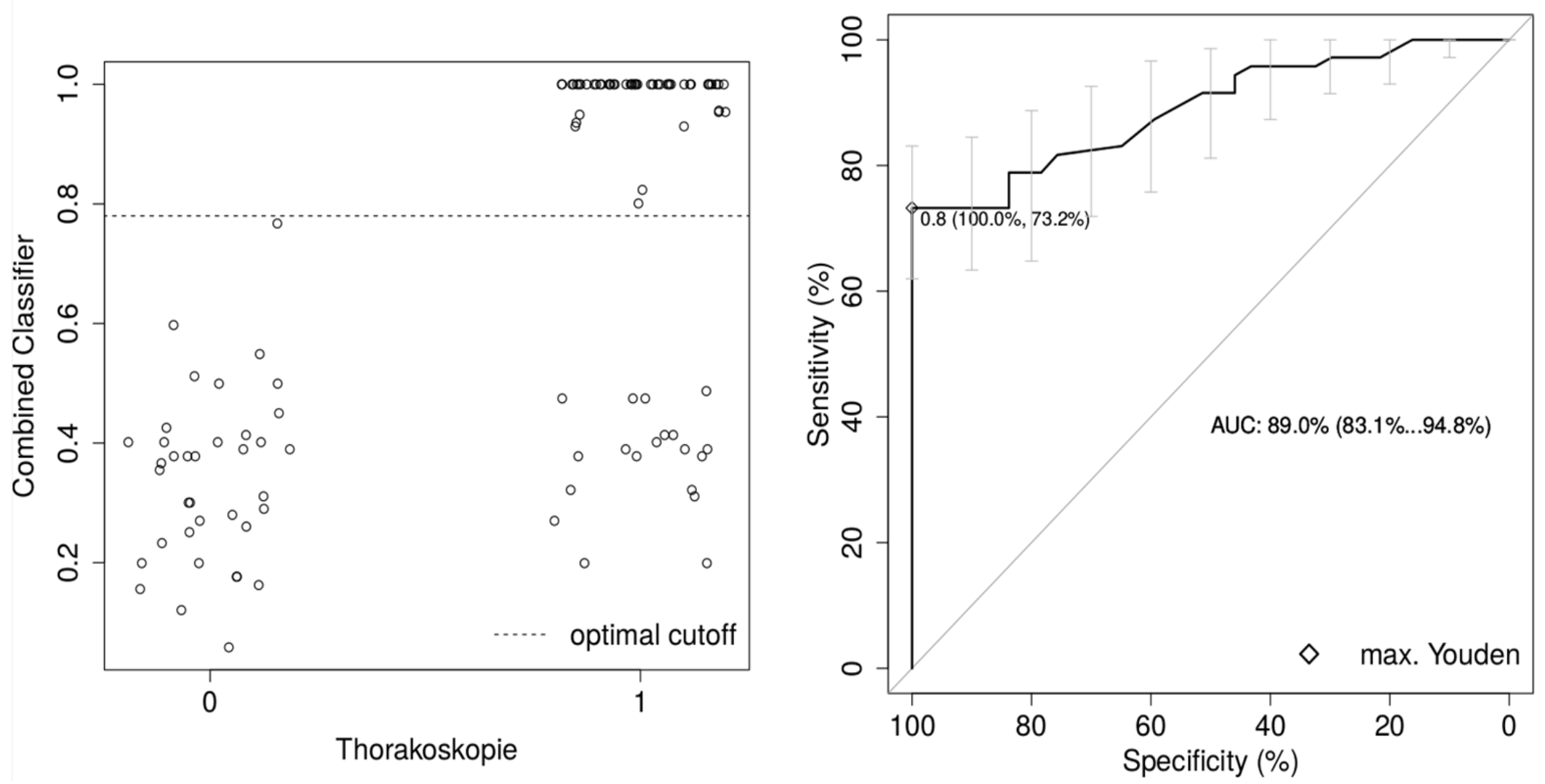

Abbildung 19: $\quad$ links: Verteilung der geschätzten Wahrscheinlichkeiten des kombinierten Klassifikators und der optimale Cutoff-Punkt nach dem Youden-Kriterium, rechts: ROC-Kurve, Punkt mit dem größten Youden-Index, AUC und 95 \%Konfidenzintervall des kombinierten Klassifikators. 


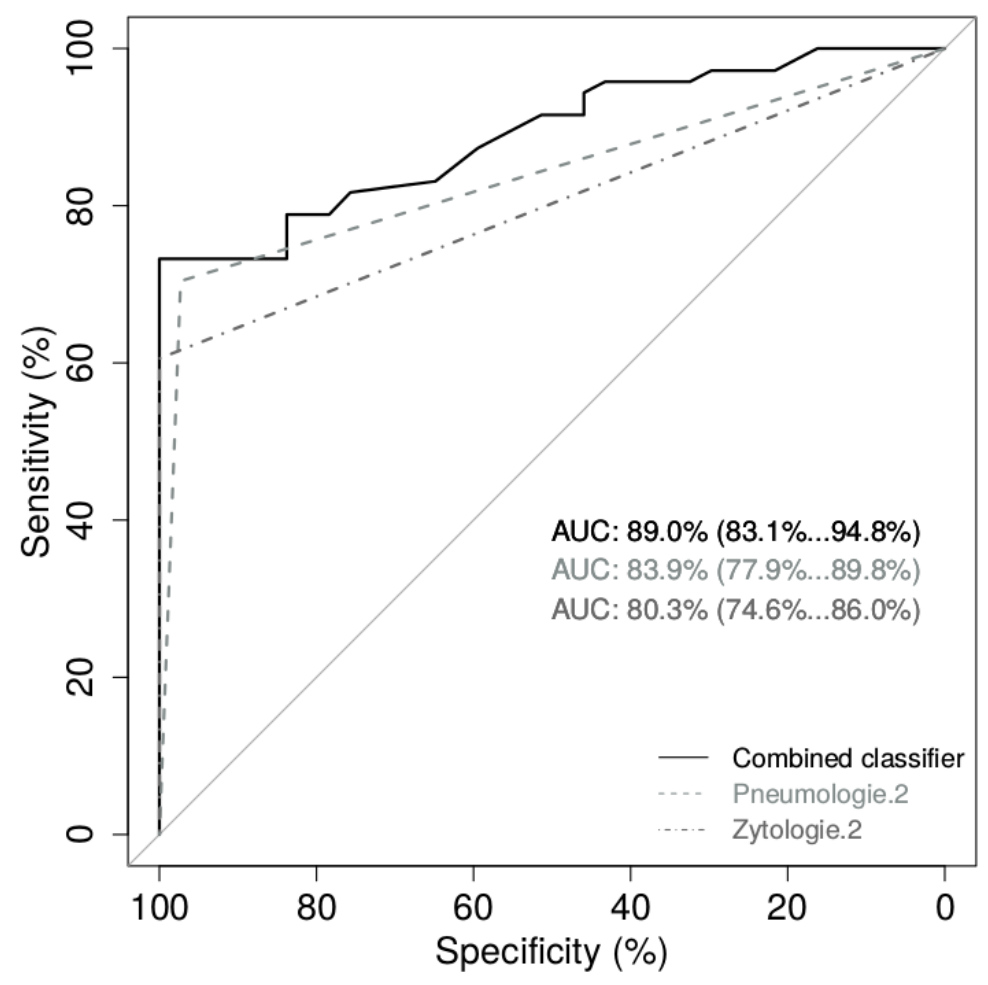

Abbildung 20: $\quad$ ROC-Kurve und AUC sowie $95 \%$-Konfidenzintervalle vom kombinierten Klasifikator (Combined classifier), Pneumologen (Pneumologie.2) und vom Zytopathologen (Zytologie.2).

\subsubsection{Falsch negative Befunde der Thorakoskopie}

In den histologischen Befunden aus der Thorakoskopie bei Patienten der Studie wurden drei falsch negative Ergebnisse gefunden.

Es handelte sich um eine 48-jährige Patientin mit vorbekanntem Ovarialkarzinom, die mit rezidivierendem Pleuraerguss in die Klinik zur thorakoskopischen Talkumpleurodese aufgenommen wurde. Bei der internistischen Thorakoskopie bei mangelndem Kollaps der Lunge gelingt nur eine ventral-kaudale Inspektion der Pleura. Es wurden jedoch $900 \mathrm{ml}$ hämorrhagischen Ergusses abgesaugt. Die Inspektion der Pleura ist hier nicht gelungen und eine Pleurodese war nicht durchführbar. Die Ursache dafür waren Verwachsungen der Pleura visceralis und der Pleura parietalis. Diese können in Rahmen eines begleitenden chronischen entzündlichen Prozesses der Pleura entstehen.

Eine ähnliche Situation fand sich bei einem 57-jährigen Patienten mit metastasiertem Adenokarzinom der Lunge. 
Bei einem 75-jährigen Patienten mit bekanntem metastasierten Adenokarzinom der Lunge und zweimalig zytologisch gesichertem Adenokarzinom (durch beide Beurteiler) wurde nach einigen Monaten unter laufender Chemotherapie eine Thorakoskopie zur Gewinnung des neuen Gewebematerials als Vorbereitung zum Anschluss an eine Studie durchgeführt. Hier wurde histologisch kein vitales Tumorgewebe beschrieben.

\subsubsection{Falsch positive Befunde der Zytologie}

Zwei Befunde des benignen Pleuraergusses wurden in vorliegender Studie von den Pneumologen als maligne bezeichnet. Bei dem Zytopathologen fand sich dagegen kein falsch positiver Befund.

Die beiden Patienten erhielten eine videoassistierte Thorakoskopie an der Universitätsmedizin Göttingen. Nach weiteren klinischen Recherchen ist davon auszugehen, dass die Ergüsse von beiden Patientinnen eine reaktive Genese haben. 


\section{Diskussion}

Die Beurteilung von 795 Ausstrichen von 620 Patienten zeigte retrospektiv unter den Bedingungen des klinischen Alltags überwiegend übereinstimmende Ergebnisse. Die aus klinischer Sicht wichtigste Information bezüglich einer Malignität des Pleuraergusses stimmt zu $90 \%$ als statistischer Wert überein. Meinem Wissen nach liegt zum ersten Mal eine Studie vor, die eine Beurteilerübereinstimmung der Pleuraergusszytologien zwischen einem hauptberuflichen Zytologen und Fachärzten für Innere Medizin und Pneumologie untersucht.

Die bis jetzt umfassendste Studie zur Beurteilungsübereinstimmung in der Zytologie des Pleuraergusses wurde von Fassina et al. (2008) mit 45 Ausstrichen durchgeführt. Diese wurden prospektiv durch 9 italienische Ärzte für Pathologie ausgewertet. Im Gegensatz zu vorliegender Studie haben die Beurteiler keine klinische oder pathologische Information bezgl. des Materials, aber eine Schulung in der zytologischen Beurteilung erhalten. Bei der Befundung der 45 Ausstriche war zwischen festgelegten Kategorien zu wählen: malignes Mesotheliom, Metastasen, nicht weiter klassifizierte maligne Zellen, benigner Erguss und unbestimmbares Präparat.

Die italienischen Beurteiler erhielten auch eine Liste mit allgemein anerkannten diagnostischen Kriterien bzgl. zytologischer Befunde bei malignem Mesotheliom, da in dem untersuchten zytologischen Material zu $38 \%$ Mesotheliome, $31 \%$ benigne Pleuraergüsse und zu $31 \%$ maligne Pleuraergüsse durch metastatische Pleurakarzinose waren. Die Beurteilerübereinstimmung zwischen einzelnen Fachärzten, berechnet mit $\kappa$, in den Kategorien maligner vs. benigner Pleuraerguss lag zwischen 0,39 und 0,95. Die Gesamtübereinstimmung resultierte mit einem $\kappa$-Wert von 0,514 . Zwischen malignen und benignen Pleuraergüssen ist mit einem $\kappa$-Wert von 0,76 die Beurteilerübereinstimmung in der hier vorgestellten Untersuchung beachtlich, insbesondere weil die der Arbeit zugrunde liegende Patientenpopulation nicht ausgewählt worden ist. Im Kontrast dazu steht hier der schlechte $\kappa$-Wert für die Kategorien maligne-benigne von nur 0,132 betreffend Ärzte in der Weiterbildung in der Studie von Fassina et al.

Die Beurteilerübereinstimmung zytologischer Präparate der Pleuraergüsse in den Kategorien maligne - benigne - suspekt sowie in den Kategorien Adenokarzinom Empyem-Karzinom - Mesotheliom - Neoplasie - nicht-kleinzelliges Karzinom - SCLC - suspekt -unspezifisch ist in vorliegender Studie mit $\kappa$ entsprechend 0,57 und 0,54 mo- 
derat. In der Studie von Fassina et al. wurde die Beurteilerübereinstimmung zwischen einzelnen Fachärzten in den Kategorien Mesotheliom-Metastasen-benigner Erguss mit einer $\kappa$ zwischen 0,39 und 0,92 berechnet. Nur 8 von 36 Beurteilerpaaren erreichen einen besseren $\kappa$-Wert (zwischen 0,55 und 0,92) als die Beurteiler in vorliegender Studie. Dies ist beachtlich, weil der $\kappa$-Wert normalerweise mit dem Anstieg der möglichen Kategorien-Zahl fällt.

\subsection{Die untersuchte Patientenpopulation im Vergleich zu anderen Studien}

In der untersuchten Population wurden insgesamt 229 (= $37 \%)$ Patienten mit einem malignen Pleuraerguss zytologisch identifiziert. Die Zahl der Patienten mit malignem Pleuraerguss erscheint sehr hoch und bei einem hohen Anteil letztendlich unklarer Pleuraergüsse (von 12,7 \%) kann sie noch unterschätzt sein. Viele Patienten in der Studie haben einen Pleuraerguss mit Fernmetastasen. Bei fehlenden klinischen Konsequenzen wurde der Staging des Pleuraergusses mit Thorakozentese und zytologischer und klinisch-chemischer Analyse der Pleuraflüssigkeit, auch bei negativem zytologischen Befund, beendet. Einige Patienten konnten aus verschiedenen Gründen nicht weiter nachbeobachtet werden. Bei initial zytologisch negativem Pleuraerguss konnten evtl. neue Hinweise auf eine Malignität im Verlauf nicht festgestellt werden.

Eine Ursache für den hohen Anteil maligner Pleuraergüsse könnte in vorliegender Studie das relativ hohe durchschnittliche Alter der Patienten von 69 Jahren sein. In einer Population von 3.811 Patienten in Hongkong (Hsu 1987) wurden nur 20,5 \% der zytologisch untersuchten Pleuraergüsse einer malignen Genese zugeordnet. Das durchschnittliche Alter dieser Patienten betrug 55,2 Jahre.

Die Patienten in vorliegender Studie sind jedoch nicht bedeutend älter als die Population der Patienten mit einem Pleuraerguss aus Böhmen (Marel et al. 1993). In dieser epidemiologischen Studie hatten 21,8\% der Patienten einen malignen Pleuraerguss, bei einer Pleuraerguss-Inzidenz von 0,32\% (bei 44.000 Bewohnern in der untersuchten Region). Das durchschnittliche Alter der Patienten mit Pleuraerguss betrug 66,7 Jahre. In einer Zeit von 1 Jahr wurden insgesamt 142 mit einem Pleuraerguss identifiziert, davon bei 49 post mortem. Die häufigste Ursache für einen Pleuraerguss war kardial (44,8 $\%$ ), gefolgt von Neoplasie und parapneumonischem Erguss (17,0 \%). In der Gruppe der 
Patienten, bei denen ein Pleuraerguss zu Lebzeiten identifiziert wurde, folgte Neoplasie als Ursache für den Erguss mit 17,2 \% an dritter Stelle nach kardialer Ursache und Pleuraerguss bei Pneumonie. Diese Daten wurden im Jahre 1988 erhoben. Laut des tschechischen Instituts für Informationen und Statistik des Gesundheitswesens (Cancer incidence in the Czech Republic 2011) hat sich die Inzidenz der malignen Erkrankungen in der Tschechischen Republik zwischen 1988 und 2011 vom 122,8 pro 100.000 Bewohner auf 229,8 pro 100.000 Bewohner fast verdoppelt. So ist es möglich, dass aktuell der Anteil von malignen Pleuraergüssen in der tschechischen Population höher ist.

In der neueren Studie von Porcel et al. (2014) ist der Anteil der malignen Pleuraergüsse in einer auf Pleuraerkrankungen spezialisierten universitären Abteilung bei vergleichbarem durchschnittlichen Alter von 69 Jahren mit $27 \%$ deutlich höher. Im Vergleich zu vorliegender Studie fällt der deutlich höhere Anteil von Patienten mit Tuberkulose (9\%) auf. Dies hat eine Bedeutung in Ländern mit höherer Prävalenz der Tuberkulose wie z. B. Südafrika. In einer kleinen Studie aus Western Cape (Burgess et al. 1996) war Tuberkulose mit $27 \%$ die häufigste Ursache des Pleuraergusses, gefolgt von Herzinsuffizienz (18\%) und Neoplasie $(17 \%)$ bei einem durchschnittlichen Alter von 63 Jahren. Der Anteil von spezifischen Pleuraergüssen, die entweder durch eine Pleurabiopsie oder kulturell gesichert wurden, beträgt in vorliegender Studie nur 1,6 \% (= 10 Fälle).

So ist der Anteil der Patienten mit malignem Pleuraerguss nicht nur vom Alter, sondern auch von lokaler epidemiologischer Situation abhängig. Es wurden 29 Proben (3,6 \%) von 26 Patienten mit malignem Pleuraerguss durch Mesotheliom gefunden. Das ergibt einen Anteil von 11,4\% aller Patienten mit malignem Pleuraerguss und ist im Vergleich zu anderen Studien hoch.

In der schon genannten Studie von (Porcel et al. 2014) mit 3.000 Patienten mit konsekutiver Thorakozentese betrug der Anteil der Patienten mit einem Pleuramesotheliom nur $3 \%$ (= 33 Fälle). Nach der epidemiologischen Studie von Marel et al. (Marel et al. 1993 ) in einer gut definierten Region wurden gar keine Mesotheliome gefunden.

Dies kann an der Industriestruktur in Nordhessen in der Vergangenheit liegen. Ein großer Teil der Mesotheliomen bei den Patienten der Studie ist Folge eines beruflichen Kontaktes mit Asbest. Zu den größten Betrieben, die Asbest bearbeitet haben und wo am häufigsten Patienten der Lungenfachklinik Immenhausen mit Mesotheliom gearbei- 
tet haben, gehören: das Großkraftwerk Main-Weser in Borken, Kraus-Maffei-Wegmann in Kassel, die u.a. Waggons produziert haben, sowie das Textilunternehmen Gottschalk \& Co in Kassel.

Auch die lokalen Versorgungstrukturen des Gesundheitssystems spielen eine wichtige Rolle in der Verteilung der Pleuraergussursachen in der untersuchten Population. Bei Patienten einer Prager pneumologischen Universitätsklinik (Marel et al. 1995) kann man sehen, dass das durchschnittliche Alter der Patienten mit malignem Pleuraerguss mit 57 Jahren signifikant höher ist $(\mathrm{p}<0,01)$ als das der Patienten mit benignem Pleuraerguss von 47 Jahren. Zum anderen betrug der Anteil der malignen Pleuraergüsse 44,6 \%. Davon, abhängig vom pneumologischen Profil der Klinik, waren 57,9 \% auf ein Bronchialkarzinom zurückzuführen. Diese Prozentzahl korreliert mit dem Anteil der Patienten mit malignem Pleuraerguss durch Bronchialkarzinom $(61,4 \%)$ in der vorliegenden Studie.

Die zuletzt genannten Autoren beurteilen mit 18,7\% einen relativ hohen Prozentsatz der Patienten mit einem paramalignen Pleuraerguss. Diese Gruppe wurde definiert als solche Gruppe, bei der klinisch zwar ein Malignom bekannt ist, jedoch weder eine zytologische Untersuchung des Pleurapunktates noch eine Pleurabiopsie oder eine Autopsie einen Anhalt für eine Pleurakarzinose ergab. In vorliegender Studie könnten es potentiell 57 Patienten (9,2 \% aller Fälle) sein. Dieser Gruppe gehören vor allem Patienten an, bei denen aufgrund des Tumorleidens im Stadium IV nach TNM-System keine potentielle kurative Therapieoption bestand. Deswegen verzichtet man hier auf die weitere bioptische oder thorakoskopische Abklärung. Des Weiteren erhielt ein Teil der Patienten eine Punktion schon unter laufender Chemotherapie. Dies kann eine Bedeutung im Falle eines Adenokarzinoms der Lunge und einer Therapie mit Pemetrexed haben. $\mathrm{Zu}$ den Nebenwirkungen dieses Medikamentes gehört auch die Bildung von Ergüssen in den serösen Höhlen. Auch eine linksführende kardiale Dekompensation mit Pleuraerguss unter volumenösen Infusionsprogramm kann zur Bildung eines Pleuraergusses führen. Die Zahl dieser Patienten wurde jedoch in dieser Studie nicht ermittelt.

So ähnelt der prozentuale Anteil der Patienten mit einem malignen Pleuraerguss auf dem Boden eines Bronchialkarzinoms in vorliegender Studie dem Anteil aus einer großen universitären Lungenklinik. 


\subsection{Sensitivität und Spezifität der zytologischen Befunde}

Die Beurteilerübereinstimmung der zytologischen Befunde zwischen den Pneumologen und dem hauptberuflichen Zytopathologen bezüglich der Malignität des Pleuraergusses ist beachtlich. Aus klinischer Sicht wäre es interessant zu wissen, wie gut beide Beurteiler in der zytologischen Befundung waren. Dafür wurden die histologischen Befunde der 128 Thorakoskopien, die aus verschiedenen Gründen nach Thorakozentese durchgeführt wurden, ausgewertet.

Die Pneumologen haben hier eine Sensitivität von $69 \%$ und eine Spezifität von $95 \%$ bei PPV von $96 \%$ und NPV von $63 \%$ erreicht. Entsprechend wurde bei hauptamtlichen Zytologen eine Sensitivität von $58 \%$ bei Spezifität von $100 \%$ und PPV von $100 \%$ und NPV von $58 \%$ festgestellt.

Die Sensitivität der zytologischen Untersuchung der Pleuraergüsse bei Fachärzten in der Studie von Fassina et al. (2008) variierte zwischen $65 \%$ und 90,3\% mit einem mittleren Wert von $81 \%$. Eine Spezifität wurde zwischen $64,3 \%$ und $100 \%$ mit einem mittleren Wert von 81,3\% berechnet. Entsprechend variierte der PPV zwischen 84,4 \% und $100 \%$ (mittlerer Wert 91,2\%) und der NPV zwischen 54 und 76,9\% (mittlerer Wert 67,4\%). In der Gruppe der Ärzte in Weiterbildung zur Facharzt für Pathologie wurde wie bei Fachärzten für Pathologie eine hohe Sensitivität von $82,8 \%$ bei viel niedrigerer Spezifität von 44,6 \% beobachtet. Der PPV (77,0 \%) und der NPV (57,5\%) waren niedriger als bei Fachärzten. Die Ärzte in der Weiterbildung haben häufiger die benignen Pleuraergüsse als maligne klassifiziert.

Bei der Studie von Fassina et. al (2008) handelt sich um eine prospektive Studie, bei der teilnehmende Beurteiler vor der zytopathologischen Befundung speziell geschult wurden. Gleichwohl sind die Spezifität und Sensitivität der Ergebnisse vorliegender retrospektiven Studie unter reallife-Bedingungen besser als die schlechtesten Ergebnisse der Fachärzte in der Studie von Fassina et al.

Aus statistischer Sicht besteht kein signifikanter Unterschied zwischen den Pneumologen und dem Zytopathologen im Hinblick auf Sensitivität und Spezifität der zytologischen Befunde. Bei den Pneumologen ist jedoch eine leichte Tendenz zu falsch positiven Ergebnissen und parallel tendenziell eine etwas bessere Spezifität bemerkbar. Dies 
ist am ehesten durch direkten Einbezug in die Behandlung der untersuchten Patienten und somit auch durch besseren Zugang zu klinischen Informationen zu erklären.

Die hier erreichten Werte der Spezifität und Sensitivität sind vergleichbar mit denen in der Studie von Porcel et. al. Dort betrug die Sensitivität der ersten zytologischen Untersuchung $51 \%$. Auch bei bis zu drei Mal wiederholten zytologischen Untersuchungen der malignen Pleuraergüsse war eine deutlich verringerte Sensitivität der Zytologie in der Erkennung von Mesotheliomen (27\%) und Plattenepithelkarzinomen (25\%) feststellbar. In der Studie aus Prag (Marel et al. 1995) war die Zytologie bei 60,8 \% der Patienten (davon 60 Patienten mit malignem Pleuraerguss und 18 Patienten mit entzündlichem Pleuraerguss) die entscheidende Untersuchung zur Differenzierung zwischen malignem und benignem Erguss.

So sind Sensitivität und Spezifität in vorliegender Studie vergleichbar mit anderen Studien mit großem Patientenkollektiv.

Unter klinischen Bedingungen werden die Pleuraergüsse der Patienten aus der Fachklinik für Lungenerkrankungen in Immenhausen zumeist durch Fachärzte für Pneumologie und einen hauptberuflichen Zytopathologen beurteilt. Nach der Berechnung der Vertrauensintervalle der Flächen unter der Kurve für die beiden Beurteiler in dem Modell der logistischen Regression ergaben sich keine statistisch signifikanten Unterschiede bzgl. des Gütekriteriums.

Mit einer Sensitivität von $73 \%$ und Spezifität von $100 \%$ würden sich die zytologischen Ergebnisse des Pleuraergusses von Patienten der Lungenfachklinik Immenhausen bezüglich der Sensitivität in die besten Ergebnisse aus der Literatur einreihen. Bei den bekannten Studien bezüglich der Sensitivität und Spezifität der zytologischen Untersuchung des Pleuraergusses erreichte nur Pinto (1996) eine Sensitivität von $76 \%$ wie in Punkt 3.1.2 dargestelltem Modell und eine Spezifität von $100 \%$.

Metzgeroth et al. (2008) gibt in einer deutschen Studie zur zytologischen Beurteilung von 1.243 serösen Ergüssen eine Sensitivität, nur für karzinombedingte Pleuraergüsse, von $57 \%$ an. Die Autoren zählen auch suspekte Pleuraergüsse zu positiv-malignen hinzu und geben eine gesamte Sensitivität von $84 \%$ an bei einer Spezifität von $92 \%$ für eine konventionelle Zytologie. 


\subsection{Wahl des Goldstandards}

In der vorliegenden retrospektiven Studie wurden histopathologische Befunde der Thorakoskopie als Vergleichsparameter zur Berechnung der Treffsicherheit der zytologischen Befunde beider Beurteiler gewählt. Aus der klinischen Sicht wird eine Thorakoskopie als weitere diagnostische Maßnahme bei negativem zytologischen Befund aus der Thorakozentese empfohlen. Ein Vergleich der Befunde ermöglicht nicht nur die Überprüfung der klinisch und radiologisch für eine Neoplasie suspekten Befunde, sondern auch im Falle einer positiven Zytologie und Notwendigkeit einer thorakoskopischen Pleurodese eine Bestätigung des malignen Befundes. Eine blinde Pleurabiopsie zeigt in Vergleich zur Zytologie eine geringere Sensitivität. Eine bildgesteuerte Pleurabiopsie ist nur dann möglich, wenn eine Verdickung der Pleura darstellbar ist. Eine rein klinische Beurteilung des Verlaufes erscheint bei Patienten der Studie ungeeignet, da viele von ihnen im Verlauf auswärts nachbeobachtet oder behandelt wurden. Bei Patienten mit malignem Pleuraerguss im fortgeschrittenen Stadium der Krankheit bringt eine weitere histologische Sicherung der Pleurakarzinose zumeist keinen späteren therapeutischen Gewinn. In der Arbeit zugrunde liegendem Patientenkollektiv gibt es viele Patienten mit Multimorbidität, sodass hier rein klinisch keine sichere Trennung zwischen paramalignem Pleuraerguss bei Retentionspneumonie oder kardialem Pleuraerguss, insbesondere unter Chemotherapie oder Diuretikatherapie erfolgen kann.

Die Thorakoskopie mit einer Sensitivität von 80 - $100 \%$ (Boutin et al. 1990) erscheint für diese retrospektive Studie auch bei bekannter Einschränkung durch Auswahl der Patienten im klinischen Alltag nach früher ernannten Kriterien die verlässlichste Methode zur annähernden Überprüfung der Treffsicherheit von zytologischen Befunden des Pleuraergusses.

\subsection{Falsch negative Befunde der Thorakoskopie}

Auch in der Literatur wurden Fälle von falsch negativen histologischen Befunden aus der Thorakoskopie beschrieben. In der prospektiven Studie von Menzies und Charbonneau (1991) mit 102 Patienten und 104 Thorakoskopien wurden 2 falsch negative Befunde bei einem NPV von $93 \%$ gefunden. Boutin et al. (1990) fanden in ihrer Studie eine Sensitivität der Thorakoskopie von 97 \%. Falsch negative Fälle waren durch Verwachsungen der Pleura erklärt. 


\subsection{Falsch positive Befunde der Zytologie im Vergleich zur Thorako- skopie}

Zwei Befunde (von 128) des benignen Pleuraergusses wurden in vorliegender Studie von den Pneumologen als maligne bezeichnet. Bei dem Zytopathologen fand sich dagegen kein falsch-positiver Befund.

Man muss davon ausgehen, dass die reaktiv veränderten Mesothelien als Zellen von einem Adenokarzinom interpretiert wurden. Ursache für falsch positive Zytologien können in diesen Fällen fehlende ausreichende Erfahrung, ein Urteilsfehler, aber auch ein lang bestehender Erguss sein.

Falsch positive Befunde der Zytologie sind selten, jedoch haben sie ein großes Potential für ernsthafte Fehler in der Diagnostik der Patienten mit Malignom. Die Frequenz von falsch-positiven Ergebnissen in der Literatur variiert zwischen $0 \%$ und 9,1\% (Kutty et al. 1981).

Laut Von Haam (1962) sind falsch positive Befunde in der Zytologie abhängig von Zelldegeneration oder Entzündungsreaktion mit Proliferation der Mesothelzellen. Nach Durchsicht der Literatur (Grunze 1964; Järvi et al. 1972; Motherby et al. 1999) können Schwierigkeiten der Identifizierung maligner Zellen auf Veränderungen der Mesothelzellen beruhen. Ursache für die Veränderung der Mesothelzellen können bei einem Stauungserguss Hypoxie oder Anoxie sein. Veränderungen der Mesothelzellen wurden auch u.a. bei Leberzirrhose, tuberkulöser Pleuritis, Lupus erythematodes und MeigsSyndrom beschrieben. Die zytologische Unterscheidung zwischen Zellen eines Mesothelioms, Adenokarzinoms und reaktiv proliferierten Mesothelien ist eine der schwersten Herausforderungen (Cakir et al. 2009). Die Zahl der Mesotheliomfälle in vorliegender Studie ist höher als in der Studie von Porcel et al. (2014), wo von 3.077 Patienten mit einem Pleuraerguss bei 22 Patienten (0,7 \%) eine Diagnose von Pleuramesotheliom gestellt wurde. Eine Sensitivität der Zytologie für diese Patienten betrug jedoch nur $27 \%$ und war signifikant niedriger $(\mathrm{p}<0,002)$ als die Sensitivität der zytologischen Untersuchung bei restlichen Krankheitsbildern. Die Sensitivität in vorliegender

Studie ist vergleichbar mit der aus der Studie von Porcel et. al. trotz eines viel höheren Anteils von Pleuraergüssen durch ein Mesotheliom. 


\subsection{Stärken und Schwächen der Studie}

Da es sich um eine retrospektive Studie handelt, können Fehler betreffend die Datensammlung nicht vollständig vermieden werden. Die Datengewinnung fand nicht nach einem standardisierten Verfahren statt. Fehler bei der Zuordnung von zytologischen Befunden nach Namen, Geburtsdatum und Datum der Thorakozentese sind wenig wahrscheinlich.

Die Informationen über die letztendliche Ursache des Pleuraergusses wurden aus den Patientenakten, insbesondere aus Entlassungsbriefen entnommen. Diese wurden von Ärzten mit unterschiedlicher klinischer Erfahrung verfasst. Die Datensammlung erforderte individuelle und manchmal erneute Interpretation der Untersuchungsergebnisse. Dies betrifft vor allem multimorbide Patienten mit Neoplasien. Bei einer möglichen multifaktoriellen Genese des Ergusses wurde dieser als unklar klassifiziert. Auch die zytologisch negativen Befunde, bei fehlendem standardisiertem Verfahren, konnten nicht immer im Verlauf überprüft werden. Das führt möglicherweise zur Unterschätzung der Zahl falsch-negativer Befunde und zur Verzahnung der Informationen über die Ätiologie der Pleuraergüsse. Andererseits konnten bei genauer Durchsicht der Behandlungsakten zwei falsch-negative Befunde der Thorakoskopie identifiziert werden.

Es handelt sich um eine Studie unter den Bedingungen des „täglichen klinischen Lebens“ eines großen deutschen Lungentumorzentrums. Eine prospektiv durchgeführte Studie könnte die Ergebnisse der Beurteiler verfälschen. Aus sozialwissenschaftlicher Methodenlehre ist der Hawthorne-Effekt, das heißt ein verändertes Verhalten von Personen, die bewusst an einer wissenschaftlichen Studie teilnehmen, bezüglich der Zielvariablen des Versuchs bekannt. Dies könnte bei Beurteilern in vorliegender Studie die zytologischen Ergebnisse beeinflussen (Preisendörfer 2005).

\subsubsection{Unterschiedliche Probemengen des Pleuraergusses}

Für die weitere Bearbeitung im klinischen Labor wurde von jedem Patienten - nicht dokumentiert - ca. $20 \mathrm{ml}$ Pleuraerguss entnommen. Normalerweise werden maximal 7,5 ml des Ergusses unbehandelt in Heparin-Röhrchen in das zytologische Labor der LungenClinic Großhansdorf versandt. Die restliche Menge von max. ca. $15 \mathrm{ml}$ wurde für die zytologische Untersuchung durch Pneumologen in der Lungenfachklinik Immenhausen zentrifugiert und ausgestrichen. Somit entstehen die zytologischen Präparate 
für die beiden Beurteiler aus unterschiedlichen Mengen Pleuraerguss. Allgemein ist zwischen den Lungenfachärzten, die sich täglich mit der Diagnostik des Pleuraergusses beschäftigen, die Meinung verbreitet, dass ein größeres Volumen der Pleuraflüssigkeit für die zytologische Untersuchung eine bessere Sensitivität bietet.

In den letzten Jahren haben sich mehrere Autoren mit der notwendigen Menge der Pleuraflüssigkeit für eine zytologische Untersuchung beschäftigt. Eine retrospektive Analyse von Sallach et al. (2002) mit 374 Pleuraergussproben zeigte keine statistisch signifikanten Unterschiede in der Sensitivität der Pleuraergusszytologie zwischen den Proben aus unterschiedlichen Quartilen (0,2 - $10 \mathrm{ml}, 15$ - $80 \mathrm{ml}, 100-775 \mathrm{ml}$ und 800 - $2.800 \mathrm{ml}$ ). Die Sensitivität der Zytologie im Quartil zwischen 0,2 und $10 \mathrm{ml}$ betrug $53,9 \%$ und fiel schlechter als in vorliegender Studie aus. Ein NPV für die Proben bis $10 \mathrm{ml}$ betrug bei Sallach et al. 84,6\% und verringerte sich statistisch nicht signifikant mit dem Volumen des Pleuraergusses. Nach der prospektiven Studie von Abouzgheib et al. (2009) zeigten sich diagnostisch bezüglich der Malignität keine Unterschiede bei $50 \mathrm{ml}$ Proben als auch bei großvolumigen Proben $(890 \pm 375 \mathrm{ml})$ gleicher Patienten. Diese Studie beurteilt nicht die Sensitivität der zytologischen Untersuchung.

Die Studie von Sallach et al. wurde von Baumann (2002) kommentiert. Der Autor suggeriert, dass die Zellen in der Flüssigkeit in der Pleurahöhle nicht homogen verteilt sind aus Gründen der Gravitation. Dieser Effekt sollte vor allem bei krebskranken Patienten durch eine Einschränkung der Mobilität verstärkt werden. Somit wäre die zytologische Ausbeute weniger von der Pleuraergussmenge als viel mehr von der Punktionsstelle abhängig.

Die oben genannten Ergebnisse korrelieren mit dem Ergebnissen von Thomas et al. (2011). Pleuraergussvolumina von mehr als $50 \mathrm{ml}$ steigern nicht die Sensitivität der Pleuraergusszytologie. Die Autoren bemerken auch, dass die Kapazität des handelsüblichen Zentrifungenbehälters maximal $50 \mathrm{ml}$ betrug. Die falsch-negative Befunde bei Pleuraergussmengen $<25 \mathrm{ml}$ lagen bei $48 \%$ und bei Pleuraergussmengen $>25 \mathrm{ml}$ bei $22 \%$. Diese Ergebnisse repräsentieren nur einen kleinen Prozentsatz der Proben und berücksichtigen nicht die falsch-negativen Ergebnisse der Pleurabiopsie. Bezüglich der Pleurabiopsietechnik geben die Autoren keine näheren Informationen. 
Der im Jahre 2012 revidierte Behandlungspfad des The Royal College of Pathologists (Denton et al. 2010) empfiehlt eine Entnahme von $20 \mathrm{ml}$ Erguss zur zytologischen Untersuchung. Somit ist die minimale Menge des Ergusses, die zur sicheren zytologischen Beurteilung führt, weiterhin nicht klar. In der schon unter Punkt 4.2 erwähnten Studie von Metzgeroth et al. (2008) mit hoher zytologischer Sensitivität bezüglich der karzinomatösen Pleuraergüssen wurden jeweils $10 \mathrm{ml}$ Punktat untersucht.

Es ist nicht ausgeschlossen, dass die größere Menge des Ergusses die Sensitivität der Untersuchung in der Studie erhöhen würde. Die tendenziell höhere Sensitivität der zytologischen Untersuchung der Pneumologen könnte durch die größere Ergussmenge, die ihnen zu Verfügung stand, erklärt werden.

\subsubsection{Transportzeit der Proben}

Die entnommenen Pleuraergussproben konnten für die beurteilenden Pneumologen in wenigen Stunden labortechnisch aufgearbeitet werden, sodass meistens noch am gleichen Tag die Beurteilung der fertigen Pleuraergusspräparate erfolgte. Die Proben für den Zytopathologen wurden per Kurierpost nach Großhansdorf innerhalb von ca. 24 Stunden versandt. Waren die Proben am Tag vor einem Feiertag oder einem Samstag entnommen, wurden diese zuerst auf $4{ }^{\circ} \mathrm{C}$ gekühlt und am nächsten Arbeitstag versandt. Die längsten Transportzeiten haben 5 Tage nicht überschritten. Dieses Vorgehen kann zur Veränderung der Zellen in der Pleuraergussprobe führen und somit unterschiedliche Beurteilungsbedingungen für die Pneumologen verursachen.

In einer amerikanischen Studie werden die Effekte einer verlängerten Aufbewahrung der frisch gewonnen serösen Körperflüssigkeiten untersucht (Manosca et al. 2007). Unter dem Aspekt der Zellmorphologie untersuchte man in dieser kleinen Studie zytologische Präparate von 10 unterschiedlichen, auch malignen Pleuraergüssen. Die durch Aufbewahrung der Proben unter $4{ }^{\circ} \mathrm{C}$ entstehenden Zellartefakte wurden in allen zytologischen Präparaten sichtbar und in manchen Proben schon am Entnahmetag beobachtet. $\mathrm{Zu}$ den Zellveränderungen gehörten vor allem die Bildung von Membranbläschen auf der Oberfläche der apoptotischen Zellen, sogenannte blebs, Vakualisation der Zellzytoplasmen sowie Zellaggregationen. Das Blebing wurde am häufigsten beobachtet in den malignen Zellen, aber auch in kleinerer Ausprägung in Mesothelien. Diese Verän- 
derungen hatten jedoch laut diesen Autoren keinen Einfluss auf die zytomorphologische Beurteilung der Präparate.

Die Arbeit von Antonangelo et al. (2012) zeigt, dass die Pleuraergussproben von 30 Patienten, gesammelt in den EDTA-Röhrchen und aufbewahrt unter unterschiedlichen thermischen Bedingungen (Raumtemperatur von $21^{\circ} \mathrm{C}$ vs. Kühlschrank mit $4{ }^{\circ} \mathrm{C}$ ) schon nach 3-4 Tagen quantitative Zellveränderungen zeigten. Zeit sowie Temperatur der Aufbewahrung können, wie die Autoren feststellen, potentielle präanalytische Fehler in der Pleuraergusszytologie verursachen. Untersuchte Zellen waren: Leukozyten, Makrophagen und Mesothelzellen. Letztere könnten in vorliegender Studie eine Bedeutung für die Differenzierung zwischen Adenokarzinom, Mesotheliom und aktivierten Mesothelzellen haben. Präanalytische Fehler bei der zytologischen Beurteilung der Proben in der LungenClinic Großhansdorf sind wegen der Transportzeiten nicht ausgeschlossen. Dies könnte auch die nicht signifikanten Unterschiede in der Sensitivität der zytologischen Beurteilung beider Beurteiler erklären.

Auch die Unterscheidung der Exsudate von Transsudaten, die für diese Studie aus den Befunden der LungenClinic Großhansdorf entnommen wurde, kann durch längere Transportzeit beeinflusst sein. Die wichtigsten laborchemischen Parameter sind hier Protein, Gesamt-LDH und Cholesterin.

Nur eine Studie beschäftigt sich mit dem Einfluss der Aufbewahrung der Proben des Pleuraergusses auf laborchemische Analysen (Antonangelo et al. 2010). Die Proben wurden in Laborröhrchen ohne Zusatz von einem Antikoagulans unter Raumtemperatur aufbewahrt. Hier blieb die Konzentration von Protein und Cholesterin bis zum siebten Tag stabil. Der Spiegel von LDH sank ab den 5 Tag. Die mit $4{ }^{\circ} \mathrm{C}$ aufbewahrten Proben zeigten ebenso über 7 Tage stabile Werte von Protein und Cholesterin. Die Konzentration von LDH sank schon nach 3 Tagen.

Genaue Aufzeichnungen über die Transportzeiten der Proben wurden in vorliegender Studie nicht geführt. Man schätzt, dass nur wenige Proben länger als 4 Transporttage brauchten. Somit hat die Transportzeit der Proben in vorliegender Studie keinen wesentlichen Einfluss auf die Bestimmung der o.g. klinisch-chemischen Parameter. 


\subsubsection{Zugang zu klinischen Informationen}

Sowohl Pneumologen als auch Zytopathologen schöpfen die Informationen bezüglich der klinischen Situation, die zur Entnahme des Pleuraergusses führte, aus den schriftlichen Anforderungen. Die Pneumologen sind jedoch zumeist auch direkt involviert in die klinische Behandlung der Patienten, bei denen eine zytologische Untersuchung des Pleuraergusses angefordert wurde.

Großen Einfluss auf die Beurteilung der zytologischen Präparate haben menschliche Erfahrung, Wahrnehmung und Interpretation. Dies führt zu niedrigen Beurteilerübereinstimmungen in vielen zytologischen Studien (Dey 2007). Die Diagnose eines malignen oder benignen Pleuraergusses wird durch einen klinisch tätigen Arzt, der nicht nur für die Diagnose, sondern auch für die Therapie zuständig ist, nie völlig objektiv gestellt. Die Pneumologen in vorliegender Studie kennen zumeist eine genaue Anamnese, radiologische Aufnahmen und bronchoskopische Befunde der Patienten. Der Zytopathologe verfügt vor der Beurteilung des zytologischen Präparates nur über die Informationen auf dem Anforderungsschein. Es handelt sich hier oft um sehr eingeschränkte Informationen, wie z.B. die Frage: „Pleuraerguss rechts, Malignität?“. Angesicht der großen Variabilität möglicher zytologischer Befunde, die nur auf zytomorphologischer Beurteilung basieren, ist es notwendig, dass die Beurteiler über die vollständige klinische Information über den Patienten verfügen. Die Beurteilungen der Pneumologen und des Zytopathologen bezüglich der Sensitivität und Spezifität unterscheiden sich nicht signifikant. Unklar bleibt, ob das klinische Wissen der wenig in der zytologischen Befundung erfahrenen Pneumologen die fehlenden klinischen Informationen des Zytopathologen ausgleicht. Möglicherweise erklärt eine gute klinische Information bei Pneumologen den Trend zu Überinterpretation des Befundes bei etwas niedrigerem PPV. Diese Fragen können letztlich nicht sicher beantwortet werden.

\subsection{Schlussfolgerung}

Bei guter Übereinstimmung der zytologischen Ergebnisse der Pleuraergüsse in den Kategorien maligne/benigne sind die Befunde von Pneumologen verlässlich. Die Übereinstimmung der Befunde in der Kategorien Adenokarzinom/nicht-kleinzelliges Karzinom/kleinzelliges Karzinom/Karzinom/Neoplasie/Pleuraempyem ist moderat. In der täglichen Praxis ist jedoch eine alleinige Feststellung der malignen Zellen bei fortgeschrittener maligner Erkrankung ausreichend. Sollten genauere Angaben bezüglich des 
Primarius notwendig sein oder ist der Pleuraerguss eine einzige Krankheitsmanifestation, wird man zur weiteren Abklärung immuzytochemische Untersuchungen durchführen. Eine parallele, auf zytomorphologischen Kriterien basierende zytologische Untersuchung des gleichen Pleuraergusses durch den Zytopathologen aus der LungenClinic Großhansdorf und vor Ort steigert nicht die Treffsicherheit der Methode. Die Studie spiegelt normale Behandlungsbedingungen von Patienten mit einem unklaren Pleuraerguss in Deutschland wider. Sie kann auf andere pneumologische Zentren, in denen Fachärzte für Pneumologie sich mit Pleuraergusszytologie täglich beschäftigen, übertragen werden. Die letztendlich statistisch nicht signifikanten Unterschiede zwischen den zytologischen Befunden der Pneumologen und des Zytopathologen können auch durch unterschiedliche Mengen des untersuchten Pleuraergusses, unterschiedliche Zeiten zwischen Thorakozentese und zytologischer Aufarbeitung der Proben, durch Transportzeiten sowie unterschiedliche Zugänge zu klinischen Informationen beeinflusst werden. Gleichwohl zeigen sich erkennbare Trends in der Treffsicherheit der Befunde.

Die Beurteilung des Pleuraergusses durch geübte Fachärzte für Pneumologie ist ein unter Alltagsbedingungen sicheres Verfahren. Im Falle einer Untersuchung vor Ort entfallen die Transportzeiten. Dies kann zur Verkürzung der Zeit bis zur endgültigen Diagnose und therapeutischen Entscheidung, insbesondere bei onkologischen Patienten, führen. 


\section{Zusammenfassung}

Das Auftreten eines Pleuraergusses kann sowohl im Verlauf von mehreren Erkrankungen der Atemwege als auch anderer Organe beobachtet werden. Die zytologische Untersuchung spielt eine wichtige Rolle bei der Diagnose von malignen Ergüssen und der Planung weiterer therapeutischer Maßnahmen.

Das Ziel der Studie ist ein Vergleich der zytologischen Befunde von klinisch tätigen Pneumologen und der sogenannten „Einsenderzytologie“ mit unterschiedlichem Grad der Erfahrung.

Es wurden Ergebnisse der 795 Pleuraergusszytologien von 606 Patienten, die in vier folgenden Jahren (2011-2014) eine diagnostische Thorakozentese erhielten, ausgewertet. Im Vergleich der Befunde in den Kategorien maligne vs. benigne vs. suspekt wurde zwischen Beurteilern eine moderate Übereinstimmung $(\kappa=0,57)$ bei einer prozentualen Übereinstimmung von $80 \%$ erreicht.

Die Kategorie „suspekt“ beinhaltet jedoch Befunde, die in der täglichen klinischen Versorgung der Patienten keinen Einfluss auf die therapeutische Entscheidung haben. So ist die Beurteilerübereinstimmung in den Kategorien maligne vs. benigne gut $(\kappa=0,76)$ mit einer prozentualen Übereinstimmung von $90 \%$. Der $\kappa$-Wert zwischen den Kategorien Adenokarzinom vs. nicht-kleinzelliges Karzinom vs. kleinzelliges Karzinom vs. Karzinom vs. Neoplasie vs. Pleuraempyem vs. unspezifisch fiel mit einem $\kappa$ von 0,54 und einer prozentualen Übereinstimmung von $75 \%$ moderat aus.

Die 111 zytologischen Befunde der Pneumologen und 123 Befunde des Zytopathologen wurden mit histologischen Ergebnissen der Thorakoskopien verifiziert. Die Werte der Sensitivität, Spezifität, PPV und NPV für Pneumologen und für den Zytopathologen sind mit den Werten aus der Literatur vergleichbar und zeigen keine statistisch signifikanten Unterschiede. Gleichwohl zeigen sich erkennbare Trends in der Treffsicherheit der Befunde. Die Unterschiede können aus den Schwächen der Studie resultieren: Dem unterschiedlichen Zugang zu klinischen Informationen bzgl. der Patienten, unterschiedlichen Transportzeiten der Proben sowie unterschiedlichen Mengen des Pleuraergusses. Die Studie untersucht zum ersten Mal die Beurteilerübereinstimmung bei zytologischen Befunden zwischen Pneumologen und Zytopathologen. Diese ist im klinischen Alltag hoch. Die in der Zytologie geübten klinischen Pneumologen können verlässliche zytologische Befunde der Pleuraergüsse liefern. 


\section{Literaturverzeichnis}

Abouzgheib WM, Bartter TM, Dagher H, Pratter MM, Klump W (2009): A Prospective Study of the Volume of Pleural Fluid Required for Accurate Diagnosis of Malignant Pleural Effusion. Chest $\underline{135}$, 999-1001

Altman DG, Bland JM (1994): Diagnostic tests. 1: Sensitivity and specificity. BMJ $\underline{308}$, 1552

Antonangelo L, Vargas FS, Acencio MMP, Carnevale GG, Corá AP, Teixeira LR, Sales RKB, Genofre EH (2010): Pleural fluid: Are temperature and storage time critical preanalytical error factors in biochemical analyses? Clin Chim Acta Int J Clin Chem 411, 1275-1278

Antonangelo L, Vargas FS, Acencio MMP, Corá AP, Teixeira LR, Genofre EH, Sales RKB (2012): Effect of temperature and storage time on cellular analysis of fresh pleural fluid samples. Cytopathol Off J Br Soc Clin Cytol 23, 103-107

Antony VB (1999): Pathogenesis of malignant pleural effusions and talc pleurodesis. Pneumol Stuttg Ger 53, 493-498

Assi Z, Caruso JL, Herndon J, Patz EF (1998): Cytologically proved malignant pleural effusions: distribution of transudates and exudates. Chest $\underline{113}, 1302-1304$

Atay Z, Topalidis T: Cytodiagnostik der serösen Höhlen. 1. Auflage; Pabst, Lengerich 1994

Baumann MHM (2002): A pulmonary myth unmasked? [Editorial]. Chest $\underline{122}$, 18751877

Bedrossian CWM (1998): Diagnostic problems in serous effusions. Diagn Cytopathol $\underline{19}, 131-137$

Bender R (2001): Interpretation von Effizienzmaßen der Vierfeldertafel für Diagnostik und Behandlung. Med Klin Munich Ger 1983 96, 116-121

Bender R, Ziegler A, Lange S (2007): Logistische Regression. Dtsch Med Wochenschr

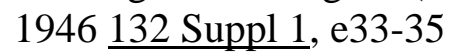

Bergmann DT, Bölükbas S, Beqiri S, Schirren J (2006): Diagnostische videoassistierte Thorakoskopie. Chir $\underline{77}$, 998-1006

Bibby AC, Clive AO, Slade GC, Morley AJ, Fallon J, Psallidas I, Pepperell JCT, Slade MG, Stanton AE, Rahman NM, Maskell NA (2015): Survival in Patients With Malignant Pleural Effusions Who Developed Pleural Infection: A Retrospective Case Review From Six UK Centers. Chest 148, 235-241

Bielsa S, Porcel JM, Castellote J, Mas E, Esquerda A, Light RW (2012): Solving the Light's criteria misclassification rate of cardiac and hepatic transudates. Respirol Carlton Vic 17, 721-726 
Böcking A (1998): Standardisierung der zytopathologischen Diagnostik. Pathol $\underline{19}$, 236-241

Boutin C, Astoul P, Seitz B (1990): The role of thoracoscopy in the evaluation and management of pleural effusions. Lung 168 Suppl, 1113-1121

Burgess LJ, Maritz FJ, Taljaard JJ (1996): Epidemiology of pleural effusions. South Afr Med J Suid-Afr Tydskr Vir Geneeskd 6ㅜ, 186

Cakir E, Demirag F, Aydin M, Unsal E (2009): Cytopathologic differential diagnosis of malignant mesothelioma, adenocarcinoma and reactive mesothelial cells: A logistic regression analysis. Diagn Cytopathol 37, 4-10

Cancer incidence in the Czech 2011. http://www.uzis.cz/en/category/tematicke-rady/health-statistics/cancer; Zugriff am 02.12.2015

Canto A, Rivas J, Saumench J, Morera R, Moya J (1983): Points to consider when choosing a biopsy method in cases of pleurisy of unknown origin. Chest $\underline{84}$, 176-179

Chakrabarti BM, Ryland I, Sheard JM, Warburton CJM, Earis JEM (2006): The Role of Abrams Percutaneous Pleural Biopsy in the Investigation of Exudative Pleural Effusions. Chest 129, 1549-1555

Chernow B, Sahn SA (1977): Carcinomatous involvement of the pleura: an analysis of 96 patients. Am J Med $\underline{63}, 695-702$

Cohen J (1960): A Coefficient of Agreement for Nominal Scales. Educ Psychol Meas $\underline{20}, 37-46$

Colins JD, Burwell D, Furmanski S, Lorber P, Steckel RJ (1972): Minimal detectable pleural effusions. A roentgen pathology model. Radiology 105, 51-53

Dahmer J: Anamnese und Befund: die symptom-orientierte Patientenuntersuchung als Grundlage klinischer Diagnostik - ein interaktives Taschenbuch für Studium und Praxis. 10., völlig überarb. und erw. Aufl.; Thieme, Stuttgart [u. a.] 2006

Defrancis N, Klosk E, Albano E (1955): Needle biopsy of the parietal pleura; a preliminary report. N Engl J Med 252, 948-951

Denton K, Giles T, Smith P, Chandra AA, Desai M (2010): Tissue pathways for exfoliative cytology and fine needle aspiration cytology. https://www.rcpath.org/resourceLibrary/tissue-pathways-exfoliative-cytologyfnacytology-jan10.html; Zugriff am 25.11.2015

Dey P (2007): Time for evidence-based cytology. CytoJournal $\underline{4}, 1$

Diaz-Guzman E, Budev MM (2008): Accuracy of the physical examination in evaluating pleural effusion. Cleve Clin J Med 75, 297-303 
Eberli F, Russi E: Schmerzen im Bereich des Thorax. In: Siegenthaler W (Hrsg.): Siegenthalers Differentialdiagnose: innere Krankheiten - vom Symptom zur Diagnose. 19., vollst. neu bearb. Aufl.; Thieme, Stuttgart [u. a.] 2005, 249-254

Fassina A, Fedeli U, Corradin M, Da Frè M, Fabbris L (2008): Accuracy and reproducibility of pleural effusion cytology. Leg Med Tokyo Jpn 10, 20-25

Felson B, Weinstein AS, Spitz HB: Röntgenologische Grundlagen der Thoraxdiagnostik: Ein programmierter Text. Übers. v. Grenzmann M. Thieme, Stuttgart 1968

Ferrer J, Roldan J, Teixidor J, Pallisa E, Gich I, Morell F (2005): Predictors of Pleural Malignancy in Patients With Pleural Effusion Undergoing Thoracoscopy. Chest $\underline{127}, 1017-1022$

Grouven U, Bender R, Ziegler A, Lange S (2007): Der Kappa-Koeffizient. Dtsch Med

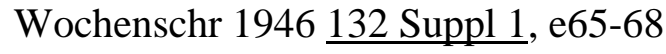

Grunze H (1964): The comperative diagnostic accuracy, efficiency and specificity of cytologic technics used in the diagnosis of the pleural and pericardial cavities. Acta Cytol $\underline{8}, 150-163$

Hausheer FH, Yarbro JW (1987): Diagnosis and treatment of malignant pleural effusion. Cancer Metastasis Rev $\underline{6}, 23-40$

Hooper C, Lee YCG, Maskell N (2010): Investigation of a unilateral pleural effusion in adults: British Thoracic Society pleural disease guideline 2010. Thorax $\underline{65}$, ii4ii17

Hsu C (1987): Cytologic detection of malignancy in pleural effusion: a review of 5,255 samples from 3,811 patients. Diagn Cytopathol $\underline{3}, 8-12$

Järvi OH, Kunnas RJ, Laitio MT, Tyrkkö JE (1972): The accuracy and significance of cytologic cancer diagnosis of pleural effusions. (A followup study of 338 patients). Acta Cytol 16, 152-158

Johnston WW (1985): The malignant pleural effusion. A review of cytopathologic diagnoses of 584 specimens from 472 consecutive patients. Cancer $\underline{56}$, 905-909

Khan MAI, Ambalavanan S, Thomson D, Miles J, Munavvar M (2012): A comparison of the diagnostic yield of rigid and semirigid thoracoscopes. J Bronchol Interv Pulmonol $\underline{19}, 98-101$

Kinasewitz GT (1997): Transudative effusions. Eur Respir J 10, 714-718

Koegelenberg CFN, Bolliger CT, Theron J, Walzl G, Wright CA, Louw M, Diacon AH (2010): Direct comparison of the diagnostic yield of ultrasound-assisted Abrams and Tru-Cut needle biopsies for pleural tuberculosis. Thorax $\underline{65}, 857-862$

Köhler D, Schönhofer B, Voshaar T: Pneumologie: ein Leitfaden für rationales Handeln in Klinik und Praxis. 2., aktualisierte und erw. Aufl.; Thieme, Stuttgart 2014 
Kutty CP, Remeniuk E, Varkey B (1981): Malignant-appearing cells in pleural effusion due to pancreatitis: case report and literature review. Acta Cytol 25, 412-416

Landis JR, Koch GG (1977): The Measurement of Observer Agreement for Categorical Data. Biometrics 33, 159-174

Light RW (2006): Parapneumonic effusions and empyema. Proc Am Thorac Soc $\underline{3}$, 7580

Light RW (2011): Pleural effusions. Med Clin North Am 95, 1055-1070

Light RW, Hamm H (1997): Malignant pleural effusion: would the real cause please stand up? Eur Respir J 10, 1701-1702

Light RW, Macgregor MI, Luchsinger PC, Ball WC (1972): Pleural effusions: the diagnostic separation of transudates and exudates. Ann Intern Med 77, 507-513

Lim MH, Garrettc J, Mowlem L, Yap E (2013): Diagnosing malignant pleural effusions: how do we compare? N Z Med J 126, 42-48

Lin J, Iannettoni MD (2003): The role of thoracoscopy in the management of lung cancer. Surg Oncol 12, 195-200

Loddenkemper R (1981): Thoracoscopy: results in non cancerous and idiopathic pleural effusions. Poumon Coeur 37, 261-264

Loddenkemper R (2005): Management der malignen Pleuraergüsse. Pneumol Stuttg Ger $\underline{59}, 120-135$

Lynch TJ (1993): Management of malignant pleural effusions. Chest $\underline{103}$, 385S-389S

Manosca F, Schinstine M, Fetsch PA, Sorbara L, Maria Wilder A, Brosky K, Erickson D, Raffeld M, Filie AC, Abati A (2007): Diagnostic effects of prolonged storage on fresh effusion samples. Diagn Cytopathol $\underline{35}, 6-11$

Marchetti GP, Pinelli V, Tassi GF (2011): 100 Years of Thoracoscopy: Historical Notes. Respiration $\underline{82}, 187-192$

Marel M, Zrůstová M, Stasný B, Light RW (1993): The incidence of pleural effusion in a well-defined region. Epidemiologic study in central Bohemia. Chest 104, 1486-1489

Marel M, Stastny B, Melínová L, Svandová E, Light RW (1995): Diagnosis of pleural effusions. Experience with clinical studies, 1986 to 1990. Chest 107, 1598-1603

Menzies R, Charbonneau M (1991): Thoracoscopy for the diagnosis of pleural disease. Ann Intern Med 114, 271-276

Metzgeroth G, Kuhn C, Schultheis B, Hehlmann R, Hastka J (2008): Diagnostic accuracy of cytology and immunocytology in carcinomatous effusions. Cytopathology 19, 205-211 
Meyer PC (1966): Metastatic carcinoma of the pleura. Thorax 21, 437-443

Mishra E, Davies H, Lee YCG: Malignant pleural disease in primary lung cancer. In: Spiro SG, Janes SM, Huber RM (Hrsg.): Thoracic Malignancies. European Respiratory Society Journals Ltd, Sheffield 2009, 318-335

Moskowitz H, Platt RT, Schachar R, Mellins H (1973): Roentgen visualization of minute pleural effusion. An experimental study to determine the minimum amount of pleural fluid visible on a radiograph. Radiology 109, 33-35

Motherby H, Nadjari B, Friegel P, Kohaus J, Ramp U, Böcking A (1999): Diagnostic accuracy of effusion cytology. Diagn Cytopathol 20, 350-357

Mulvey RB (1965): The effect of pleural fluid on the diaphragm. Radiology $\underline{84}, 1080$ 1086

Noppen M, De Waele M, Li R, Gucht KV, D'haese J, Gerlo E, Vincken W (2000): Volume and Cellular Content of Normal Pleural Fluid in Humans Examined by Pleural Lavage. Am J Respir Crit Care Med 162, 1023-1026

Pereira TC, Saad RS, Liu Y, Silverman JF (2006): The diagnosis of malignancy in effusion cytology: a pattern recognition approach. Adv Anat Pathol 13, 174-184

Pinto MM (1996): CA-15.3 assay in effusions: comparison with carcinoembryonic antigen and CA-125 assay and cytologic diagnosis. Acta Cytol $\underline{40}, 437-442$

Pokieser L: Pleura. In: Pokieser L, Bernhardt K, Kreuzer A, Schalleschak L (Hrsg.): Klinische Zytologie der Lunge und Pleura: Handbuch und Farbatlas. Springer Wien 2001, 125-160

Porcel JM, Vives M, Esquerda A, Salud A, Pérez B, Rodríguez-Panadero F (2004): Use of a panel of tumor markers (carcinoembryonic antigen, cancer antigen 125, carbohydrate antigen 15-3, and cytokeratin 19 fragments) in pleural fluid for the differential diagnosis of benign and malignant effusions. Chest $\underline{126}, 1757-1763$

Porcel JM, Esquerda A, Vives M, Bielsa S (2014): Etiology of pleural effusions: analysis of more than 3,000 consecutive thoracenteses. Arch Bronconeumol $\underline{50}, 161-$ 165

Preisendörfer P: Organisationssoziologie: Grundlagen, Theorien und Problemstellungen. 1. Auflage; VS, Verl. für Sozialwiss., Wiesbaden 2005

Riedel U, Schönfeld N, Savaser A, Serk M, Loddenkemper R (1999): Diagnostischer Wert der Tumormarker TPA-M, CYFRA 21-1 und CEA bei Pleuraergüssen Prospektiver Vergleich bei thorakoskopisch untersuchten Patienten mit Pleuaerguß. Pneumol Stuttg Ger 53, 471-476

Rittmeyer A, Altmannsberger HM, Goeckenjan G (2004): Stellenwert des zytologischen Nachweises von Ber-EP4 im Pleurapunktat. Pneumologie $\underline{58}$, P34 
Rodríguez-Panadero F, López Mejías J (1989): Low glucose and pH levels in malignant pleural effusions. Diagnostic significance and prognostic value in respect to pleurodesis. Am Rev Respir Dis 139, 663-667

Rodriguez-Panadero F, Janssen JP, Astoul P (2006): Thoracoscopy: general overview and place in the diagnosis and management of pleural effusion. Eur Respir J $\underline{28}$, $409-422$

Romero-Candeira S, Fernández C, Martín C, Sánchez-Paya J, Hernández L (2001): Influence of diuretics on the concentration of proteins and other components of pleural transudates in patients with heart failure. Am J Med 110, 681-686

Sahn SA (1990): The pathophysiology of pleural effusions. Annu Rev Med $\underline{41}, 7-13$

Sahn SA (1997): Pleural diseases related to metastatic malignancies. Eur Respir J $\underline{10}$, 1907-1913

Sallach SM, Sallach JA, Vasquez E, Schultz L, Kvale PM (2002): Volume of Pleural Fluid Required for Diagnosis of Pleural Malignancy. Chest 122, 1913-1917

Schirren J, Trainer S, Schneider P, Hendricks H, Müller KM, Vogt-Moykopf I (1994): Sind videsoassistierte thoracoskopische Rekonstruktionsverfahren in der onkologischen Chirurgie vertretbar? Chirurg $\underline{65}, 664-670$

Schubert J: Leitfaden der Zytopathologie für Internisten. Karger, Freiburg 2014

Thomas SC, Davidson LRR, McKean ME (2011): An investigation of adequate volume for the diagnosis of malignancy in pleural fluids. Cytopathology 22, 179-184

Travis WD, Brambilla E, Noguchi M, Nicholson AG, Geisinger K, Yatabe Y, Ishikawa Y, Wistuba I, Flieder DB, Franklin W, et al. (2013): Diagnosis of Lung Cancer in Small Biopsies and Cytology. Arch Pathol Lab Med 137, 668-684

Valdés L, Alvarez D, Valle JM, Pose A, San José E (1996): The etiology of pleural effusions in an area with high incidence of tuberculosis. Chest $\underline{109}, 158-162$

Von Haam E (1962): A comparative study of the accuracy of cancer cell detection by cytological methods. Acta Cytol $\underline{6}, 508-518$

Wang NS (1975): The preformed stomas connecting the pleural cavity and the lymphatics in the parietal pleura. Am Rev Respir Dis 111, 12-20

Whitaker D (2000): The cytology of malignant mesothelioma. Cytopathol Off J Br Soc Clin Cytol 11, 139-151

Wirtz MA, Caspar F: Beurteilerübereinstimmung und Beurteilerreliabilität: Methoden zur Bestimmung und Verbesserung der Zuverlässigkeit von Einschätzungen mittels Kategoriensystemen und Ratingskalen. Hogrefe, Göttingen [u.a.] 2002 


\section{Danksagung}

Ich bedanke mich bei dem Leiter des Bereiches Pneumologie Forschung und Lehre der Klinik für Kardiologie und Pneumologie der Universitätsmedizin Göttingen und Ärztlichem Leiter der Lungenfachklinik Immenhausen, Herrn Prof. Dr. Stefan Andreas, für das Überlassen des Themas, die Möglichkeit der Durchführung der Untersuchungen sowie für die hervorragende Betreuung während der Arbeit.

Besonderer Dank gilt Herrn Dr. Achim Rittmeyer für zahlreiche fachliche Hinweise, die Möglichkeit zu anregenden Diskussionen sowie die kritische Durchsicht des Manuskripts.

Ebenso großer Dank gilt Herrn Dr. Achim Rittmeyer, Frau Dr. Birgit Zwerger sowie Herrn Priv.-Doz. Dr. Lutz Welker für die Überlassung der zytologischen Befunde sowie Dr. Marc Hinterthaner für die Überlassung der Befunde der Thorakoskopien.

Weiterhin gilt ein Dank den nichtärztlichen Mitarbeitern der Lungenfachklinik Immenhausen, insbesondere dem Team des klinischen Labors unter Leitung von Frau Carmen Bachmann für die Unterstützung bei meinen Recherchen.

Bei Herrn Dr. jur. Holger Kilian bedanke ich mich für das Korrektur-Lesen und anregende Diskussionen über die „Tücken“ der deutschen Sprache. 
